\title{
ANALYSIS AND ENVIRONMENTAL IMPACT REDUCTION STRATEGIES FOR SODIUM CHLORIDE BASED WINTER MAINTENANCE PRACTICES
}

\author{
A Dissertation \\ Presented to \\ the faculty of the School of Engineering and Applied Science \\ University of Virginia \\ In Partial Fulfillment \\ of the requirements for the Degree \\ Doctor of Philosophy in Environmental Engineering
}

by

G. Michael Fitch

January 2012 


\section{APPROVAL SHEET}

The dissertation is submitted in partial fulfillment of the

requirements for the degree of

Doctor of Philosophy in Environmental Engineering

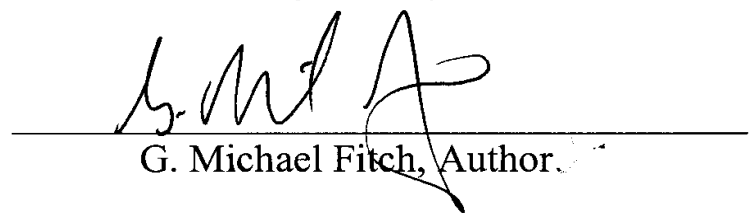

This dissertation has been read and approved by the Examining Committee:

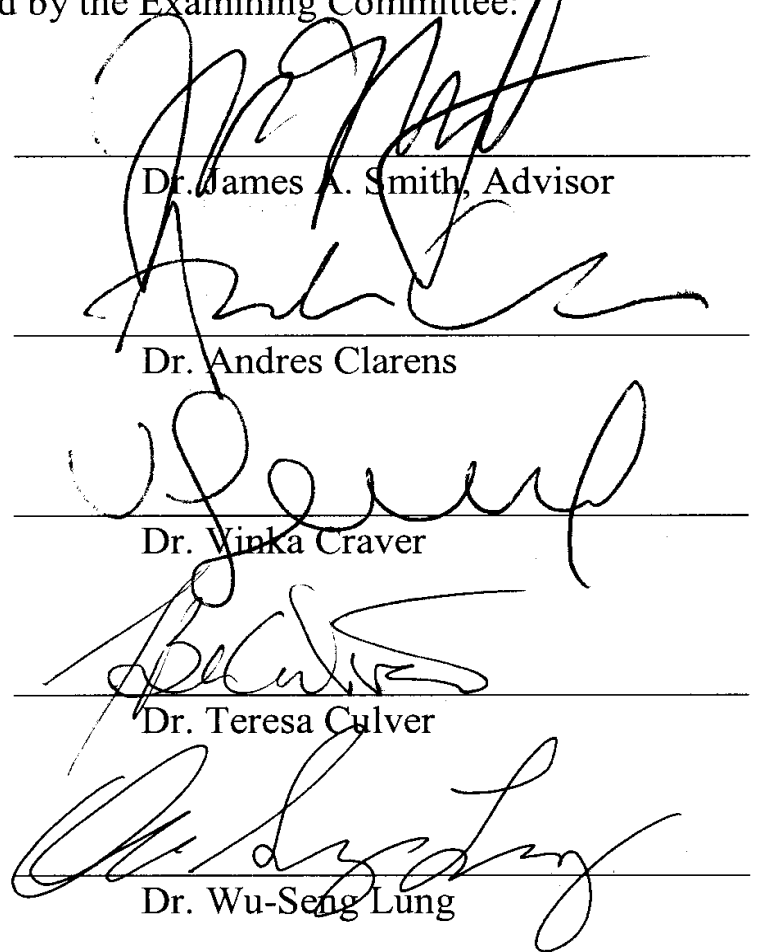

Accepted for the School of Engineering and Applied Science:

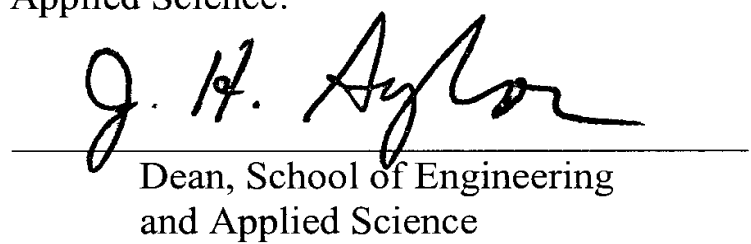

January 2012 


\begin{abstract}
Departments of Transportation throughout the United States are struggling to identify ways to maintain acceptable levels of service on their roadways during periods of winter precipitation while minimizing the damage inflicted on the natural environment. Chemicals and practices employed during these periods of winter maintenance can have a negative effect on ground and surface water, soils, and vegetation. The Virginia Department of Transportation (VDOT) has invested millions of dollars upgrading its winter maintenance chemical storage facilities to prevent the unnecessary release of these chemicals to the environment. The management of stormwater collected at these facilities has proven challenging as disposal options become more limited and costly.

This research effort serves to aid VDOT in better managing the stormwater collected at its maintenance facilities with the goal of minimizing the department's winter maintenance activities on the environment. This was accomplished by characterizing the existing stormwater problem, identifying methods to minimize the generation of stormwater, examining treatment options, determining the feasibility of reusing a portion of the stormwater for the purposes of brine generation, and, by way of a lifecycle assessment (LCA), estimating and comparing the impacts on the environment when three different chemical approaches (including brine) were employed.

It was found that VDOT generates tens of millions of gallons of relatively dilute salt-laden stormwater on an annual basis. Given the average salinity of this stormwater, it was also determined that treatment of this stormwater by way of reverse osmosis could be expected to reduce chloride values to less that $20 \mathrm{mg} / \mathrm{L}$. The volume of water that could be expected to be treated by reverse osmosis, however, was hindered by low
\end{abstract}


system throughput volumes. This in combination with the total treatment volumes that would be generated by VDOT, even during the driest of years, would limit the practicality of using reverse osmosis.

Though treatment by the methods examined in this research effort was not viable, it was discovered that if collection minimization efforts were instituted and the department converted to the use of $\mathrm{NaCl}$ brine as its primary winter maintenance chemical instead of dry $\mathrm{NaCl}$, the volume of stormwater requiring disposal would be minimal, as the stormwater could be used for the production of brine. Assuming average winter precipitation totals, approximately 60 million gallons of stormwater that would normally require some type of disposal could be reapplied to the roadway in the form of brine. This would result in an estimated cost savings of nearly $\$ 10$ million.

Beyond the financial benefits accrued to the department by way of brine production using stormwater, by way of a life cycle analysis it was determined that the overall impacts to the environment in terms of energy consumption, total chloride loading, water consumption, green house gas emissions, and biochemical oxygen demand would also decrease significantly when compared to current winter maintenance practices. Depending on storm duration, calculated impacts were reduced by approximately 30 to 40 percent when using brine produced with stormwater in place of dry salt. 


\section{TABLE OF CONTENTS}

LIST OF FIGURES ...............................................................................................................viii

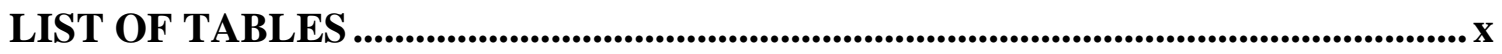

PUBLICATIONS RESULTING FROM THIS WORK.................................................1

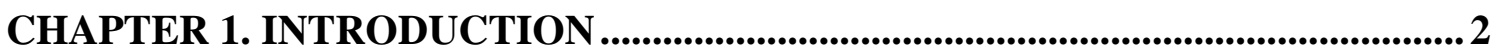

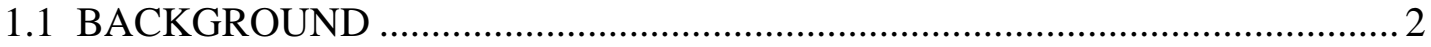

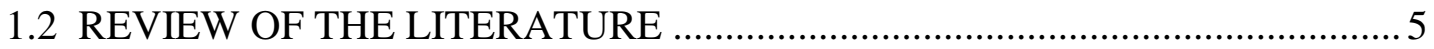

1.3 RESEARCH OBJECTIVES AND REPORT ORGANIZATION .......................

\section{CHAPTER 2. PROBLEM CHARACTERIZATION AND IDENTIFICATION OF} MINIMIZATION OPPORTUNITIES........................................................................... 11

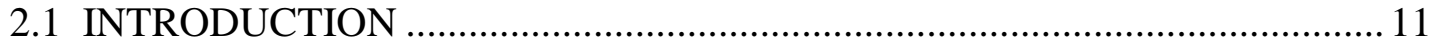

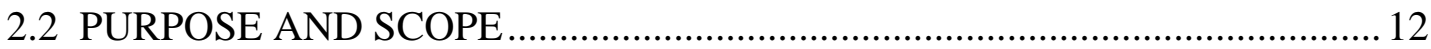

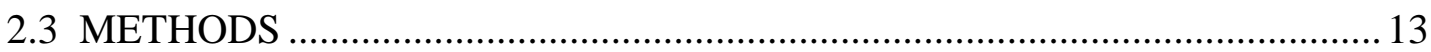

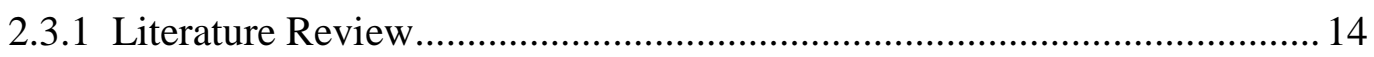

2.3.2 Survey of Transportation Entities .......................................................... 14

2.3.3 Assessment of Quality and Quantity of Salt-Contaminated Water ........... 14

2.3.3.1 Water Quality Constituents........................................................ 15

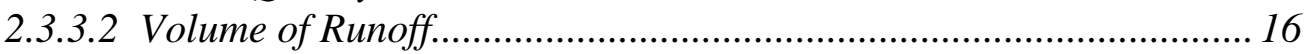

2.3.4 Evaluation of Treatment Alternatives ....................................................... 17

2.3.4.1 Current VDOT Practices ………………….............................. 17

2.3.4.2 Selection of Alternatives ........................................................... 17

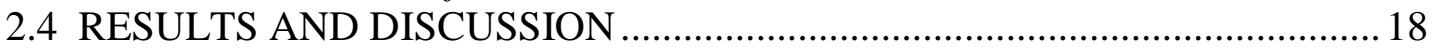

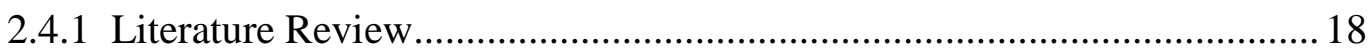

2.4.2 Survey of Transportation Entities ......................................................... 18

2.4.3 Quality and Quantity of Salt-Contaminated Water....................................2 20

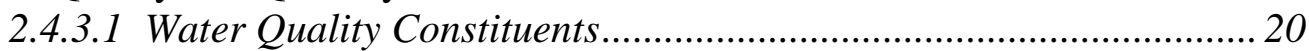

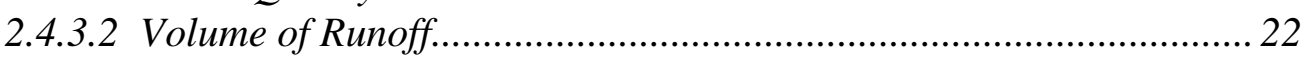

2.4.4 Current VDOT Management Practices .......................................................2 24

2.4.5 Evaluation of Other Management Alternatives ……………………….....2 25

2.4.5.1 Reduction of Runoff Volume ......................................................... 26

2.4.5.2 Runoff Treatment Alternatives ....................................................... 30

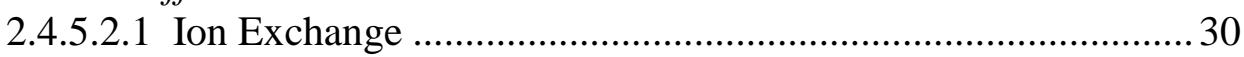

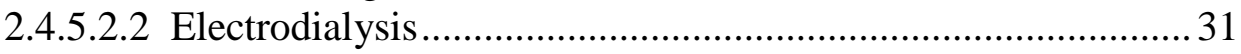

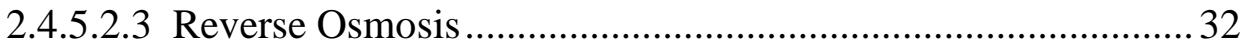

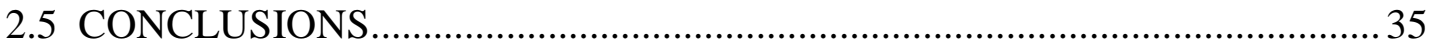

CHAPTER 3. POTENTIAL USE OF REVERSE OSMOSIS IN MANAGING SALTWATER WASTE COLLECTED .............................................................................37

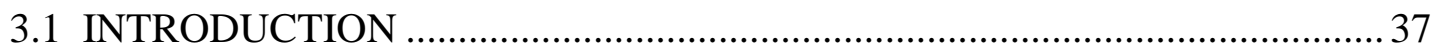

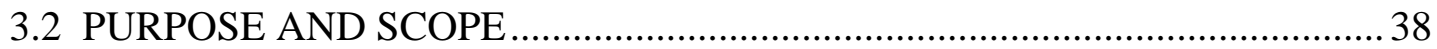




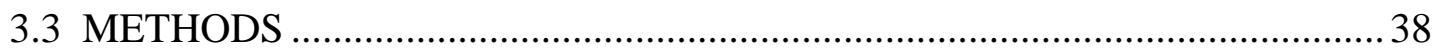

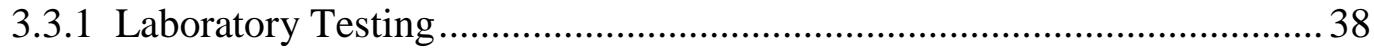

3.3.2 Field Testing ................................................................................. 40

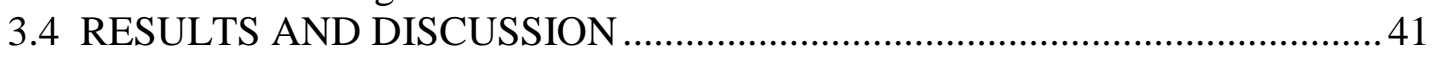

3.4.1 Laboratory Experiments......................................................................... 41

3.4.1.1 Chloride Removal ..................................................................... 41

3.4.1.2 Percent Recovery ......................................................................... 45

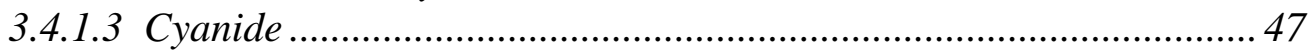

3.4.1.4 Conductivity ................................................................................ 47

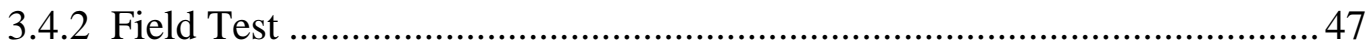

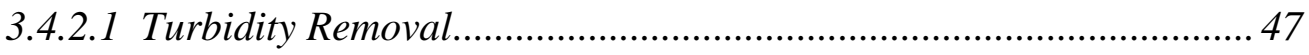

3.4.2.2 Chloride Removal ..................................................................... 49

3.4.2.3 Percent Recovery .................................................................. 51

3.4.3 Fate of Product and Waste Streams .......................................................52

3.4.4 Other Concerns .................................................................................... 54

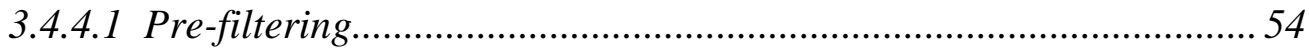

3.4.4.2 System Throughput............................................................. 55

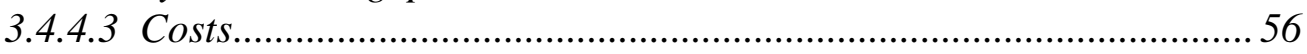

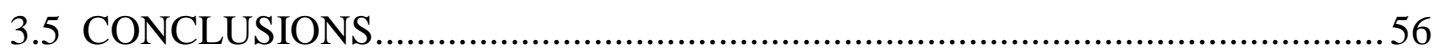

CHAPTER 4. REUSE OPTION INVESTIGATION ....................................................58

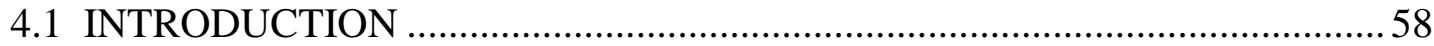

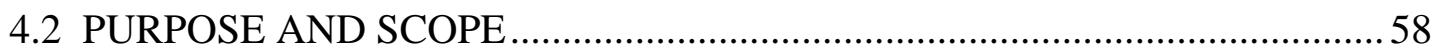

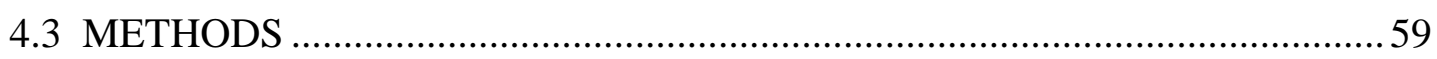

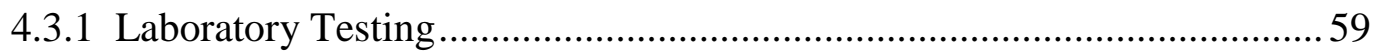

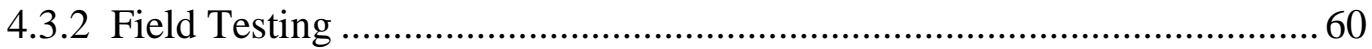

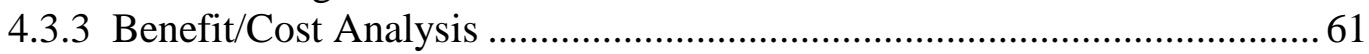

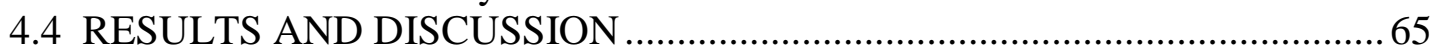

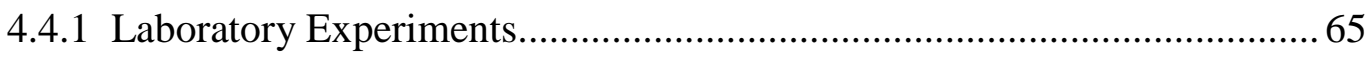

4.4.1.1 Hydraulic Retention Time and Water Temperature.......................... 65

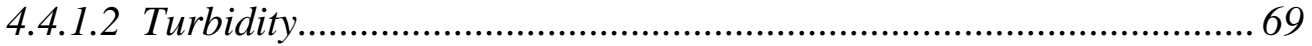

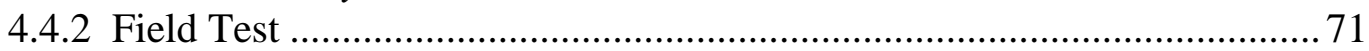

4.4.3 Benefit/Cost Analysis ............................................................................ 73

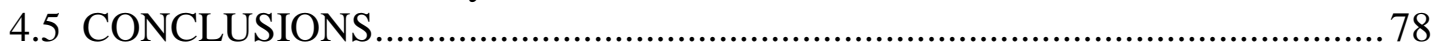

CHAPTER 5. LIFE CYCLE ASSESSMENT .................................................................81

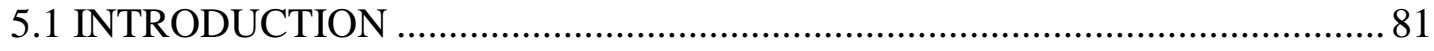

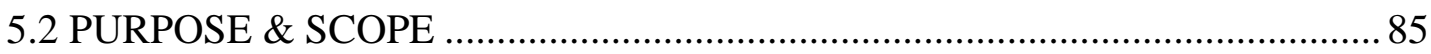

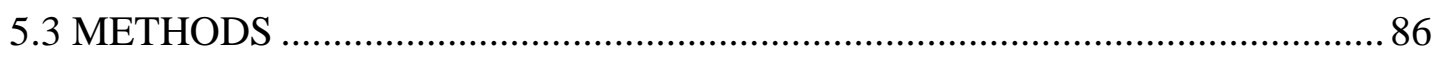

5.3.1 Evaluation of Three Winter Maintenance Treatments ..................................8 86

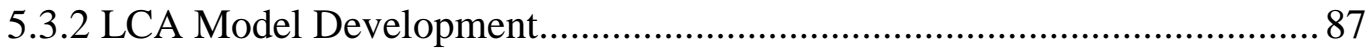

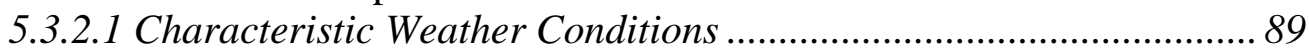

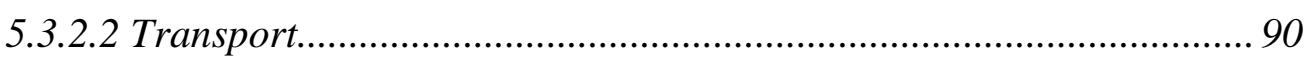

5.3.2.3 Storage and Handling ................................................................... 91

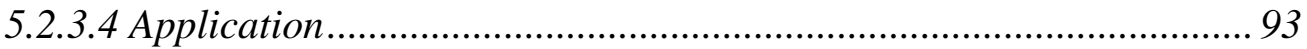

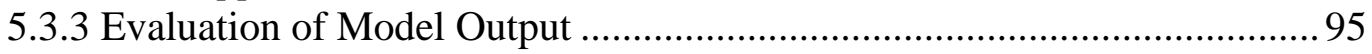




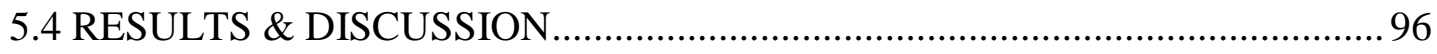

5.4.1 Evaluation of Three Winter Maintenance Treatments .............................. 96

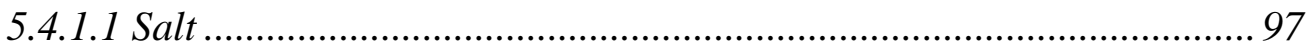

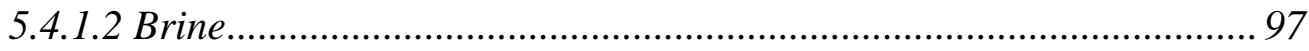

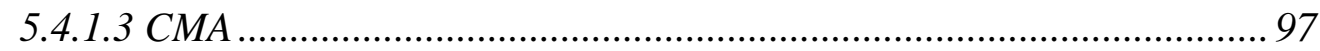

5.4.2 LCA Model Development and Output Evaluation .................................. 99

5.4.3 Implications for Departments of Transportation.................................... 104

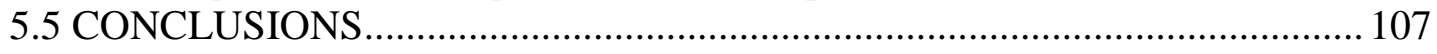

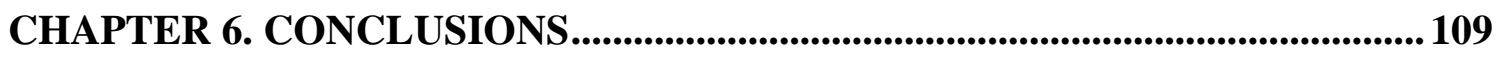

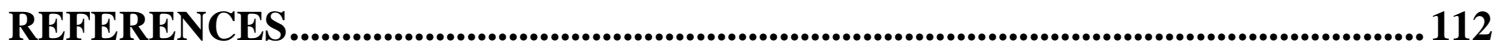




\section{LIST OF FIGURES}

Figure 1. Distribution of Sampled Salt Storage Locations in Virginia.

Figure 2. Diagram of Typical Layout of Salt Storage Facility with Average Size Pond and Loading Pad..... 22

Figure 3. Loading Pad Area versus Pond Volumes for 45 Sample Locations. 24

Figure 4. Average Number of Treatments Required for Each of VDOT's Salt Ponds Assuming Low, Average, and High Annual Precipitation 27

Figure 5. (A) Scheme of Setup for Laboratory Experiments with Reverse Osmosis Equipment; (B) Layout of Microfiltration/Reverse Osmosis Field Test 39

Figure 6. Product and Reject $\mathrm{NaCl}$ Concentrations as Function of Feed $\mathrm{NaCl}$ Concentration

Figure 7. Flows of Product and Reject as Function of $\mathrm{NaCl}$ Concentration on Feed, During Low Concentration Experiments.

Figure 8. (A) Product and Reject $\mathrm{NaCl}$ Concentrations as Function of Feed $\mathrm{NaCl}$ Concentration; (B) Flows of Product and Reject as Function of $\mathrm{NaCl}$ Concentration on Feed, During High $\mathrm{NaCl}$ Concentration Experiments

Figure 9. Product Recover Percentages and Concentration Factor on Reject Streams at $\mathrm{NaCl}$ Feed Concentrations Tested (vertical dashed line indicates maximum feed $\mathrm{NaCl}$ concentration that results in product $\mathrm{Cl}$ concentration less than $250 \mathrm{ppm}$ ) 46

Figure 10. Turbidity Reduction Resulting from Microfiltration Pretreatment (arrows indicate axis to be used for data point types).

Figure 11. Product and Reject Flows of Microfiltration Stage of Field Test (arrows indicate timing of a cleaning procedure)

Figure 12. $\mathrm{NaCl}$ Concentrations of Feed and Reject Streams and Chloride Concentration of Product Stream on Reverse Osmosis Stage in Field Experiments (arrows indicate axis to be used for data point types) 50

Figure 13. Product and Reject $\mathrm{NaCl}$ Concentrations as Function of Feed $\mathrm{NaCl}$ Concentration During Low Concentration and Field Experiments (arrows indicate axis to be used for data point types) 
Figure 14. Flows of Product and Reject as Function of $\mathrm{NaCl}$ Concentration on Feed

During Low Concentration and Field Experiments ...............................................52

Figure 15. Percentages of Salt in Brine and Volume Produced as Function of Hydraulic Retention Time (HRT) and Temperature at $18^{\circ} \mathrm{C}($ top $)$ and $5^{\circ} \mathrm{C}$ (bottom). The horizontal dashed line represents desired effluent salt percentage $(23.3 \%)$

Figure 16. Height of Salt Bed as Function of Hydraulic Retention Time (HRT) and Temperature at $18^{\circ} \mathrm{C}($ top $)$ and $5^{\circ} \mathrm{C}$ (bottom)

Figure 17. Effluent Turbidity as Function of Hydraulic Retention Time (HRT) and Temperature at $18^{\circ} \mathrm{C}($ top $)$ and $5^{\circ} \mathrm{C}$ (bottom)

Figure 18. Comparison of Turbidity Values for Effluent Samples at Time of Collection and after 4 Hours of Settling for $18^{\circ} \mathrm{C}$ (top) and $5^{\circ} \mathrm{C}$ (bottom)

Figure 19. Top: Percentages of Salt in Brine and Volume Produced as Function of Hydraulic Retention Time (HRT). Bottom: Height of Salt Bed as Function of HRT ... 72

Figure 20. Comparison of Turbidity Values for Effluent Samples at Time of Collection and after 4 Hours of Settling for Hydraulic Retention Time (HRT) $=31.8$ min (top) and HRT $=132 \min$ (bottom) 73

Figure 21. Estimated Annual Stormwater Usage for Pre-Wetting and Direct Application and Pre-Wetting Based on Low, Average, and High 5-year Total $\mathrm{NaCl}$ Application.... 74

Figure 22. Annual Benefits Obtained by Use of Pre-Wetting (PW) or Direct Application (DA) Strategies as Function of Volume of Stormwater Runoff Accumulated and Amount of Road Salt Purchased 75

Figure 23. Schematic Representation of the Three Road Treatment Processes Included In this Analysis where A. is Rock Salt, B. is Sodium Chloride Brine, and C. is Calcium

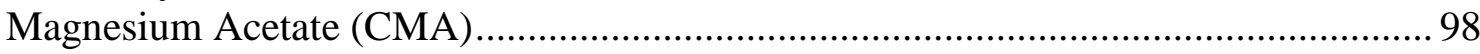

Figure 24. Effect of Brine Application to Solid Chemical Application Ratios in Driving the Environmental Impacts of Winter Maintenance 104

Figure 25. The Distribution of Burdens (Upstream V. at the DOT) for Each of the Impact Factors 105

Figure 26. Sensitivity Analysis Plots for Energy Use, Chloride Emissions, and Water Use For Brine 


\section{LIST OF TABLES}

Table 1. Mean Concentrations of Chloride, Total Suspended Solids, and Oil and Grease in Samples Collected from Saltwater Storage Ponds in VDOT Districts........................ 22

Table 2. Average Runoff Areas, Pond Areas, and Pond Volumes for VDOT Area Headquarters and Estimated Pond-Storage Volumes for VDOT Districts ...................... 23

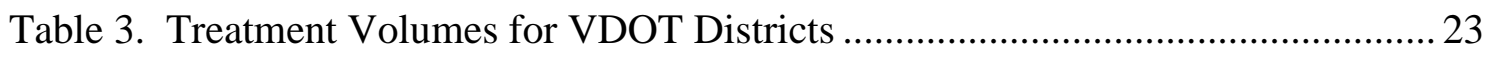

Table 4. Feed Solution Characteristics for Conditions Tested ......................................40

Table 5. Operational Conditions Used for Brine Generation .......................................6 60

Table 6. Annual and Winter Treatment Volumes ..........................................................62 62

Table 7. Road Salt Purchased by VDOT Over Recent 5-year Period ........................... 62

Table 8. Initial Per Site Capital Investment for Pre-Wetting and Direct Application of Brine.

Table 9. Number of Years Required to Recover Capital Investment for Pre-Wetting (PW) and Direct Application (DA) and Pre-Wetting as Function of Volume of Stormwater Runoff Accumulated and Amount of Road Salt Purchased......................... 77

Table 10. Salt Mining Locations and Regional Distribution Sites ................................ 90

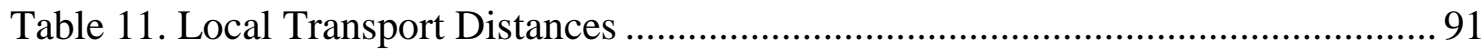

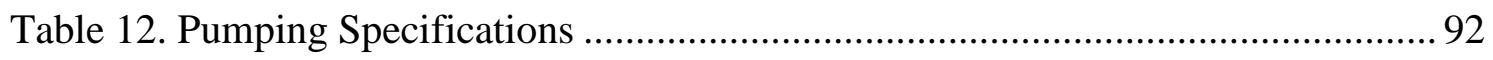

Table 13. Summary Weather Data Used In Determining Chemical Application Rates. 94

Table 14. Data Sources for the Primary Steps for All Three Winter Maintenance

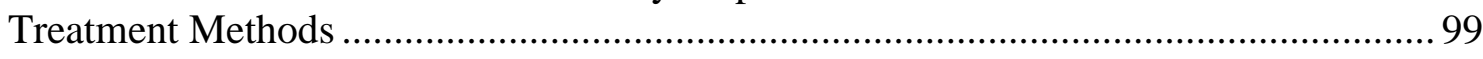

Table 15. Environmental Burdens Associated with Three Winter Maintenance Approaches 


\section{PUBLICATIONS RESULTING FROM THIS WORK}

Fitch, G.M., Bartelt-Hunt, S.L. and Smith, J.A. Characterization and Environmental Management of Stormwater Runoff from Road Salt Storage Facilities. In Transportation Research Record, Journal of the Transportation Research Board, No. 1911, Transportation Research Board of the National Academies, Washington, D.C., 2005, pp. 125-132.

Craver, V.O., Fitch, G.M., and Smith, J.A. Recycling of Salt-Contaminated Stormwater Runoff for Brine Production at Virginia Department of Transportation Road-Salt Storage Facilities. In Transportation Research Record, Journal of the Transportation Research Board, No.2055, Transportation Research Board of the National Academies, Washington, D.C., 2008, pp. 99-105.

Fitch, G.M., Oyanedel-Craver, V, Bartelt-Hunt, S.L., Fuller, M., and Smith, J.A. SaltWater Recycling for Brine Production at Road-Salt-Storage Facilities. Environmental Progress \& Sustainable Energy, Volume 28, No. 4, American Institute of Chemical Engineers, 2009, pp. 565-575.

Fitch, G.M., Smith, J.A., and Clarens, A.F. Environmental Life Cycle Assessment of Winter Maintenance Treatments for Roadways. Submitted to the Journal of Transportation Engineering, American Society of Civil Engineers, May 2011. 


\section{CHAPTER 1. INTRODUCTION}

\subsection{BACKGROUND}

There is little debate that humans have had and will continue to have influence on the natural environment in the form of resource consumption, chemical emissions, and ecological disturbances. The sources of this influence are numerous and their origins varied as are their degree of impact. The construction, maintenance, and operation of the nation's transportation system are certainly major contributors to this occurrence.

Furthermore, of all the modes and methods making up the U.S. transportation system, the motor vehicle system is said to have the greatest impact since it has the highest energy consumption, emits the most pollutants, and has the most extensive infrastructure (TRB, 1997). Most of the approximately 50 or so environmental regulations pertaining to the motor vehicle transportation system, administered either on the federal level or on the individual state departments of transportation (DOTs), have the function of minimizing the impacts related to the construction, expansion, and operation of this system (FHWA, 1998).

With well over $99.5 \%$ of the motor vehicle system already built, (i.e., new roadway construction makes up less than $0.5 \%$ of the total system on an annual basis) (USDOT, 2010), it is ironic that in general the maintenance activities conducted for this massive transportation system do not receive as much environmental scrutiny as construction activities since they often employ practices, techniques, and materials that also have the potential to negatively impact the natural environment. The environmental implications of many of these maintenance activities are not as well understood as most 
construction practices. This is possibly because maintenance activities are not regulated to the same degree as some construction or operation activities, and as a result, research in some of these areas is lagging. Therefore, understanding and improving maintenance practices associated with the motor vehicle transportation system is a logical starting point for reducing the environmental impacts associated with transportation. The simple fact that these practices apply to such large and expansive systems dramatically increases the potential for research in this area to result in significant environmental improvements.

It is estimated that approximately $\$ 2.3$ billion is spent on winter maintenance activities - defined here as the set of actions associated with removing frozen precipitation from the roadways - in the United States each year (FHWA, 2005). It is one of the few areas of roadway maintenance that has received a slowly increasing level of environmental interest. Nationally, between 10 and 20 million tons of $\mathrm{NaCl}$ are used for winter maintenance each year to treat approximately 8 million miles of road (Kelley et al., 2010). The Virginia Department of Transportation (VDOT) alone is responsible for maintaining more than 57,000 centerline miles of roadway, the third largest statemaintained highway system in the United States (FHWA, 2009). A significant part of this maintenance effort comprises the implementation of VDOT's snow removal and ice practices - its winter maintenance program. As a part of this program, VDOT currently stores more than 350,000 tons of $\mathrm{NaCl}$ distributed among approximately 300 storage facilities located throughout the state (Fitch et al., 2004).

Since the 1980s, both the United States and Canada have supported significant efforts to identify alternative chemicals that could be used for the deicing of roadways (Bacchus, 1987; Manning and Crowder, 1988; Pianca, 1984). In 1995 Environment 
Canada placed road salt on its Priority Substance list as a toxic substance (Environment Canada, 2006) and since that time, additional research projects designed minimize the environmental impacts of winter maintenance practices or to identify and evaluate alternative chemicals that could supplement or replace road salt as the predominant deicing chemical have been published (Shi et al., 2009; Levelton Consultants, Inc., 2007; Kelly et al., 2010; Fay, 2011).

Though environmental regulatory agencies in the United States have recognized that the use of chemicals for the purpose of roadway deicing has the potential to harm the environment (U.S.EPA., 1999), this concern has been focused primarily on the soil, vegetation, and water sources immediately adjacent to those roadways receiving high levels of these chemicals (Lord, 1988). The motivation for the research undertaken for this dissertation stems from (1) this increasing level of interest regarding the impacts of winter maintenance practices, (2) the relatively narrow scope of research conducted thus far which has primarily been confined to examining the impacts related to chemical application at the roadway, which has defined the environmental examination of winter maintenance practices to date, and (3), the broader concerns recently expressed by VDOT regarding the design and operation, of chemical storage facilities and the management of the stormwater generated at these locations. Overall, there is a need for a comprehensive evaluation of DOT winter maintenance activities to determine how these practices can be improved to minimize their negative impacts on the environment. 


\subsection{REVIEW OF THE LITERATURE}

Numerous studies have reported on the adverse environmental effects of road salt distributed onto highways during winter maintenance periods. Road salt has been shown to contaminate groundwater (Bester et al., 2005; Dennis, 1973; Howard and Beck, 1993; Labadia and Buttle, 1996; Ostendorf et al., 2006) and surface water (Bubeck et al., 1971; Demers and Sage, 1990; Greb et al., 2000; Mason et al., 1999; Ohno, 1990; Rosenberry et al., 1999), and it can have adverse effects on roadside soils and vegetation (Cunningham, et al., 2008; Hughes et al., 1975; Wilcox, 1986). A smaller number of studies have addressed point-source environmental contamination from snow-dumping sites. During winter months, some municipalities transport snow that has accumulated along roadsides and in parking lots to snow dump sites. As this snow melts, deicing agents and other pollutants are released to the environment (Pierstorff and Bishop, 1980; Scott, 1980; Scott and Wylie, 1980). Although these and numerous other studies have examined the environmental effects of salt used by transportation agencies, very little data exist on how to dispose of, use, or treat the salt water properly captured and stored by these agencies, although contamination from salt storage facilities is a potential source of environmental contamination.

The Transportation Association of Canada (2003) developed syntheses of best management practices for road salt management. In two of these documents (4.0 Drainage and Stormwater Management and 7.0 Design and Operation of Road Maintenance Yards), significant information is provided on the environmental effects of chloride contamination on the roadside environment and on the design, layout, and operation of DOT maintenance yards. These documents recommend that runoff from 
loading pads be collected and then discharged to a sewage treatment facility or used for the production of brine. These appear to be the only two options recommended for DOTs that are properly capturing salt-laden water. No recommendations were found regarding the appropriate size and design of loading pads or ponds to help minimize runoff and maximize evaporation. Similarly, no mention of expected treatment concentrations, treatment volumes, or effluent concentration targets was found.

The Indiana Department of Transportation sponsored research at Purdue University to examine the possibility of reusing saline wash-waters at the DOT's truck washing facilities (Alleman et al., 2004) and the New Jersey Department of Transportation funded research at the New Jersey Institute of Technology to develop structural and non-structural best management practices for mitigating for salt spillage and equipment washing (Meegoda et al., 2004; Golub et al., 2008).

At present there is a scarcity of data on the quality and quantity of the stormwater runoff at salt storage facilities. The volume of contaminated water generated by DOT facilities is unknown. Further, typical concentrations or concentration ranges of salt ions, suspended solids, and organics in this runoff water are also unknown. This information is necessary for making appropriate environmental management decisions regarding treatment options, the potential for reuse, and/or the implications of discharging the captured stormwater. Other DOT agencies are faced with similar environmental concerns regarding the release of saline wastewaters and the increasing pressure from environmental regulatory agencies - and to a certain extent the general public that they are serving — to operate their facilities in a more environmentally responsible and sustainable manner. 


\subsection{RESEARCH OBJECTIVES AND REPORT ORGANIZATION}

The literature review and a survey of other state transportation agencies reveals that there is very little information available on how to manage winter maintenance practices in a sustainable fashion. Proper management of the stormwater runoff generated at salt storage facilities is one example of this lack of information. The purpose of this dissertation is to (1) develop a more complete understanding of the environmental impacts related to the storage, handling, and application of winter maintenance chemicals by VDOT, and (2) examine potential options for reducing some of these impacts. The specific objectives of this research are as follows: problem characterization, identification of minimization opportunities, analysis of treatment options, investigation of reuse options, and life cycle assessment. Each of these is briefly summarized below; and the subsequent chapters of this dissertation are dedicated to each of these:

Chapter 2: Problem Characterization and Identification of Minimization Opportunities

Evaluate both the degree and extent of the salt-water control and disposal problem currently experienced by VDOT. Included in this evaluation is a chemical characterization of the water captured and a calculation of volumes of stormwater potentially generated. Gaining an understanding of the current methods of facility operation is also necessary to discern how and why this water is generated, stored, and disposed. The implications of these current practices in terms of disposal and 
handling costs and the risks associated with retaining the water onsite will also be investigated as a part of the overall problem characterization, as will the identification of methods of reducing the volumes of water captured and stored based on the design, layout, and operation of VDOT facilities. The first and most obvious way of minimizing the problems associated with stormwater generation at these facilities is to reduce the volume of water captured. General design improvements that would be beneficial to the reduction of stormwater generation without compromising the ability to collect all runoff that is likely to contain chlorides will be developed as will the general operating procedures for these same locations.

Chapter 3: Analysis of Treatment Options

Determine what treatment options are potentially available for removing chlorides from water, given the range of concentrations found in the salt-laden stormwater, the regulatory standards for the release of such water, and the volumes of runoff that could be expected to be generated at these individual facilities. Treatment in this case constitutes removing sufficient concentrations of $\mathrm{NaCl}$ such that the treated water does not pose a contamination hazard to nearby surface water or groundwater sources, particularly underground sources of drinking water. Alternatives will need to take into consideration other chemical constituents found in stormwater. Any treatment option found to be technically feasible will need to be examined further to determine the startup, capital, and operations costs as compared to current disposal options. 
Chapter 4: Investigation of Reuse Options

Investigate the potential for reuse of the salt-contaminated stormwater runoff at VDOT road-salt storage facilities as a water source for on-site brine production. Since VDOT, like many state DOTs, is beginning to utilize an anti-icing strategy instead of just deicing (Roosevelt, 1997), the department has the need for significant volumes of salt-brine. While it seems logical that the stormwater generated at the salt storage facilities could be used in the production of this brine, the use of this water would likely introduce large variations in both water temperature and turbidity levels during the brine making process. Because of the capital costs invested in the brine production equipment and the consistency and reliability that is needed with the brine produced, a thorough understanding of the possible impacts of the use of stormwater on the final product must be determined prior to recommendation to use stormwater for its generation. More specifically, the research will need to ensure that using stormwater for brine generation will not reduce the quantity of brine that could be produced, will not compromise the quality of the brine, will not damage the brine production systems and application equipment, and again, will be an economically feasible alternative to current disposal options.

Chapter 5: Life Cycle Assessment of the Use of $\mathrm{NaCl}$ and Calcium Magnesium Acetate (CMA) Brines as a Winter Maintenance Approach 
Examine the current methods of using and managing $\mathrm{NaCl}$ to quantify the environmental impact reductions that could potentially be realized by moving to an alternative winter maintenance approach that utilizes $\mathrm{NaCl}$ or $\mathrm{CMA}$ brine. It is anticipated that the benefits of reusing stormwater for the purposes of brine generation will be greater than just the reduction in the volume of water requiring disposal. In an attempt to quantify these benefits a life cycle assessment will be conducted for three distinct winter maintenance approaches: the traditional method of dry, granular $\mathrm{NaCl}$, use of $\mathrm{NaCl}$ brine, and the use of CMA brine. CMA has long been seen as one of the most environmentally benign winter maintenance chemicals. By comparing the use of $\mathrm{NaCl}$ brine to dry $\mathrm{NaCl}$ and $\mathrm{CMA}$ brine, a relative scale for the impacts of $\mathrm{NaCl}$ brine will be developed.

Chapter 6: Summary of Major Conclusions and Research Contributions

This Chapter summarizes the conclusions for each of the subsequent chapters as well as identify areas that require further research. 


\section{CHAPTER 2. PROBLEM CHARACTERIZATION AND IDENTIFICATION OF MINIMIZATION OPPORTUNITIES}

\subsection{INTRODUCTION}

In fiscal year 2003, VDOT purchased more than 570,000 tons of $\mathrm{NaCl}$ (Fitch et al., 2004). This salt, along with various other deicing chemicals, is stored at each of VDOT's residencies and area headquarters, at least one of which is located in every county. In total, salt is stored at 292 locations throughout the state (Fitch et al., 2004). Most of the storage facilities are comprised of a building used to stockpile the chemicals, an adjacent impermeable pad that serves as a loading area for trucks, and a stormwater storage pond or collection basin. The pad is designed to contain any chemicals that may be spilled during the loading process; the runoff from this area is directed to and stored in the nearby stormwater pond. The pond itself is designed to be impermeable to prevent infiltration of the runoff containing varying concentrations of deicing chemicals. The majority of the ponds VDOT constructs are deliberately wide and shallow to facilitate evaporation. Unfortunately, this design also increases the volume of water captured during a precipitation event. Assuming the evaporation rate of the water in the pond is greater than the runoff and direct precipitation inflow rate, the ponds are relatively effective in containing the salt-laden water. However, at many VDOT storage facilities, the holding capacities of the ponds are exceeded by the combination of runoff from the loading pad and direct precipitation to the pond surface. 
Allowing the stormwater ponds containing salt water to overtop and infiltrate has obvious environmental implications. As a consequence, VDOT has been forced to dispose of the salt water by one of three methods: (1) connecting directly to a publicly owned treatment works (POTW) system, (2) pumping and transporting the salt water to a POTW system by tank truck, or (3) applying the salt water to gravel roads (the hygroscopic nature of the $\mathrm{NaCl}$ provides temporary dust suppression). Each option has significant shortcomings. Many parts of the state have few gravel roads, thereby all but eliminating the option of road spraying. The associated costs of the other two disposal systems are very high because of expensive connection and disposal fees and hauling rates. In addition, POTW systems (especially the smaller capacity facilities) are becoming increasingly reluctant to accept salt water because their systems are not designed to remove salt. Large influxes of $\mathrm{NaCl}$ can disrupt the sensitive chemical and biological reactions that make these facilities effective at removing more typical sanitary and industrial wastewater streams.

\subsection{PURPOSE AND SCOPE}

The purpose of this first phase of the research was to perform a chemical characterization of the water captured in the ponds and to develop a more thorough understanding of the water capture, storage, and disposal problem VDOT faces. As a part of the complete problem characterization, an effort was made to identify opportunities to minimize the volume of stormwater captured. Based on the chemical characterization information and estimated volumes of water that would require treatment following implementation of reduction strategies, an initial estimation of the practicality 
of portable water treatments using reverse osmosis (RO), electrodialysis, and ion exchange resins was evaluated to determine which of these technologies warranted further study as a treatment alternative applicable for VDOT.

\subsection{METHODS}

To meet the study objectives, four tasks were undertaken:

1. The literature on the management of contaminated stormwater runoff from salt storage facilities was reviewed.

2. A number of departments of transportation (DOTs) and municipalities were surveyed by email with regard to the methods they use to capture, store, treat, and/or dispose of water captured at their salt storage facilities.

3. Facility information and water quality data from a subset of VDOT's 292 salt storage locations were collected. These data along with regional rainfall and evaporation estimates were used to predict water treatment volumes.

4. Based on the results of the data collection and analysis effort, alternative management and treatment options that would reduce current costs and increase environmental protection were examined. 


\subsubsection{Literature Review}

A literature review was conducted to determine methods and technologies used for sodium chloride removal and to gain a better understanding of the levels of chlorides that would be acceptable in the effluent following treatment.

\subsubsection{Survey of Transportation Entities}

An e-mail survey was conducted by use of the Snow-Ice Mailing List sponsored by the University of Iowa Institute of Hydraulic Resources. This mailing list serves a variety of geographically dispersed groups of public and private transportation professionals who are interested in winter maintenance. The purpose of the survey was to identify environmental management approaches being implemented by other state DOTs and municipalities to minimize and treat runoff water collected at salt storage facilities. In addition, a number of DOTs, consultants, and Canadian provinces were contacted in person, by telephone, and by e-mail.

\subsubsection{Assessment of Quality and Quantity of Salt-Contaminated Water}

To determine the quality and quantity of water from the detention ponds at VDOT's salt storage facilities, data regarding surface area and volume, runoff area, and several key water quality constituents were collected from five randomly selected storage facilities in each of VDOT's nine districts, for a total of 45 sampling sites. Figure 1 shows the district boundaries, the location of salt storage facilities, and the sites chosen for sampling. 


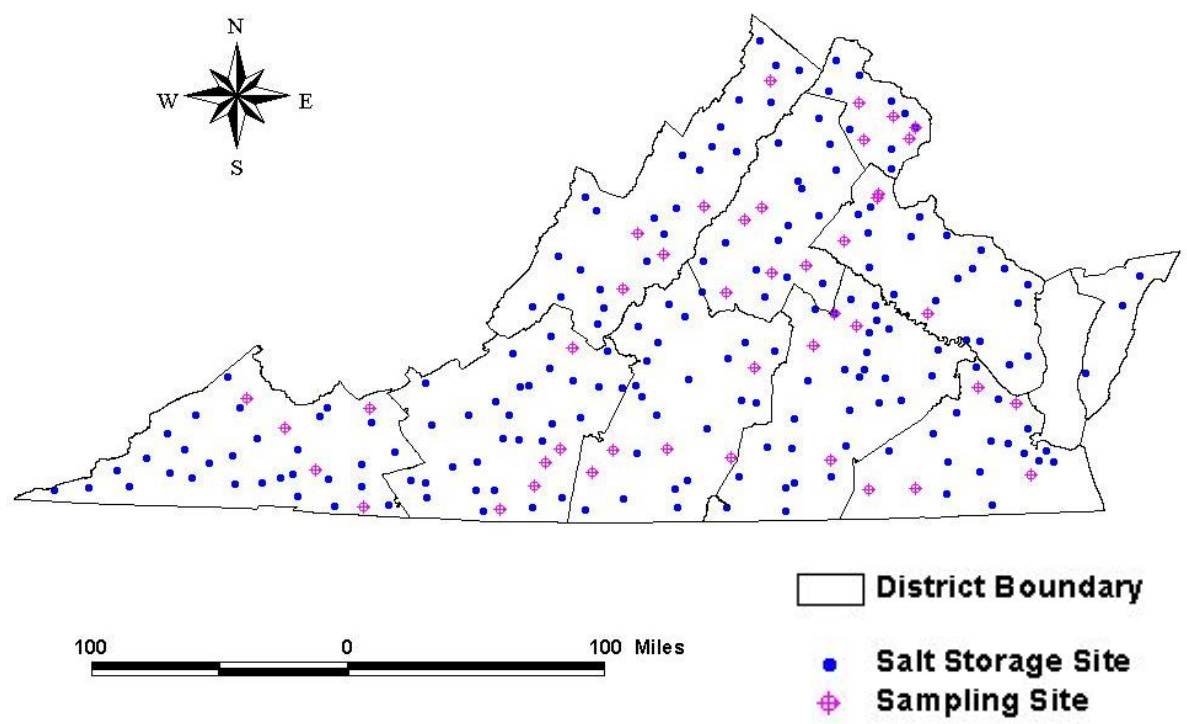

Figure 1. Distribution of Sampled Salt Storage Locations in Virginia

\subsubsection{Water Quality Constituents}

Data were collected from the sampling sites from December 2003 through March 2004. One grab sample was taken from each pond and analyzed in the laboratory for chloride ion concentration and total suspended solids (TSS). An additional sample was collected from each pond and sent to a contract laboratory for analysis of oil and grease. Samples were collected as deep as possible (to ensure the collection of the highest salinity water in the pond) without disturbing the bottom sediment.

The concentration of chloride ion in the samples was determined using a calibrated chloride ion selective electrode. TSS was analyzed according to Standard Method 2540D (American Public Health Association, American Water Works Association, and Water Environment Federation, 1995). The water sample was mixed well and was filtered through a pre-weighed standard glass-fiber filter. The residue retained on the filter was oven-dried at $105^{\circ} \mathrm{C}$. The filter containing the residue was 
weighed upon removal from the oven, with the increase in the weight of the filter representing the TSS.

\subsubsection{Volume of Runoff}

Measurements were taken to estimate the volumes of runoff that would be generated and the volumes of water that could be stored in the detention basins at each location sampled. The runoff area for each site was assumed to be equal to the area of the paved surface that drained into the detention pond. In some cases, this was significantly larger than the actual loading pad area at the sites. The surface areas and volumes of the ponds were estimated by measuring the length, width, and depth of each pond and estimating the slope of the sidewalls. The volume of salt water captured at each site was calculated by multiplying the measured surface areas and precipitation values and subtracting the volume lost to evaporation from the pond surface.

Calculations were made using total annual precipitation estimates and precipitation estimates for the months of November through March, as these five months covered the period when VDOT is most likely to apply salt. Historical precipitation data from 1965 through 2003 were obtained from the Southeast Regional Climate Center (2004). Three stations with historical climate data from 1965 through 2003 were located in each of the nine districts. An attempt was made to choose stations in different geographical locations in the district so that differences in precipitation across the district would be taken into account. Next, the annual precipitation recorded at each of the 27 stations was summed for each year in the 38-year period. The overall lowest amount of precipitation among the 27 stations occurred in 1965. The highest amount of 
precipitation occurred in 2003, and average precipitation occurred in 1973. Monthly evaporation averages were taken from 30 years of data collected at five regional stations throughout the state (Virginia State Climatology Office, 2001). The average treatment and storage volumes for the five sites in each of VDOT's nine districts was then multiplied by the total number of storage sites in each district to provide district volume and storage totals.

\subsubsection{Evaluation of Treatment Alternatives}

\subsubsection{Current VDOT Practices}

To determine the feasibility of any treatment technology, it must be compared with existing practices. To gain a better understanding of VDOT's method of handling salt-laden drainage water, the supervisors of each of VDOT's area headquarters sampled were asked to provide information regarding the handling and fate of the water captured

in the stormwater collection basins. Specific items requested included approximate pond volume, fate of the collected water, frequency of removal, and costs associated with removal.

\subsubsection{Selection of Alternatives}

Three treatment options (RO, ion exchange, and electrodialysis) were selected for evaluation as a means of treating the runoff water collected at salt storage facilities. Manufacturers and users of these technologies were consulted to determine system capacities with respect to throughput volumes, removal efficiencies, equipment purchase costs, operational costs, maintenance issues, and brine-production percentage estimates. 
Management options that would reduce the volume of salt-contaminated water generated at the salt storage facilities were also considered.

\subsection{RESULTS AND DISCUSSION}

\subsubsection{Literature Review}

The review of the literature revealed relatively limited information on the management of contaminated stormwater runoff from salt storage facilities. The Transportation Association of Canada (2003) developed syntheses of best management practices for road salt management. In two of these documents (4.0 Drainage and Stormwater Management and 7.0 Design and Operation of Road Maintenance Yards), significant information is provided on the environmental effects of chloride contamination on the roadside environment and on the design, layout, and operation of DOT maintenance yards. These documents recommend that runoff from loading pads be collected and then discharged to a sewage treatment facility or used for the production of brine. These appear to be the only two options recommended for DOTs that are properly capturing salt-laden water. No recommendations were found regarding the appropriate size and design of loading pads or ponds to help minimize runoff and maximize evaporation. Similarly, no mention of expected treatment concentrations, treatment volumes, or effluent concentration targets was found.

\subsubsection{Survey of Transportation Entities}

Very little information pertaining to the use of treatment technologies specifically for chloride removal was obtained from the e-mail survey. Although many states were 
interested in finding out more about the findings of the research effort, only a few responders were able to provide information relevant to the survey. The Indiana DOT, in conjunction with Purdue University, is beginning to use the rinse water (generated when washing down the salt spreaders) for the production of brine to be used as a pre-wetting agent. Salt is added to the rinse water after sediment, oil, and grease have been removed (Alleman, 2003). The Utah DOT also collects wash water and loading pad runoff in asphalt-lined retention basins. They use a portion of this collected water to make brine at approximately 25 stations. The retention basins are sized such that they are able to collect not only wash water, but also all runoff from each maintenance station site. Water that is not used for the production of brine evaporates, allowing for the removal of sediment once a year to a landfill (Bernhard, 2003). The Minnesota DOT experimented with the use of runoff from its salt storage facilities to make brine but found they were generating far more brine than they could use and subsequently halted the brinegenerating process (Vasek, 2003). The City of Calgary reportedly uses solar powered pumps to pump water from collection ponds to the top of their maintenance yard, thereby increasing evaporation by allowing the water to flow across the asphalt surface (R. Hodgins, unpublished data). The Kentucky DOT has a National Pollutant Discharge Elimination System (NPDES) discharge permit that allows them to discharge water collected in their basins provided chloride concentrations are below $1200 \mathrm{mg} / \mathrm{L}$ (Jett, 2003).

The New York State DOT (Anderson, 2004), the Ontario Ministry of Transportation (Blackburn, 2004), and the Colorado DOT (Santangelo, 2004) are all using or developing systems to treat wash water resulting from the cleaning of vehicles 
used for the application of deicing chemicals;. Colorado's system cleans and recycles the water using a series of filters. Reportedly, all contaminants were lowered to drinking water standards with the exception of chlorides. Consequently, they are testing other materials that can be used to impregnate the filters to aid in the removal of chlorides (Santangelo, 2004). New York is in the process of constructing facilities using crushed glass as a filtering medium for the wash water prior to it going to an evaporation pond (Anderson, 2004). The Ontario Ministry of Transportation recycles their wash water for the production of brine (Blackburn, 2004).

\subsubsection{Quality and Quantity of Salt-Contaminated Water}

\subsubsection{Water Quality Constituents}

Table 1 presents average concentrations of chloride, TSS, and oil and grease for each VDOT district. The chemical composition of the detention pond water was quite varied, with chloride concentrations ranging from 140 to $3100 \mathrm{mg} / \mathrm{L}$. Based on the standard deviation of the sample population, it can be predicted that $95 \%$ of VDOT's ponds will have chloride concentrations below $3200 \mathrm{mg} / \mathrm{L}$. The statewide average chloride concentration was $1600 \mathrm{mg} / \mathrm{L}$. In comparison, as stated previously, the Kentucky DOT has a NPDES permit to release water from its salt water basins provided the chloride concentration is below $1200 \mathrm{mg} / \mathrm{L}$. Almost all of the chloride concentrations were significantly greater than state and federal regulatory guidelines for drinking water and surface water quality criteria, with individual values routinely exceeding $2000 \mathrm{mg} / \mathrm{L}$. The Virginia anti-degradation limit for sodium is $270 \mathrm{mg} / \mathrm{L}$ (Virginia State Water Control Board, 2004), and the U.S. Environmental Protection Agency's National Secondary 
Drinking Water Regulation maximum contaminant level for chloride is $250 \mathrm{mg} / \mathrm{L}$ (U.S. Code, 2002). These secondary standards are non-enforceable guidelines for contaminants that could cause cosmetic or aesthetic (taste/odor) effects in water (U.S. Code, 2002). In addition, even though 45 chloride samples were analyzed, all the samples were collected during a year when the statewide precipitation was the highest it had been in 40 years. It is not unreasonable to assume that this resulted in a higher than normal dilution of the chlorides collected in the ponds. Therefore, sampling during drier years would likely result in higher measured chloride concentrations.

TSS values ranged from 3 to $270 \mathrm{mg} / \mathrm{L}$, with a statewide average of $20 \mathrm{mg} / \mathrm{L}$. Ninety-five percent of all of VDOT's ponds would be expected to have concentrations below $100 \mathrm{mg} / \mathrm{L}$ based on the standard deviation and average of the concentrations for the samples collected. The $270 \mathrm{mg} / \mathrm{L}$ concentration found at one of the sites appears to be an anomaly. These low concentrations are the result of the sediment settling after the water enters the ponds. Most of the pond bottoms did have significant accumulations of sediment. The low TSS concentrations are advantageous to all three of the treatment systems being considered.

Oil and grease concentrations ranged from less than $2 \mathrm{mg} / \mathrm{L}$ to $193 \mathrm{mg} / \mathrm{L}$. With the exception of the highest reading, almost all of the sites had relatively low concentrations $(<6 \mathrm{mg} / \mathrm{L})$, as indicated by the statewide average oil and grease concentration of approximately $2 \mathrm{mg} / \mathrm{L}$. Again, these low concentrations are beneficial with respect to the treatment systems VDOT could potentially use. 
Table 1. Mean Concentrations of Chloride, Total Suspended Solids, and Oil and Grease in Samples Collected from Saltwater Storage Ponds in VDOT Districts.

\begin{tabular}{cccc}
\hline $\begin{array}{c}\text { Sampling Site } \\
\text { (District) }\end{array}$ & $\begin{array}{c}\text { Chloride } \\
(\mathbf{p p m})\end{array}$ & $\begin{array}{c}\text { Total Suspended } \\
\text { Solids } \\
(\mathbf{m g} / \mathbf{L})\end{array}$ & $\begin{array}{c}\text { Oil and Grease } \\
(\mathbf{m g} / \mathbf{L})\end{array}$ \\
\hline A & 942 & 8.8 & 4.5 \\
B & 597 & 14.3 & 0.4 \\
C & 2118 & 10.2 & 1.2 \\
D & 1807 & 8.7 & 1.7 \\
E & 1322 & 5.3 & 1.8 \\
F & 1825 & 15.0 & 2.0 \\
G & 2604 & 23.0 & 1.0 \\
H & 1665 & 65.0 & 2.2 \\
I & 1578 & 33.0 & 39.0 \\
\hline
\end{tabular}

\subsubsection{Volume of Runoff}

Measured pond areas ranged from $38 \mathrm{~m}^{2}$ to $1350 \mathrm{~m}^{2}$. Pond volumes were extremely varied, with measured values as low as $38 \mathrm{~m}^{3}$ and as high as $568 \mathrm{~m}^{3}$. Saltloading-pad areas ranged from $66 \mathrm{~m}^{2}$ to $2000 \mathrm{~m}^{2}$. A typical layout for a storage site with an average-size pond and loading pad is shown in Figure 2. The average runoff areas, pond volumes, and salt water storage values calculated for each district are shown in Table 2.

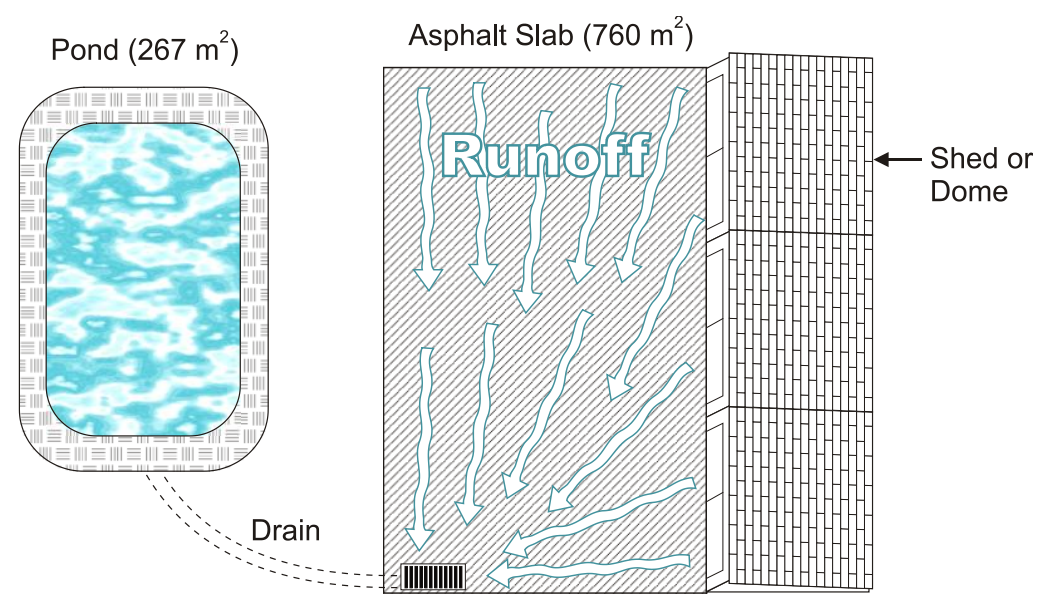

Figure 2. Diagram of Typical Layout of Salt Storage Facility with Average Size Pond and Loading Pad 
Table 2. Average Runoff Areas, Pond Areas, and Pond Volumes for VDOT Area Headquarters and Estimated Pond-Storage Volumes for VDOT Districts

\begin{tabular}{|c|c|c|c|c|c|c|}
\hline $\begin{array}{l}\text { Sampling Site } \\
\text { (District) }\end{array}$ & $\begin{array}{c}\text { Runoff Area } \\
\left(\mathbf{m}^{2}\right)\end{array}$ & $\begin{array}{c}\text { Pond Area } \\
\left(\mathbf{m}^{2}\right)\end{array}$ & $\begin{array}{c}\text { Pond Volume } \\
\left(\mathbf{m}^{3}\right)\end{array}$ & $\begin{array}{c}\text { Pond Volume } \\
\text { (gal) }\end{array}$ & $\begin{array}{l}\text { No. Sites/ } \\
\text { District }\end{array}$ & $\begin{array}{c}\text { District } \\
\text { Storage Volume } \\
\text { (gal) }\end{array}$ \\
\hline $\mathrm{A}$ & 272 & 215 & 321 & 84,667 & 41 & $3,471,353$ \\
\hline B & 616 & 167 & 198 & 52,306 & 25 & $1,307,652$ \\
\hline $\mathrm{C}$ & 651 & 196 & 142 & 37,486 & 24 & 899,665 \\
\hline D & 277 & 196 & 202 & 53,363 & 28 & $1,494,157$ \\
\hline E & 1,207 & 102 & 104 & 27,474 & 39 & $1,071,482$ \\
\hline F & 2,336 & 640 & 247 & 65,251 & 17 & $1,109,259$ \\
\hline G & 508 & 128 & 265 & 70,006 & 46 & $3,220,258$ \\
\hline $\mathrm{H}$ & 489 & 164 & 371 & 97,929 & 36 & $3,525,430$ \\
\hline I & 492 & 597 & 717 & 189,411 & 36 & $6,818,810$ \\
\hline Total & & & & & 292 & $22,918,066$ \\
\hline
\end{tabular}

Table 3 shows the treatment volumes calculated for each district. Minimum (1965 rainfall data), average (1973 rainfall data), and maximum (2003 rainfall data) volumes were calculated assuming precipitation was collected for the entire year and for the 5-month winter maintenance period. The evaporation data collected for Virginia did not have values for the months of November, December, January, February, or March, so no loss in treatment volume was assumed for the winter months.

Table 3. Treatment Volumes for VDOT Districts

\begin{tabular}{|c|c|c|c|c|c|c|}
\hline \multirow[b]{2}{*}{ District } & \multicolumn{3}{|c|}{ Annual Treatment Volumes (gal) } & \multicolumn{3}{|c|}{ Winter Treatment Volumes (gal) } \\
\hline & Minimum & Average & Maximum & Minimum & Average & Maximum \\
\hline A & $2,993,625$ & $4,162,455$ & $5,720,895$ & $1,740,258$ & $2,748,915$ & $3,545,451$ \\
\hline B & $3,438,175$ & $5,083,195$ & $8,243,365$ & $1,727,271$ & $2,363,634$ & $3,082,248$ \\
\hline $\mathrm{C}$ & $0 *$ & $4,433,237$ & $6,078,257$ & 219,913 & $2,341,989$ & $2,948,049$ \\
\hline $\mathrm{D}$ & 900,167 & $2,129,603$ & $2,869,862$ & 701,298 & $1,558,440$ & $1,588,743$ \\
\hline $\mathrm{E}$ & $10,571,211$ & $14,164,281$ & $17,194,581$ & $4,030,299$ & $6,363,630$ & $6,493,500$ \\
\hline $\mathrm{F}$ & $7,264,381$ & $10,641,001$ & $18,606,361$ & $3,796,533$ & $5,151,510$ & $6,926,400$ \\
\hline G & $3,721,483$ & $6,665,203$ & $11,297,233$ & $1,783,548$ & $3,562,767$ & $3,735,927$ \\
\hline $\mathrm{H}$ & $2,818,428$ & $5,619,291$ & $8,433,141$ & $1,891,773$ & $3,229,434$ & $3,246,750$ \\
\hline I & $3,652,935$ & $5,730,855$ & $9,150,765$ & $2,662,335$ & $3,679,650$ & $4,320,342$ \\
\hline otal & $35,031,741$ & $58,629,120$ & $87,594,459$ & $18,553,228$ & $30,999,969$ & $35,887,410$ \\
\hline
\end{tabular}

*Evaporation greater than precipitation. 
The data in Tables 2 and 3 reveal the significant volume of salt-contaminated water generated and stored at facilities throughout Virginia. For an average rainfall year, approximately $60 \mathrm{MG}$ of contaminated runoff water is generated from the 292 facilities. Even if only the runoff generated during the 5-month winter maintenance season is considered, the volume of salt-contaminated water is in excess of $30 \mathrm{MG}$.

It is also interesting to note the large variance in both pond volumes and runoff area from district to district (Table 2). This is likely caused by inconsistencies in either loading-pad design or pond sizing. Ponds and pads have been constructed based on current site characteristics as opposed to runoff expectations and evaporation rates. Figure 3 shows a comparison of loading pad sizes to pond storage volumes. It is evident from this figure that there is a very weak relationship between these two parameters.

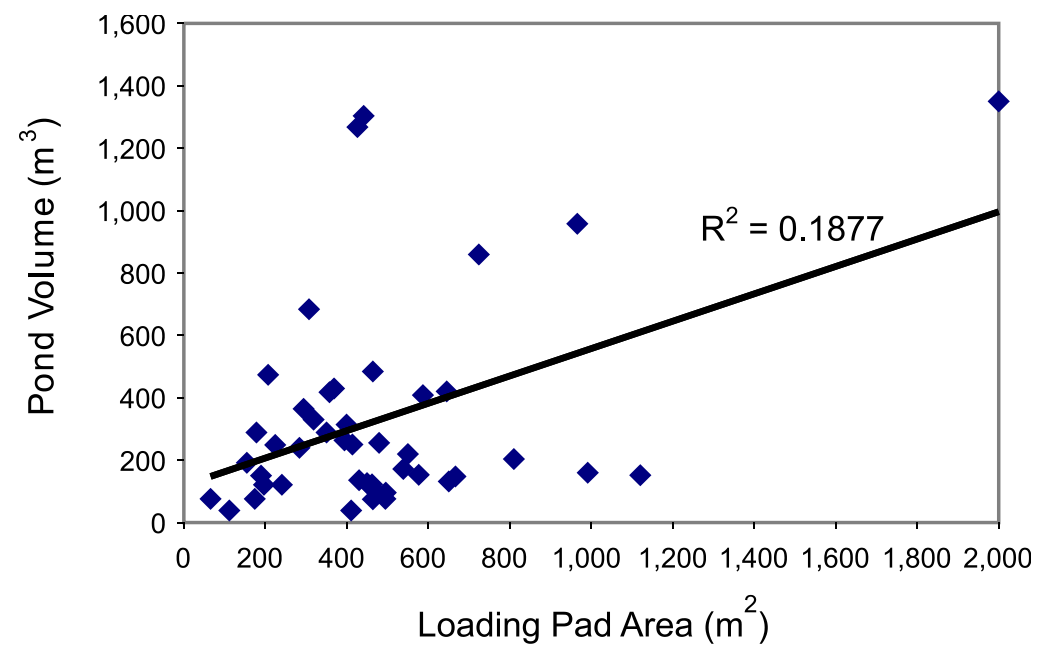

Figure 3. Loading Pad Area versus Pond Volumes for 45 Sample Locations

\subsubsection{Current VDOT Management Practices}

In Virginia, supervisors of maintenance area headquarters provided information related to their disposal methods and the costs of stormwater management. Handling practices 
were quite varied. Some locations never have their ponds pumped. Others use VDOT employees to pump, haul, and spray the salt water captured in the ponds on gravel roads. Based on billing rate information provided by area headquarters for trucks, pumps, and drivers, the costs for this type of procedure are approximately $\$ 0.08 /$ gallon. The majority of the area headquarters sampled hire a contractor to pump, haul, and dispose of captured salt water. The average per gallon cost for this disposal method is approximately $\$ 0.13$. A limited number of others discharge the contaminated stormwater runoff to POTW systems. No cost estimates were obtained for this method of disposal. The frequency of pumping varied significantly from location to location, as did the total volume of disposed water. Some facilities are pumped up to 13 times a year, and others are reportedly never pumped. Some reported pumping even during the summer, and others only during the winter.

\subsubsection{Evaluation of Other Management Alternatives}

There are two possible alternative approaches VDOT can apply to manage stormwater runoff at salt storage facilities. First, additional management strategies can be employed to reduce the volume of salt-contaminated stormwater runoff generated at each facility. Second, the runoff that is captured can be treated to remove the salt and then released back to the environment. It is also possible that a combination of these two approaches can be employed. 


\subsubsection{Reduction of Runoff Volume}

At present, stormwater runoff is directed to the storage ponds on-site. However, if salt deliveries and loading operations for a majority of facilities were limited to the five winter maintenance months (November through March), the diversion of runoff water

during the remaining seven months from the ponds to a natural discharge point would not result in environmental salt contamination. This is consistent with current VDOT guidelines; however, it does not appear that these guidelines are being followed in all cases. Based on the storage volumes measured and the expected treatment volumes calculated, the number of times each pond in each district would need to be pumped or emptied is shown in Figure 4. This information highlights the benefit of diverting all water during the non-winter months. It also shows that for particular districts, storage ponds would have to be pumped more than once even if only runoff from the winter months was collected in the storage ponds. Multiplying the number of times pumping would be required for each district for an average precipitation year by the number of ponds per district results in a total of 628 pumping events required statewide, or an average of 70 events required for each district each year. It should be noted that this calculation assumes that all runoff water is collected and none of the water is sent to POTWs or used for roadway applications. 


\section{Low Annual Precipitation}

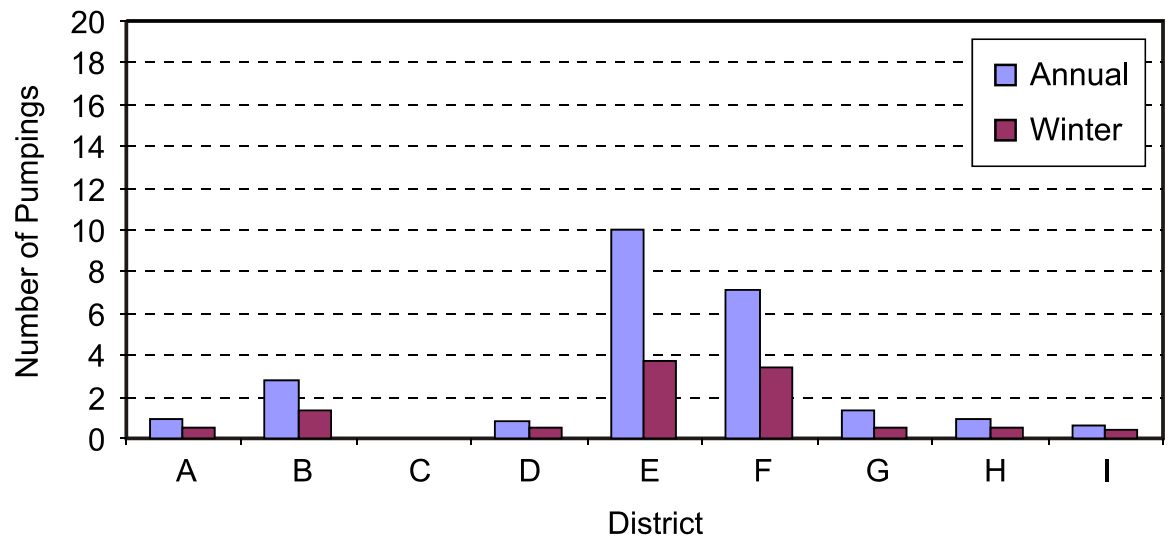

Average Annual Precipitation

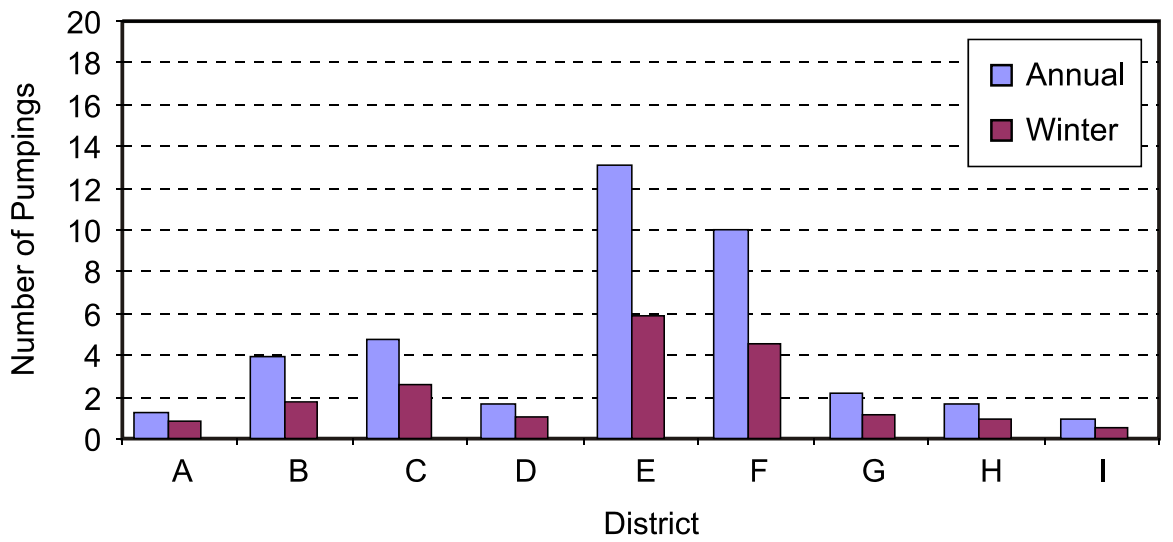

High Annual Precipitation

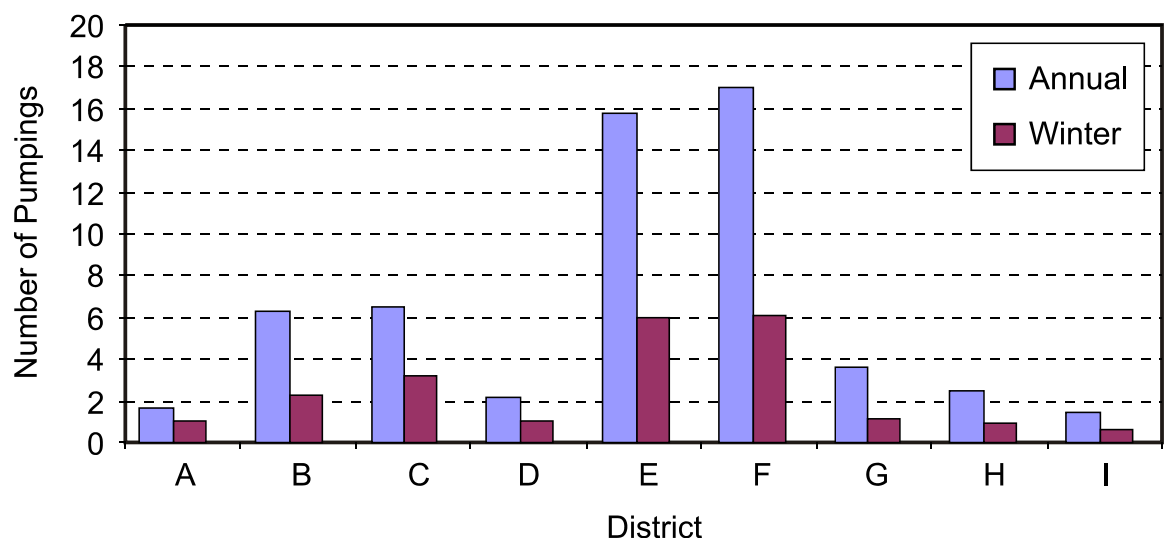

Figure 4. Average Number of Treatments Required for Each of VDOT's Salt Ponds Assuming Low, Average, and High Annual Precipitation 
Even with the evaporation losses that occur during the summer months, nearly twice the volume will require treatment if water is not diverted during the non-winter months. Diverting this water would in many cases require facility modifications, as many of the sites visited as part of this investigation do not have the valves or outlets that would be required to allow for this. Although retrofitting sites so that water diversion is possible would require substantial one-time capital costs, the potential savings from diversion are quite significant. If one assumed that VDOT was currently capturing $100 \%$ of the water that resulted from loading pad runoff year round but was then diverting all runoff collected from April through October, then VDOT could theoretically save approximately $\$ 4$ million/year by retrofitting the sites. This scenario assumes average precipitation and that all water disposed of is done so at a cost of $\$ 0.13 /$ gallon. In reality, VDOT is not paying this fee for all water that is captured, as previously explained. Another method of reducing runoff entering the collection basins is simply reducing the size of the loading pads. Assuming average precipitation, each square foot of loading pad is collecting just over 26 gallons of water per year. Assuming VDOT pays $\$ 0.13$ per gallon to dispose of this water and that $100 \%$ of the water is collected for the entire year, each square foot of loading pad results in $\$ 3.40$ in water disposal costs per year. If runoff is collected during only the winter months, each square foot of loading pad results in disposal costs of $\$ 1.46$ per year.

During site visits and discussions with VDOT staff, field personnel mentioned that the volume of salt-contaminated runoff water could also be greatly reduced by construction of steel-frame, open-sided roofs over each salt loading pad. The sizing and design of these structures would be very site specific, and although the initial capital 
costs of this approach would be substantial, operating and maintenance costs over the ensuing 10-year period would likely be small. Runoff collected at a site would be limited to precipitation that blows onto the pad from the sides and possibly rinse water from cleaning salt spreaders and the pad itself. Although it is difficult to predict this runoff volume, it is likely that the runoff produced would be less than the total evaporation for most sites. Therefore, it is reasonable to expect that no additional water treatment or management activities would be required for sites where loading pads were covered. In addition to the significant capital costs required to construct open-sided coverings for loading pads, properly determining the size of the structures would be critical. As previously shown, the loading pads themselves are quite large. Because it would not be practical to cover the entire loading pad for most sites, the optimum length and width would need to be determined to ensure sufficient room to maneuver both trucks and loaders. Diverting water from adjacent paved areas by way of berms would also be necessary to ensure that only water from the covered portion of the loading pad was directed to the storage pond. To accommodate dump type tractor-trailer unloading of salt at the larger storage facilities, the minimum height of the structure would need to be 35 feet. This height would make the structure itself more susceptible to wind uplift and the pad more susceptible to precipitation blowing in from the sides. It may be possible to cover pads where tractor-trailers do not have to be accommodated with lower structures, with the height being predicated on the height of the front loaders used. Based on construction costs for canopies constructed in conjunction with fuel pumps (Kinker, 2004), it is assumed that these type of structures could be built to serve VDOT's loading pads for approximately $\$ 50 /$ square foot. 


\subsubsection{Runoff Treatment Alternatives}

The three water treatment technologies reviewed to determine their feasibility in removing dissolved ions from water were ion exchange, electrodialysis, and RO. A brief description of each is provided here along with a general assessment of whether it would be technically feasible for VDOT to use based on the volumes of water to be treated, the starting TSS and chloride concentrations, and the assumed chloride target concentration

of $250 \mathrm{mg} / \mathrm{L}$. The approximate per gallon cost of treating salt water with each technology is also provided.

\subsection{Ion Exchange}

In an ion exchange treatment process, salt-contaminated water is pumped through a number of columns containing ion-exchange resins. The resins are characterized by ion-exchange sites that are initially saturated with $\mathrm{H}^{+}$or $\mathrm{OH}^{-}$ions. When water containing ions such as $\mathrm{Na}^{+}$or $\mathrm{Cl}^{-}$is pumped through the columns, the $\mathrm{Na}^{+}$ions exchange with $\mathrm{H}^{+}$ions, and the $\mathrm{Cl}^{-}$ions exchange with $\mathrm{OH}^{-}$ions. The $\mathrm{H}^{+}$and $\mathrm{OH}^{-}$ions released into solution form $\mathrm{H}_{2} \mathrm{O}$, resulting in no net $\mathrm{pH}$ change of the treated water. After the exchange sites on the resins are depleted, flushing them with concentrated solutions of sulfuric acid and sodium hydroxide can regenerate the resins.

Generally, it was found that water with relatively high levels of total dissolved solids (e.g., greater than $400 \mathrm{mg} / \mathrm{L}$ ) requires treatment beyond ion exchange alone. VDOT's average chloride concentrations are significantly higher than $400 \mathrm{mg} / \mathrm{L}$, so this fact alone seems to preclude the use of this technology without pretreatment. In addition to this limiting factor, ion exchange also requires on-site storage of the caustic and acid 
regeneration solutions that would pose additional liability and risks for VDOT. The highly saline wastewater resulting from the regeneration process would also require a separate disposal mechanism (Benjamin Johnson, Marlo, Inc., unpublished data).

The cost of water treatment by ion exchange (including maintenance) ranges from $\$ 0.002$ to $\$ 0.003$ per gallon treated exclusive of disposal costs of the concentrated rinse solution produced during resin regeneration (Benjamin Johnson, Marlo, Inc., unpublished data).

\subsection{Electrodialysis}

Electrodialysis is an electrochemical separation process that uses two types of membranes: one permeable to cations, the other to anions. Direct current between two electrodes provides the driving force for the ions moving through the membranes. In real-world applications, hundreds of compartments are formed by the alternating membranes to produce a stream containing the concentrate and "clean" stream. Cargill, one of the world's largest distributors of deicing salt, provided most of the information related to this technology. Specifically, Cargill constructed and is operating an electrodialysis system to treat the runoff at their Lansing, New York, bulk salt storage facility. With this system, they are capable of treating very large volumes of water with significantly higher chloride concentrations than VDOT is currently capturing (50000 to $80000 \mathrm{mg} / \mathrm{L}$ versus $2500 \mathrm{mg} / \mathrm{L}$ ). After lowering the chloride concentrations to approximately $40000 \mathrm{mg} / \mathrm{L}$, Cargill is permitted to discharge the effluent to a nearby river (Mark Crandall, Cargill, Inc., unpublished data). 
Due in part to this research effort, Cargill is in the process of designing and testing a smaller electrodialysis system based on VDOT's typical chloride concentrations. They have admittedly run into several problems that they have not experienced when aiming for higher effluent values with their larger system: increased water temperature and very low conductivity. Both of these problems stem from the relatively low chloride concentrations. Design and operation changes are being made to their test system in an attempt to overcome these two problems (Mark Crandall, Cargill, unpublished data). Cargill has been extremely helpful with this effort to identify a feasible technology and their testing of the system to meet VDOT's effluent goals continues.

No other electrodialysis applications that could be directly compared to VDOT's intended use were found. Although the final testing of Cargill's system is not complete, the very early cost estimates for treatment are in excess of $\$ 1 /$ gallon. A Cargill representative emphasized that these estimates were admittedly high and will be revised as additional data become available following more complete testing (Anthony Hensley, Cargill, Inc., unpublished data).

\subsection{Reverse Osmosis}

RO refers to the process wherein water containing one or more solutes is forced through a membrane that allows the water but not the dissolved solute(s) to pass. If no external pressure is applied to the water on either side of the membrane, water will flow from the dilute side of the membrane to the concentrated side of the membrane until a pressure differential (equal to the osmotic pressure) is reached and the system is at equilibrium. By applying an external pressure on the concentrated side of the membrane 
that is greater than the osmotic pressure, water flows from the concentrated side of the membrane to the dilute side. This results in purification of the water and the production of a more concentrated waste solution.

Unlike ion-exchange systems, RO systems do not require caustic or acid solutions for membrane regeneration, but they do require occasional membrane cleaning and eventual replacement. RO generally can achieve $90 \%$ to $98 \%$ removal of dissolved solids. This removal rate is satisfactory to treat the runoff water to a $\mathrm{Cl}^{-}$concentration less than $250 \mathrm{mg} / \mathrm{L}$, which is the U.S. Environmental Protection Agency's National Secondary Drinking Water Regulation maximum contaminant level (U.S. Code, 2002). However, the concentrated waste-stream discharge rate from the process can range between $20 \%$ and $50 \%$ of the inflow discharge. For treatment streams with only a few inorganic ions and low concentrations of TSS and organic constituents, concentrated waste-stream generation is likely to equal $20 \%$ to $30 \%$ of the inflow discharge.

The RO process is relatively sensitive to TSS concentrations greater than a few milligrams per liter. Based on the TSS values measured as a part of this study (Table 1), it may be necessary to pre-treat the pond water by ultrafiltration to remove TSS and prevent RO membrane fouling. Implementation of RO or ultrafiltration/RO systems would require consideration of several additional factors. For a mobile system, there must be treated-water discharge locations at each storage facility. Discharge sites might include sanitary/stormwater sewers, natural surface-water bodies (e.g., rivers or lakes), or spray irrigation on lots. Concentrated waste streams resulting from the RO treatment process would require storage prior to off-site disposal. It may be possible to have the existing ponds serve as storage for the waste stream. It is also possible that a portion of 
the concentrate could be used as the brine used for pre-wetting dry salt discharges to roadways. As discussed earlier, several states are doing this successfully.

The cost of water treatment by RO (including maintenance) is estimated to be about $\$ 0.00075$ per gallon, not including the disposal costs of the concentrated waste stream generated by the process (Benjamin Johnson, Marlo, Inc., unpublished data). Another way of deriving anticipated costs with RO treatment are to use known capital costs $(100$ gallons per minute $[\mathrm{gpm}] \mathrm{RO}$ unit $=\$ 62,000$, replacement membranes $=$ $\$ 14,400)$ and to assume a maximum lifetime throughput for the unit (120 MG). In this scenario, the cost per gallon is $\$ 0.00064$, but this does not take into account actual operational costs or disposal costs of the waste stream. This scenario also assumes a very long membrane life.

The cost of water treatment by ultrafiltration is comparable to the cost of RO treatment. Therefore, combining ultrafiltration with RO (including maintenance) can be expected to cost about $\$ 0.0015$ per gallon. The costs shown here for $\mathrm{RO}$ and ultrafiltration/RO do not include transportation costs, operator costs, or the cost to dispose/reuse the concentrated waste stream. For transportation, a portable, 100-gpm ultrafiltration/RO unit could potentially service each transportation district. The treatment system could, therefore, be driven to each VDOT storage location and used to treat the pond water on-site. The cost to purchase and maintain a truck for the water treatment system is approximately $\$ 12,000$ per year. A full-time driver and operator for a 100-gpm treatment system (including salary, benefits, and overhead costs) is approximately $\$ 90,000$ per year. Assuming that $25 \%$ of the treated water volume is converted to a concentrated waste stream that requires off-site disposal at a cost of $\$ 0.13$ 
per gallon, the treatment cost of an ultrafiltration/RO system (assuming an averageprecipitation year with treatment of year-round runoff water) is about $\$ 0.047$ per gallon. For an RO system not requiring ultrafiltration, the treatment cost would be about the same, as the savings from the capital costs of the ultrafiltration unit are small compared to the off-site disposal costs of the RO concentrated waste stream and the annual operator and transportation costs. The overall treatment cost of a mobile ultrafiltration/RO system (\$0.047) is less than half the cost currently paid by VDOT for off-site wastewater disposal $(\$ 0.13)$. The cost is also $58 \%$ of the cost paid by VDOT to use the wastewater for dust control on gravel roads $(\$ 0.08)$. For a statewide annual treatment volume of 58.6 MG, this could potentially result in annual saving ranging from $\$ 1.9$ million to $\$ 4.9$ million, assuming all water was captured and treated or disposed of in some manner.

\subsection{CONCLUSIONS}

Based on characterization effort it was determined that there is great variability in the size of VDOT's loading pads and associated stormwater basins. This variability results in a wide disparity in the amount of salt water collected and stored at the different facilities found statewide, but even the districts with the smallest total loading pad areas capture millions of gallons of stormwater each year that must be properly managed. It was also determined that VDOT's most commonly used disposal method (pump, haul, and dispose of at a POTW) costs approximately $\$ 0.13 /$ gallon. Therefore, no matter the treatment system employed by VDOT there is potential for cost savings that could be realized by reducing the volume of water directed to the water collection ponds through a 
combination of loading pad size reduction, diversion valve installation, and consistent implementation of existing guidelines.

Neither ion exchange nor electrodialysis appears to be a technically feasible treatment option that VDOT could implement immediately. However, based on the preliminary examination done here, both $\mathrm{RO}$ and ultrafiltration/RO appear to be technically feasible water treatment options for reducing chlorides to a concentration of $250 \mathrm{mg} / \mathrm{L}$ or less. In addition, based on preliminary information, these treatment costs are as much as 1.7 times less expensive than the water disposal costs currently being spent by VDOT to remove the salt-contaminated pond water from salt storage facilities.

It appears that by employing additional management strategies and alternative treatment technologies such as RO, VDOT could realize savings in excess of \$2 million per year. These savings might be significantly higher assuming all stormwater generated at the department's chemical storage facilities were disposed of and/or if the disposal price increases in the future. 


\section{CHAPTER 3. POTENTIAL USE OF REVERSE OSMOSIS IN MANAGING SALTWATER WASTE COLLECTED}

\subsection{INTRODUCTION}

Even with pad size reduction and the use of diversion valves, it was recognized that VDOT would still capture large volumes of water that would require disposal or treatment. Therefore, in addition to the characterization of the water captured at VDOT sites, the earlier research included an evaluation of three treatment alternatives: ion exchange, electrodialysis, and reverse osmosis (RO). The assessment was based on the findings concerning the quantity and quality of the water captured at VDOT's sites. Using this information and an assumed target chloride concentration of $250 \mathrm{mg} / \mathrm{L}$ (411 $\mathrm{mg} / \mathrm{L} \mathrm{NaCl}$ ), it was determined that $\mathrm{RO}$ was the only technology that was potentially feasible for use. The other two alternatives were determined not be cost effective or technologically feasible, given the characteristics of the VDOT sites (Fitch et al., 2004; Fitch et al., 2006).

RO has been used extensively for the treatment of water in a variety of settings including the pharmaceutical, semiconductor, power generation, pulp and paper, and chemical and petrochemical industries. The U.S. Bureau of Reclamation has even proposed using RO to treat a portion of the irrigation runoff captured within the San Joaquin Valley (Landers, 2003). Despite this wide variety of uses, almost no documentation exists regarding the use of $\mathrm{RO}$ to treat stormwater runoff and, more specifically, runoff water containing high levels of $\mathrm{NaCl}$. Therefore, although $\mathrm{RO}$ appears promising, many issues about its applicability need to be identified before VDOT 
can incur the capital costs required to use it as a means of treating salt water on a large scale. Some of these issues include the need and means of pre-filtering, waste and product stream characteristics, percent reduction in treated water volume, and unforeseen maintenance issues.

\subsection{PURPOSE AND SCOPE}

The purpose of this component of the research was to perform a pilot study of the RO treatment technology to determine if it is something VDOT should invest in and use at some of its salt storage facilities. A single RO unit was used to treat salt water in a laboratory setting where all parameters could be controlled and at a VDOT field site.

\subsection{METHODS}

To meet the study objectives, the study team undertook two primary tasks: laboratory testing and field testing of an RO unit.

\subsubsection{Laboratory Testing}

A 2000 GPD RO treatment system built by Clean Water Products was initially tested in the laboratory. The unit was built with a female plug receptacle in the back designed to work in conjunction with a float switch. The system uses a 3/4 horsepower pump to push water through a 4-inch by 40-inch RO membrane at 160 psi.

The experimental setup used to run the laboratory test is presented in Figure 5A. Salt-contaminated water was prepared using a $\mathrm{NaCl}$ concentrate solution and was mixed continuously with tap water to achieve the desired $\mathrm{NaCl}$ concentration to feed the $\mathrm{RO}$ 
unit. From the mixing tank, the feed solution passed first through two pre-filters to remove sediment greater than 5 microns in size and then to the RO filter. On the RO unit, because of the high pressures applied through the $\mathrm{RO}$ membrane, both low $\mathrm{NaCl}$ (product) and high $\mathrm{NaCl}$ (reject) concentration streams are generated. Part of the reject stream was used as a recirculation.

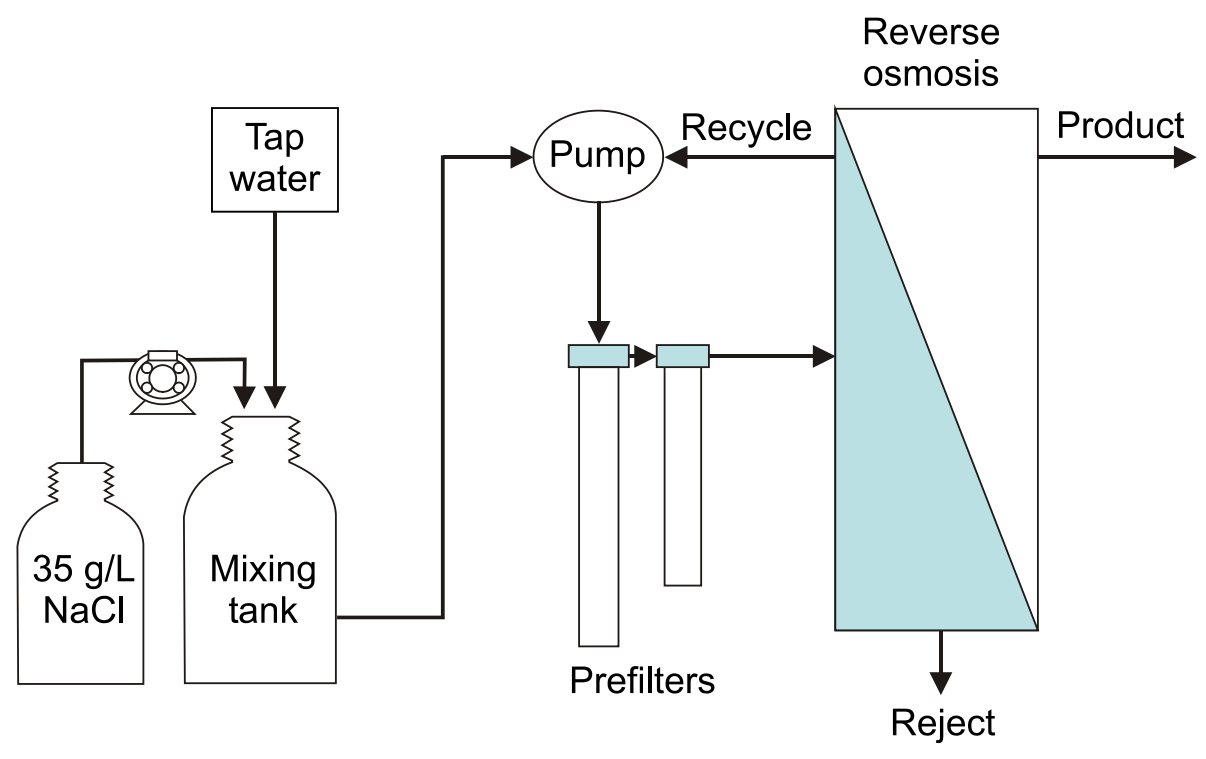

(A)

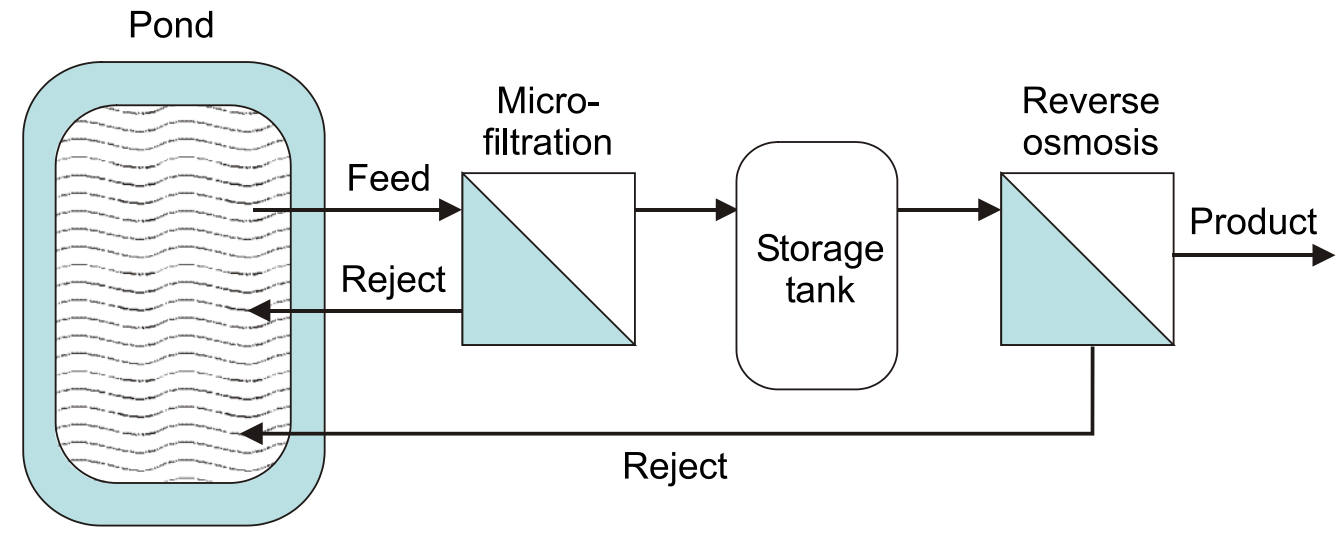

(B)

Figure 5. (A) Scheme of Setup for Laboratory Experiments with Reverse Osmosis Equipment; (B) Layout of Microfiltration/Reverse Osmosis Field Test 
A total of 13 experimental conditions (varying input $\mathrm{NaCl}$ concentrations) were applied for a minimum of 10 hours. Recirculation and reject flows were set on $1 \mathrm{gpm}$ and $2 \mathrm{gpm}$, respectively, as recommended by the system manufacturer. Table 4 shows the main characteristics of the influent used.

Chloride concentrations were measured every 30 minutes for the feed, product, and reject streams, using a chloride specific ion electrode. Chloride concentration was transformed to a $\mathrm{NaCl}$ concentration using a calibration curve. The values of the flows for the feed, product, and reject streams were measured every 30 minutes. Other parameters determined at each experimental condition were turbidity, conductivity, and cyanide concentration (cyanide was measured due to its use as an anti-caking agent for $\mathrm{NaCl})$.

Table 4. Feed Solution Characteristics for Conditions Tested

\begin{tabular}{lrlll}
\hline Test & $\begin{array}{l}\mathrm{NaCl} \\
(\mathrm{mg} / \mathrm{L})\end{array}$ & $\begin{array}{l}\text { Conductivity } \\
\left(\mathrm{mS} / \mathrm{cm}^{2}\right)\end{array}$ & $\begin{array}{l}\text { Turbidity } \\
(\mathrm{NTU})\end{array}$ & $\begin{array}{l}\text { Cyanide } \\
(\mathrm{mg} / \mathrm{L})\end{array}$ \\
\hline Low Range & 523 & 0.8 & 0.21 & $<0.002$ \\
& 985 & 1.3 & 0.39 & $<0.002$ \\
& 1565 & 2.1 & 0.45 & $<0.002$ \\
& 1653 & 2.9 & 0.55 & $<0.002$ \\
& 1870 & 3.2 & 0.36 & $<0.002$ \\
& 2230 & 3.5 & 0.59 & $<0.002$ \\
& 4076 & 4.6 & 0.47 & $<0.002$ \\
& 5612 & 7.5 & 0.59 & 0.002 \\
& 6701 & 10.44 & 0.66 & 0.002 \\
\hline High Range & 11554 & 18.54 & 0.88 & 0.002 \\
& 15680 & 23.69 & 0.92 & 0.002 \\
& 18319 & 31.98 & 0.97 & 0.004 \\
& 24587 & 44.98 & 0.99 & 0.004 \\
\hline Field Test & 3594 & 6.2 & 7.98 & N.D. \\
\hline
\end{tabular}

\subsubsection{Field Testing}

Field testing was conducted using the same RO unit tested in the laboratory. The work was performed at VDOT's Zion Crossroads Area Headquarters located in central 
Virginia. The test site has a stormwater basin with a storage capacity of approximately 45,000 gallons and a loading pad that covers nearly 600 square meters. The loading pad serves a three-bay shed and a much larger salt dome that is used as a storage area for several other area headquarters nearby.

Water was withdrawn from the stormwater pond using a 3 gpm electric sump pump and directed to the filtration system outfitted with a 2 -inch by 20 -inch 5 micron pre-filter and a 4-inch by 40-inch spiral wound microfiltration (MF) element. The MF step was needed to remove solids greater than approximately 1 micron. The filtered water was then pumped to a 330-gallon polyethylene storage tank. Once this tank was full, the water was pumped back through a 4-inch by 40-inch spiral wound compositecellulose acetate $\mathrm{RO}$ element (see Figure 5B). The maximum operating pressure for the MF and RO was 130 and 160 psi, respectively. Reject and recirculation flows were varied to maintain the proper pressure conditions but were generally kept at 1 and $3 \mathrm{gpm}$, respectively, for the MF stage and 1 and $5 \mathrm{gpm}$ for the RO stage. The waste streams from the MF and RO units were pumped back to the stormwater pond. Samples of the reject and the clean product lines were collected hourly and analyzed upon their return to the laboratory.

\subsection{RESULTS AND DISCUSSION}

\subsubsection{Laboratory Experiments}

\subsubsection{Chloride Removal}

The chloride removal results are divided into two sets. The first set presents the results obtained when the feed concentration of $\mathrm{NaCl}$ was in the range between 585 to 
$6,701 \mathrm{mg} / \mathrm{L}$ (317 to $4066 \mathrm{mg} / \mathrm{L} \mathrm{Cl}$ ). Based on prior field measurements throughout the state (Fitch et al., 2006) this range was selected to encompass the salt concentrations found in the vast majority of stormwater storage ponds. In a few cases, significantly higher salt concentrations were detected (caused by improper salt storage). Therefore, a second, higher range of salt concentrations (greater than $10,000 \mathrm{mg} / \mathrm{L} \mathrm{NaCl}$ ) was studied.

Figure 6 shows the $\mathrm{NaCl}$ concentration on the product and reject streams as a function of the $\mathrm{NaCl}$ feed concentration. For this range of feed concentrations, product stream concentrations were lower than $155 \mathrm{mg} / \mathrm{L}$. For the product streams, $\mathrm{NaCl}$ concentration tended to decrease exponentially with decreasing $\mathrm{NaCl}$ feed concentration. Reject stream $\mathrm{NaCl}$ concentrations decreased linearly with decreasing $\mathrm{NaCl}$ concentration in the feed solution. Previous water analyses at a small number of sites in 2004 showed that $\mathrm{NaCl}$ concentrations in the stormwater runoff ponds were between 1,483 and 4,284 mg/L. For this range of feed concentrations and based on the removal efficiencies obtained in the laboratory, $\mathrm{Cl}$ concentrations of the product stream would be less than $20 \mathrm{mg} / \mathrm{L}$ and flow of product higher than $4 \mathrm{~L} / \mathrm{min}$. The product flow decreased as the $\mathrm{NaCl}$ feed concentration increased (Figure 7), while the flow rate for the reject remained constant. 


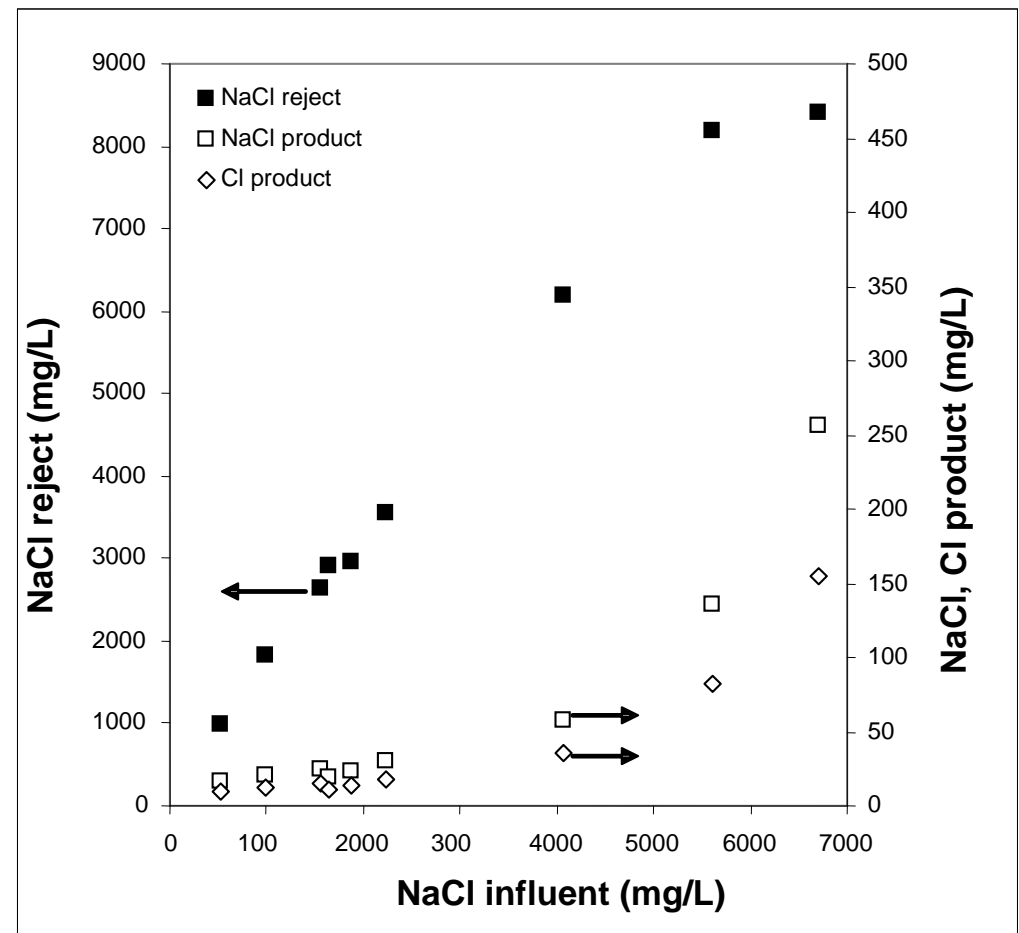

Figure 6. Product and Reject $\mathrm{NaCl}$ Concentrations as Function of Feed $\mathrm{NaCl}$ Concentration

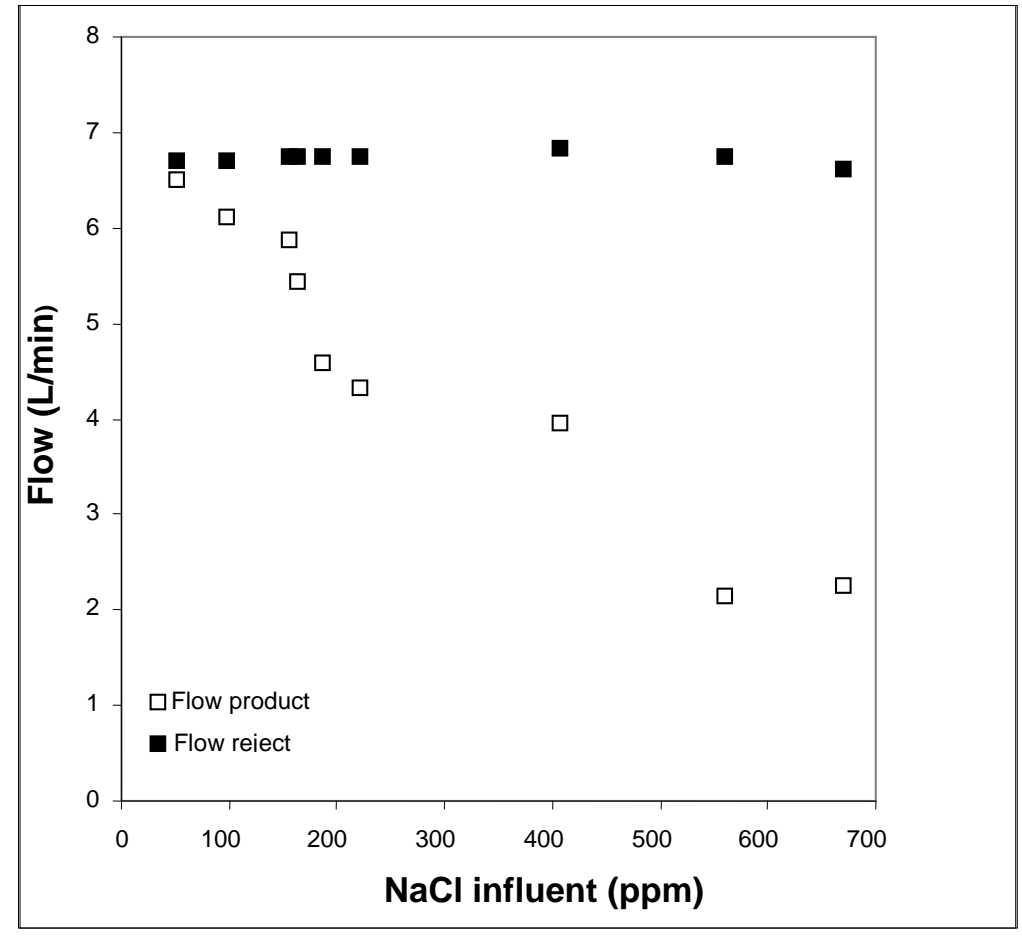

Figure 7. Flows of Product and Reject as Function of NaCl Concentration on Feed, During Low Concentration Experiments 
Figure 8A shows the product $\mathrm{NaCl}$ and $\mathrm{Cl}$ concentrations and reject $\mathrm{NaCl}$ concentration as a function of the $\mathrm{NaCl}$ feed concentration during the experiments at high $\mathrm{NaCl}$ concentration. The results reveal a linear increase in $\mathrm{Cl}$ concentration in the product stream and the reject stream with increasing feed $\mathrm{NaCl}$ concentration. The concentrations of $\mathrm{Cl}$ in the product streams for these high concentrations were several times higher than the assumed goal of $250 \mathrm{mg} / \mathrm{L}$. With regard to the product flow, it decreased sharply with the increase in $\mathrm{NaCl}$ in the feed, with a minimum flow of 80 $\mathrm{mL} / \mathrm{min}$ when the feed concentration was $24,000 \mathrm{mg} / \mathrm{L} \mathrm{NaCl}$ (Figure $8 \mathrm{~B}$ ). From these results, it is apparent that a low flow performance should be expected from the RO unit at high $\mathrm{NaCl}$ concentrations. This can be explained by the fact that the maximum operational pressure of the RO unit used in this experiment is $160 \mathrm{psi}$, which is considered a "low-pressure" RO unit. Low-pressure RO is commonly used to produce drinking water from brackish raw water with $\mathrm{NaCl}$ concentrations lower than 12,000 $\mathrm{mg} / \mathrm{L}$. High-pressure RO units are able to treat seawater $(\mathrm{NaCl}>34,000 \mathrm{mg} / \mathrm{L})$ because they can operate at pressures as high as 1,000 psi (Taylor and Jacobs, 1997). Although these high-pressure systems would be able to treat the water with $\mathrm{NaCl}$ concentrations as high as $24,000 \mathrm{mg} / \mathrm{L}$, they would be much more expensive to operate than would the lowpressure systems tested. 

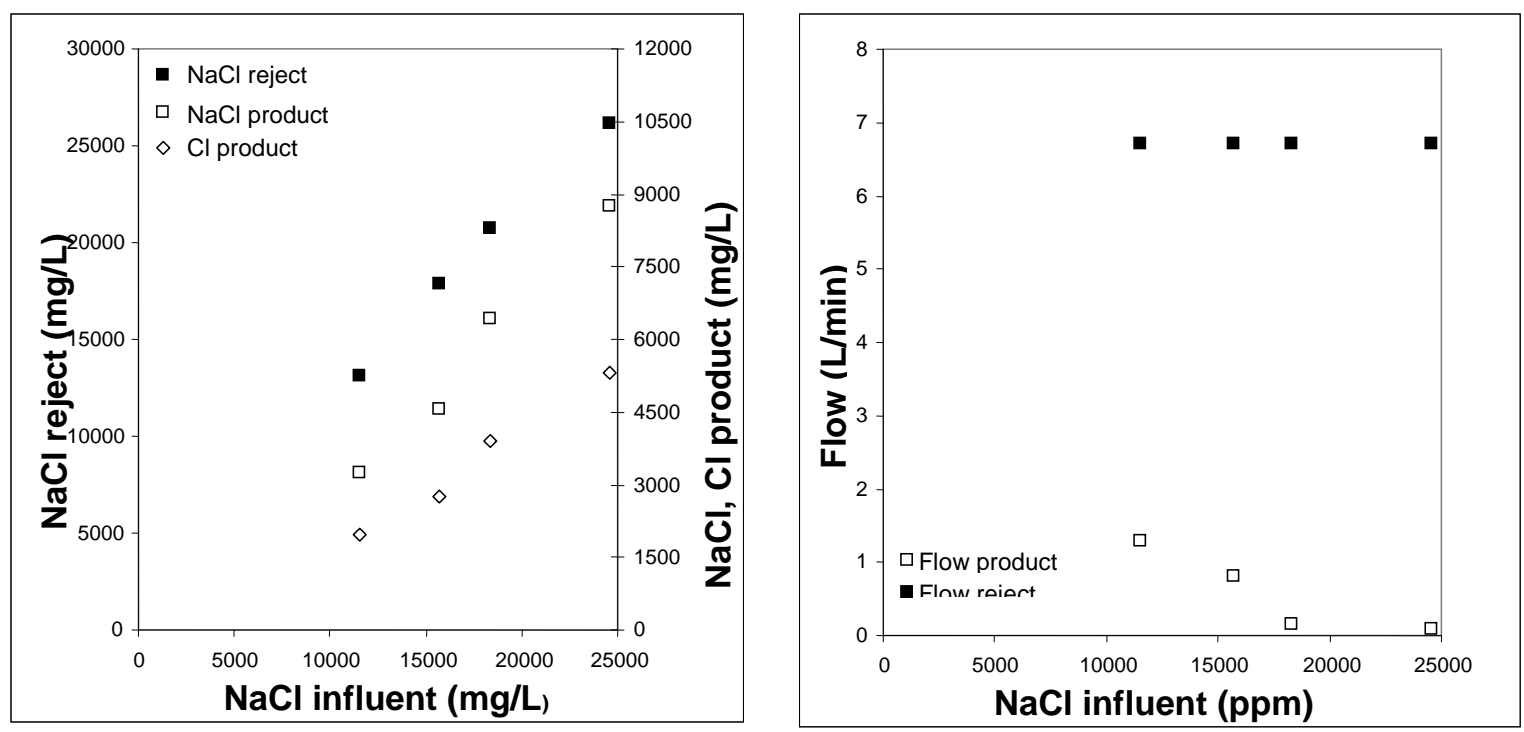

Figure 8. (A) Product and Reject NaCl Concentrations as Function of Feed NaCl Concentration; (B) Flows of Product and Reject as Function of $\mathrm{NaCl}$ Concentration on Feed, During High NaCl Concentration Experiments

\subsubsection{Percent Recovery}

Figure 9 shows the percent recovery and concentration factors for all $\mathrm{NaCl}$ feed concentrations tested. The percent recovery and concentration factor were calculated in accordance with the following two equations:

$$
\begin{aligned}
& \mathrm{r}=\left(\mathrm{Q}_{\mathrm{p}} / \mathrm{Q}_{\mathrm{f}}\right) * 100 \\
& \mathrm{CF}=(1 /(1-0.01 \mathrm{r}))
\end{aligned}
$$

where $\mathrm{r}$ is percent recovery, $\mathrm{Q}_{\mathrm{p}}$ is product flow, $\mathrm{Q}_{\mathrm{f}}$ is feed flow, and $\mathrm{CF}$ is concentration factor (increase in concentration of the reject flow expressed as a factor of the feed flow). Percent recovery decreases rapidly with the increase of $\mathrm{NaCl}$ in the feed stream. This occurred because the product flow decreased, especially at $\mathrm{NaCl}$ concentrations higher than $10,000 \mathrm{mg} / \mathrm{L}$. Common percent recovery values for low-pressure RO systems normally range between $70 \%$ and $85 \%$ (Taylor and Jacobs, 1997). The percent recovery values found here are lower than those found in other studies (Taylor and Jacobs, 1997) 
It is possible that these values could be increased by altering the reject and recycle flow values used (7.5 and 11.2 L/min, respectively). The concentration factors were also negatively affected by the increase of the $\mathrm{NaCl}$ in the feed stream. However in the range of 1,485 to $4,284 \mathrm{mg} / \mathrm{L} \mathrm{NaCl}$, the percent recovery was approximately $40 \%$ and the concentration factors were in the range of 1.5 to 2.0. This indicates that the volume of brackish water can be reduced by half and the concentration of $\mathrm{NaCl}$ in the reject can be doubled.

After more than 17,000 gallons of water were treated with the RO unit, no sign of fouling was observed. This was validated by repeating one of the first feed concentrations tested and comparing the values for product flow with the result previously obtained (data not shown).

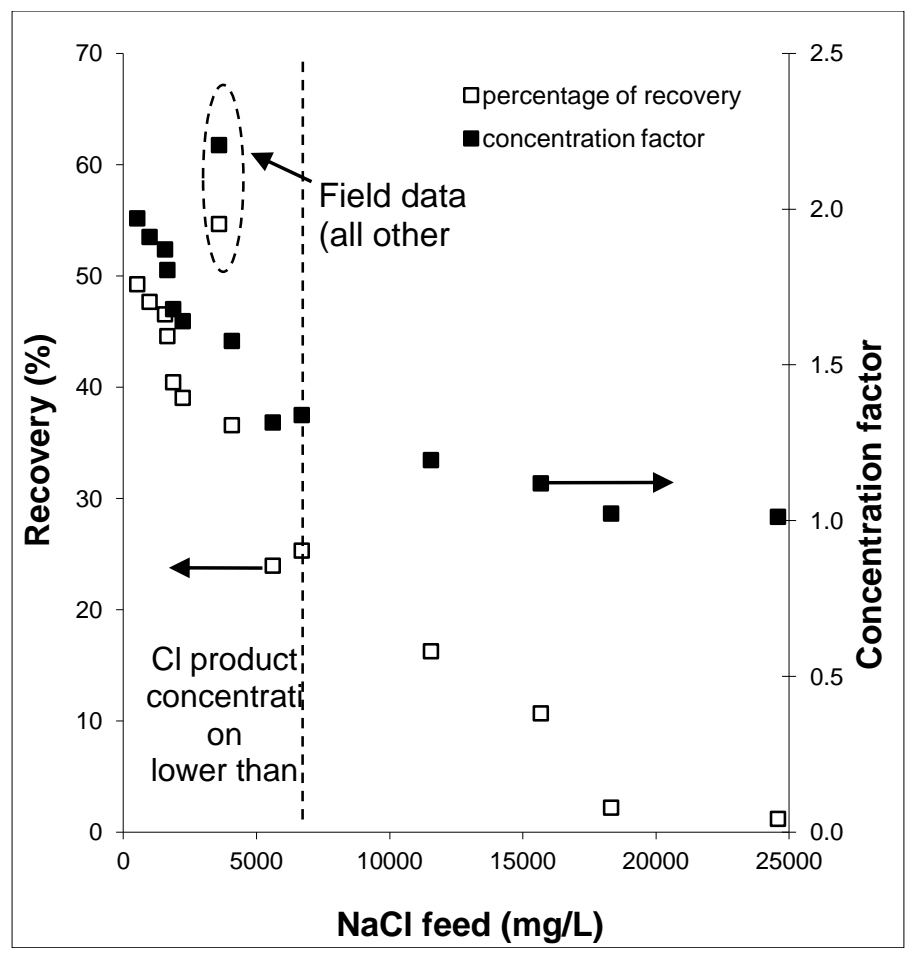

Figure 9. Product Recover Percentages and Concentration Factor on Reject Streams at $\mathrm{NaCl}$ Feed Concentrations Tested (vertical dashed line indicates maximum feed $\mathrm{NaCl}$ concentration that results in product $\mathrm{Cl}$ concentration less than $250 \mathrm{ppm}$ ) 


\subsubsection{Cyanide}

Cyanide was not detected in the product stream; in the reject stream, the maximum concentration measured was $0.002 \mathrm{mg} / \mathrm{L}$. The low concentrations in both streams were close to the detection limit of the HACH 8029 method used $(0.002 \mathrm{mg} / \mathrm{L})$, reducing the precision of the results. In future experiments, the digestion of the sample could be considered because cyanide can form a complex with organic matter and other inorganic compounds. The HACH method used in this study can detect cyanide only in its free form and not as a complex with other compounds.

\subsubsection{Conductivity}

The conductivity reduction on the product was proportional to the reduction of the $\mathrm{NaCl}$ concentration; this result was expected since $\mathrm{NaCl}$ was the main source of conductivity in the feed solution.

\subsubsection{Field Test}

\subsubsection{Turbidity Removal}

The MF unit was able to remove more than $96 \%$ of the turbidity originally present in the pond water (7.99 NTU). The average values for the product streams and reject streams were 0.27 and 10.15 NTU, respectively (see Figure 10). During the MF stage, no reduction of the $\mathrm{NaCl}$ concentration was observed. In spite of the promising results with regard to turbidity removal, a rapid reduction of the product flow was observed for the duration of the field test. Figure 11 shows the flow values for the product and reject streams as a function of time. It is likely the reduction in product flow was related to the 
fouling of the surface of the membrane. One disadvantage of spiral-wound MF elements is that they cannot be backwashed. The only cleaning procedure possible for this type of filter is a chemical wash. The cleaning procedure consisted of the recirculation of a trisodium phosphate solution for 15 minutes (as recommended by the manufacturer). After every cleaning process, the MF unit product flow increased.

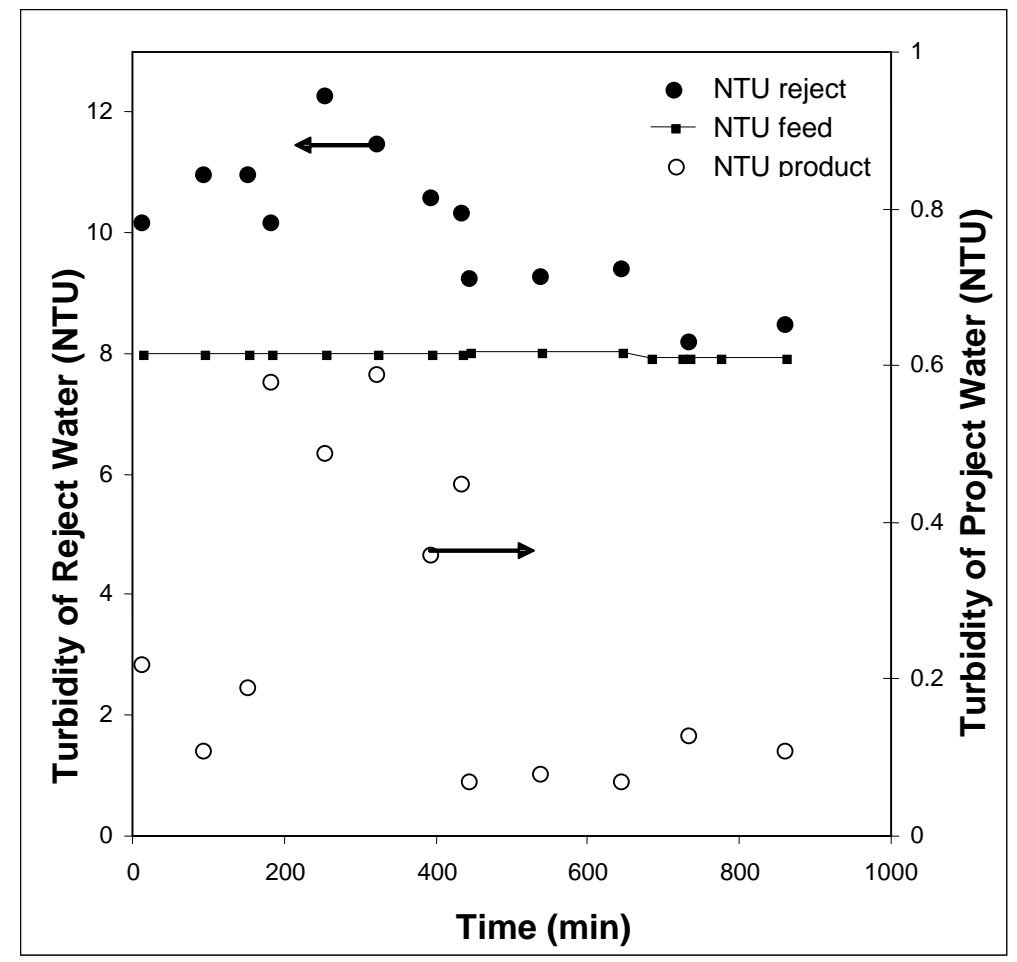

Figure 10. Turbidity Reduction Resulting from Microfiltration Pretreatment (arrows indicate axis to be used for data point types)

Based on the results obtained in the field test, the MF unit would require cleaning approximately every 3 hours. Cleaning at such frequent intervals is inconvenient and can significantly reduce the volume of saltwater that can be treated during a given time period. To reduce the cleaning frequency, some type of pretreatment would be necessary. The two most common types are coagulant and powdered activated carbon. Metal coagulants are normally injected into the raw water through a feed line, after which the 
water enters a reservoir for mixing and coagulation. It appears that the coagulation of smaller particles into larger ones reduces the penetration of various materials, including colloidal and larger organic macromolecules, into pores of the membrane (Redondo, 2001). Considering the layout of the typical VDOT salt storage site, the pond could be used as a mixer and coagulant tank. A new set of experiments would need to be conducted to determine the appropriate coagulant to use and its optimal dose.

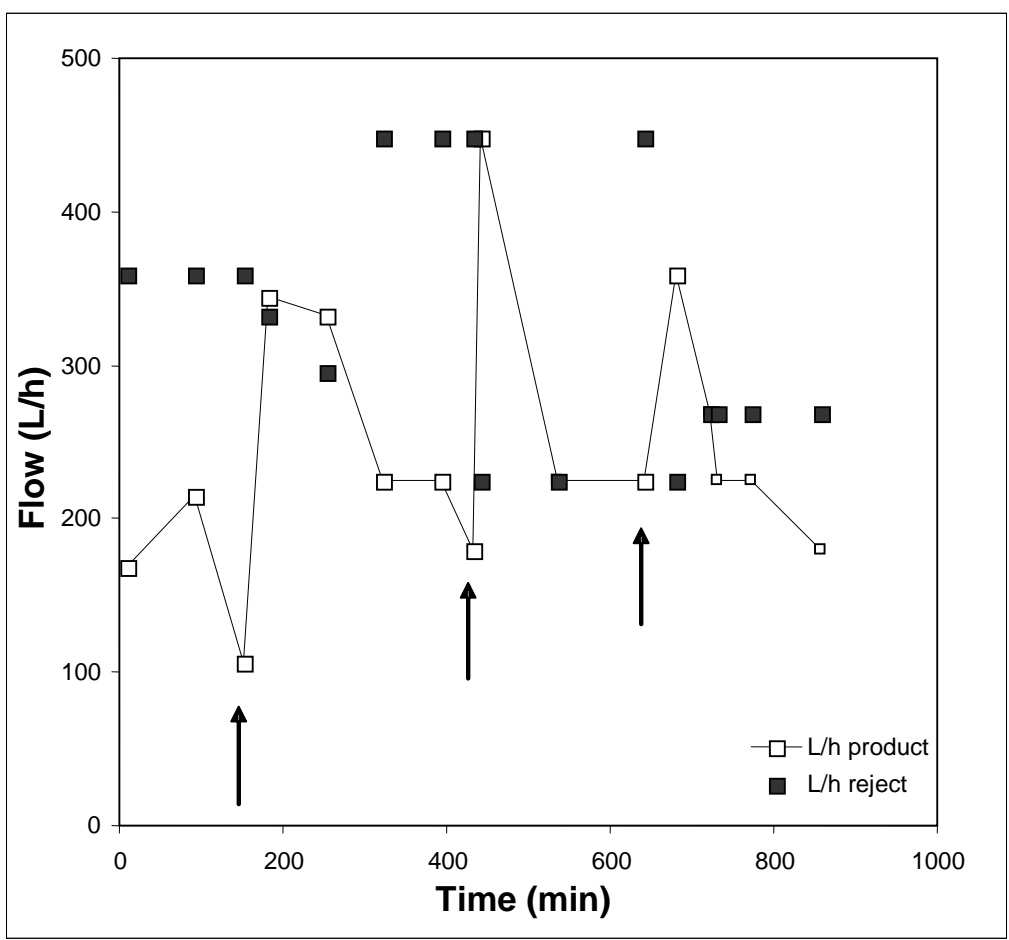

Figure 11. Product and Reject Flows of Microfiltration Stage of Field Test (arrows indicate timing of a cleaning procedure)

\subsubsection{Chloride Removal}

With regard to the $\mathrm{RO}$ stage, Figure 12 shows the $\mathrm{NaCl}$ concentrations of the feed and reject streams and the $\mathrm{NaCl}$ and $\mathrm{Cl}$ concentrations of the product stream. The small dip in the feed stream $\mathrm{NaCl}$ levels, and the corresponding drop in the product and reject $\mathrm{NaCl}$ levels, is thought to be due to the precipitation occurring during this time period, 
resulting in a slight dilution of the $\mathrm{NaCl}$. The overall performance of the $\mathrm{RO}$ unit, however, was very stable, and no sign of reduction in the product flow was observed during the experimental period.

Figure 13 shows the principal average values obtained during the field test and the previously plotted laboratory removal rates. The concentration of $\mathrm{Cl}$ in the product stream was higher than expected based on the results obtained in the laboratory testing but was still lower than $250 \mathrm{mg} / \mathrm{L}$. This difference may be caused by the presence of other ions, in addition to $\mathrm{NaCl}$, that also contribute to the increase of the osmotic pressure of the pond water. This phenomenon did not occur in the laboratory since the only source of ions was $\mathrm{NaCl}$.

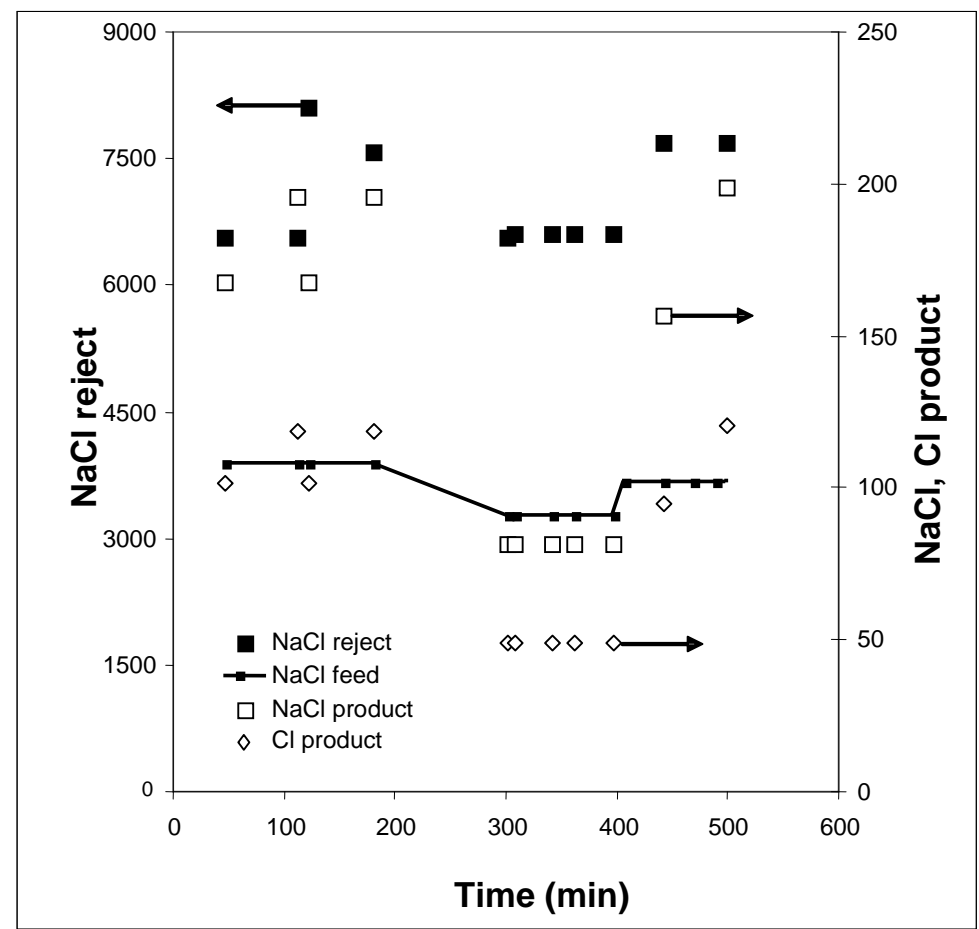

Figure 12. NaCl Concentrations of Feed and Reject Streams and Chloride Concentration of Product Stream on Reverse Osmosis Stage in Field Experiments (arrows indicate axis to be used for data point types) 


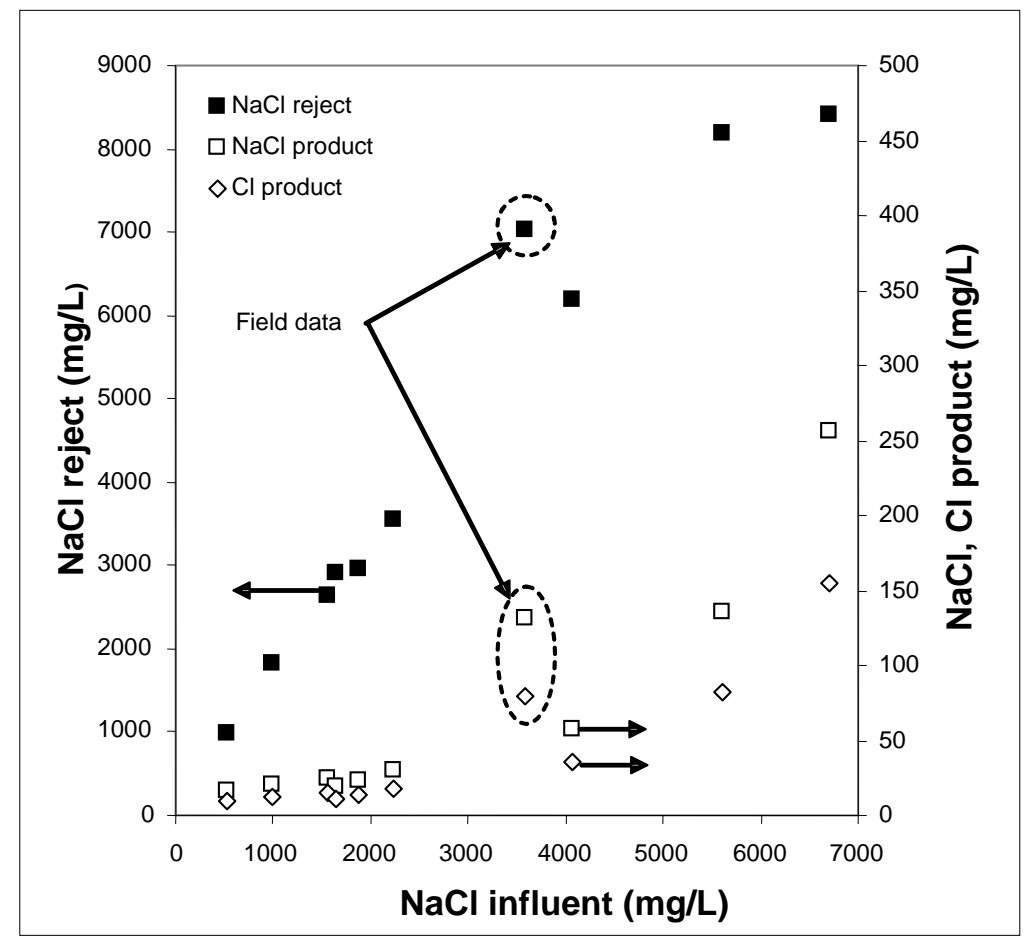

Figure 13. Product and Reject $\mathrm{NaCl}$ Concentrations as Function of Feed $\mathrm{NaCl}$ Concentration During Low Concentration and Field Experiments (arrows indicate axis to be used for data point types)

\subsubsection{Percent Recovery}

The differences between the laboratory data and the field data with regard to product and reject flows are related to the different operational conditions tried during the field test. A reject flow of $3.7 \mathrm{~L} / \mathrm{min}$ (1 gpm) and a recirculation flow of $18.7 \mathrm{~L} / \mathrm{min}(5$ gpm) were used. Figure 14 shows an increase in the product flow at the new operational condition tested. The new operational condition also had a positive effect on the percent recovery and concentration factor (see Figure 9). 


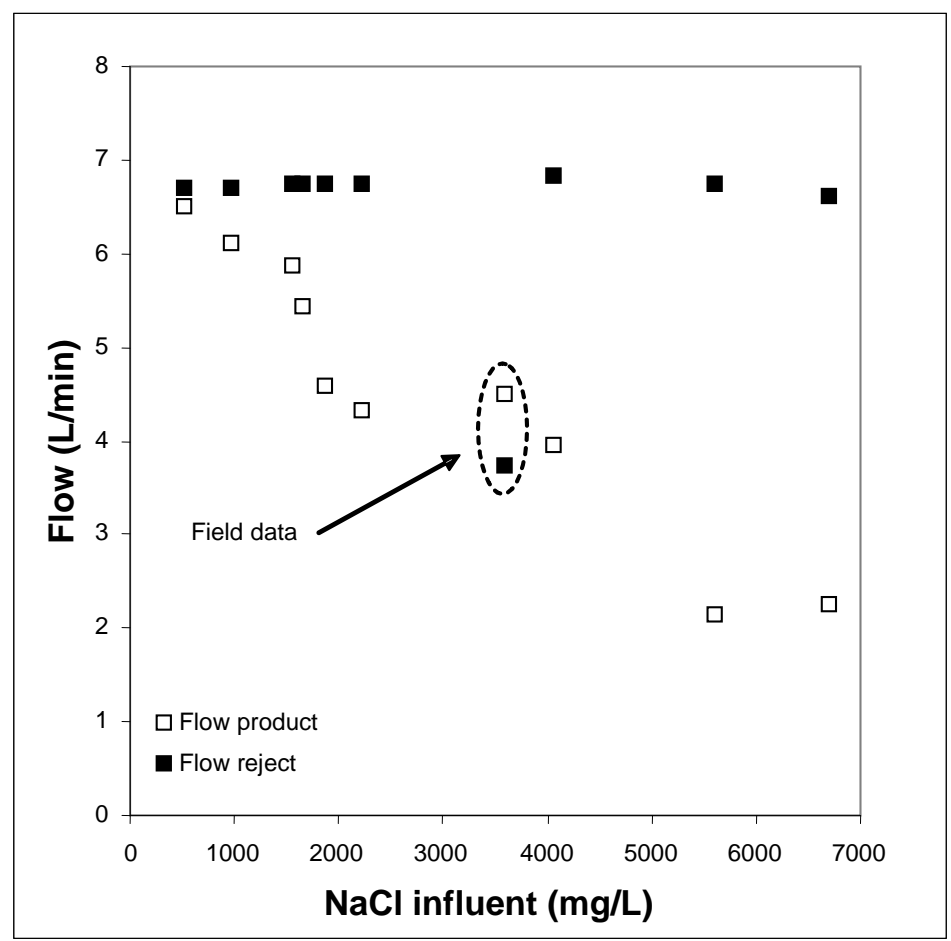

Figure 14. Flows of Product and Reject as Function of $\mathrm{NaCl}$ Concentration on Feed During Low Concentration and Field Experiments

\subsubsection{Fate of Product and Waste Streams}

Based on the percent recovery values measured in the laboratory and the field test, and the large volumes of salt water captured by VDOT, the fate of the product and waste streams must be considered when making a decision regarding the feasibility of RO as a treatment option for VDOT captured salt water. There is no clear standard for chloride pertaining specifically to stormwater discharge. Based on values obtained in the initial research, the statewide average value for chlorides in VDOT's stormwater ponds is approximately $1,600 \mathrm{mg} / \mathrm{L}$, with $95 \%$ of VDOT's sites expected to have chloride values below 3,200 mg/L (Fitch et al., 2004, 2006). Given the percent chloride reductions measured in the field, it can be expected that treatment with RO would decrease these values to below 50 and $100 \mathrm{mg} / \mathrm{L}$, respectively. If the state regulatory agencies were to 
set the chloride discharge limit for VDOT at $250 \mathrm{mg} / \mathrm{L}$ (based on the EPA's National Secondary Drinking Water Regulation), low pressure RO treatment would be sufficient for the treatment of nearly all of VDOT's collected salt water. Conversely, if VDOT's discharge limit is set at $25 \mathrm{mg} / \mathrm{L}$ (based on the Virginia Department of Environmental Quality's groundwater standards), more than half of the water would not meet this requirement when treated by RO. This alone would make the use of RO by VDOT infeasible.

The fate of the waste stream produced by RO treatment is not dependent on regulatory interpretation, but it will be determined by whether VDOT begins using salt brine for direct application as a part of its anti-icing program (this is currently being explored at several locations by VDOT). Assuming VDOT does begin to use salt brine for direct application, it seems practical to store the highly concentrated RO waste stream in storage tanks (above ground or under ground) and add additional salt to raise the $\mathrm{NaCl}$ concentration to the desired $23 \%$.

Specific storage requirements would be dependent on the volume of salt brine applied during the winter maintenance season, the volume and concentration of stormwater captured, and the reduction in volume achieved by the RO treatment process. The specific values for each of these variables will vary considerably from site to site, but based on the initial research and the findings of this study, the following can be assumed with regard to the average site:

- The stormwater storage capacity will be 40,000 gallons, which will need to be emptied two times per year. 
- The $\mathrm{NaCl}$ concentration in the stormwater will be approximately $2,600 \mathrm{mg} / \mathrm{L}$.

- If treated with RO, the volume of stormwater will be reduced approximately $50 \%$.

These numbers, in conjunction with salt brine application estimates, would allow the calculation of on-site storage requirements. The obvious advantage of using the RO waste stream is that it is being used as the base for the salt brine, for which VDOT would normally have to pay. Therefore, this type of end use would save money by reducing both the costs associated with the disposal of the waste stream and the costs of salt brine production.

\subsubsection{Other Concerns}

Even though most of the results of this research appear promising, several problems need to be solved before RO can be used extensively to treat salt water captured by DOTs.

\subsubsection{Pre-filtering}

First, a feasible mechanism for pre-filtering must be identified. This may be accomplished through the use of some type of pretreatment, as discussed earlier, or through the use of a more advanced pre-filtering system (i.e., one that would allow for the backwashing of the filter) than was used as a part of this experiment. Because the 
stormwater runoff ponds seem to be ideal environments for algae growth, it is likely that the relatively high turbidity found in the field test will be found in most of the ponds requiring treatment. Therefore, the turbidity must be reduced before RO filtering can be used.

\subsubsection{System Throughput}

Second, throughput volumes must be increased. Because of the large volumes of water captured and the relatively small storage capacity for most ponds, many ponds will require several pump and treat cycles each year. Based on a maximum throughput of 760 gpd as measured in the field for VDOT's average $\mathrm{NaCl}$ concentrations, and assuming a conservative statewide treatment volume of $30 \mathrm{MG}$ (this assumes diversion of stormwater will take place from April through October, a total of $300 \mathrm{RO}$ units would need to be purchased and operate at least 26 weeks of the year. This calculation does not take into account downtime due to maintenance or repair and also assumes the previously described problems related to pre-filtration could be overcome. In order to make this more feasible from a system throughput perspective, RO systems capable of treating tens of thousands of gallons per day would be necessary (versus the unit tested which was rated at $2000 \mathrm{gpd}$ ). Though costly, these higher volume systems do exist. Assuming the chloride removal and percent recovery values found in this research are scalable, these larger systems should be feasible treatment options. 


\subsubsection{Costs}

While obtaining accurate cost information for the purchase and operation of an RO system was not the primary goal of this research effort, based on limited purchase price information (Fitch et al., 2004, 2006) and published average operating cost information (Mallevialle et al., 1996), it is postulated that total costs associated with RO treatment would range between $\$ 0.05$ and $\$ 0.08$ per gallon. It should be noted, however, that actual treatment prices are subject to a number of variables including the number and size of units purchased, expected usable life of these units, as well as the volumes and concentrations of the of the water to be treated. These variables will be dependent on the volumes of water collected and storage capacities of specific sites. Additionally, if the reject stream can be stored and used for either pre-wetting or direct brine application, these treatment costs could be further offset by reducing the volumes of common prewetting chemicals such as calcium chloride and magnesium chloride.

\subsection{CONCLUSIONS}

Given the range of $\mathrm{NaCl}$ values found in VDOT's stormwater ponds at its salt storage sites, $\mathrm{Cl}$ values in the product stream resulting from $\mathrm{RO}$ treatment would be expected to average under $20 \mathrm{mg} / \mathrm{L}$. However, because of the wide variability in $\mathrm{NaCl}$ concentrations at ponds throughout the state, a small number of these sites could have $\mathrm{Cl}$ values above $250 \mathrm{mg} / \mathrm{L}$ following treatment. The feasibility of RO use by VDOT will be at least somewhat dependent on the $\mathrm{Cl}$ levels allowed by the Virginia environmental regulatory agencies for surface water discharge. If this level is set near the $250 \mathrm{mg} / \mathrm{L}$ 
secondary drinking water standard, low pressure $\mathrm{RO}$ is still potentially a feasible means of salt water treatment for VDOT (with respect to the $\mathrm{Cl}$ removal efficiency).

A potentially bigger deterrent for VDOT is the fact that treatment of stormwater containing salt in the range of 2,000 to $3,000 \mathrm{mg} / \mathrm{L} \mathrm{NaCl}$ - typical of most storage facilities - with a low pressure RO system will result in a total volume reduction of only approximately $50 \%$ (i.e., approximately $50 \%$ of the volume will be "clean" and the remaining volume will exit the system as reject). The remaining volume would still require additional management steps (such as disposal). One potential alternative is the use of RO reject (i.e., concentrated waste) for the production of brine used for pre-wetting dry $\mathrm{NaCl}$ and/or direct brine application. This would reduce the volume of waste to be disposed of and further offset the costs associated with RO treatment. It may be even more efficient, however, simply to use the salt water collected (prior to RO treatment) for brine creation.

Regardless, if RO is used for stormwater treatment, removing turbidity by way of pre-filtering will likely be difficult. Turbidity levels were quite high in most of the stormwater ponds examined. This coupled with the inability to backwash the spiralwound MF filter commonly used for low pressure RO systems causes significant system downtime and decreased system throughput volumes. 


\section{CHAPTER 4. REUSE OPTION INVESTIGATION}

\subsection{INTRODUCTION}

With no feasible treatment alternative identified, VDOT is still in search of an environmentally appropriate and economically feasible means of managing significant volumes of salt water captured at its maintenance facilities each year. VDOT currently uses chloride solutions $\left(\mathrm{CaCl}_{2}, \mathrm{MgCl}_{2}\right.$, or $\left.\mathrm{NaCl}\right)$ to pre-wet dry granular $\mathrm{NaCl}$ prior to its application. In addition, VDOT uses salt brine solution on a limited basis for direct liquid application as part of its anti-icing program (Roosevelt, 1997, 2008). If some fraction of the stormwater that is currently collected and disposed of as waste could be used in the making of brine solution for the purposes of pre-wetting and direct application, potentially significant volumes of water would no longer require neither treatment nor disposal.

\subsection{PURPOSE AND SCOPE}

The purpose of this component of the research was to investigate the reuse of the salt-contaminated stormwater runoff at VDOT road-salt storage facilities as a water source for on-site brine production. Since the utilization of captured stormwater would likely introduce large variations in both water temperature and turbidity levels during the brine making process, better understanding the potential effects of these changes was deemed important. More specifically, the research effort was designed to ensure that using stormwater for brine generation (1) would not have a significant effect on the quantity of brine that could be produced, (2) would not compromise the quality of the 
brine, (3) would not damage the brine production systems and application equipment, and (4) would be an economically feasible alternative to current disposal options.

The feasibility of this approach was quantified through bench-scale experiments in the laboratory using synthetic water samples and pond water samples collected from the field. A field test was conducted at one VDOT area headquarters (AHQ).

\subsection{METHODS}

To achieve the study objectives, the study team undertook two primary tasks: laboratory testing and field testing of a bench-scale brine generation unit.

\subsubsection{Laboratory Testing}

A $0.07 \mathrm{~m}^{3}$ brine generation unit was built as a 1:100 scale of the ABS-1500 automatic brine generation system manufactured by GVM, Inc. A full scale system is currently being used in a pilot study investigating on-site brine production at VDOT's Prince George AHQ (Petersburg Residency). The system consists of a rectangular (32 $\mathrm{cm}$ height, $80 \mathrm{~cm}$ width, and $28 \mathrm{~cm}$ depth) receptacle where the dry salt is deposited. At the bottom of the tank, two perforated polyvinyl chloride (PVC) pipes introduce the tap water from the bottom of the tank; water flows upward through the salt bed and salt is

dissolved into the water. The system uses a $0.2-\mathrm{m}^{3}$ feed tank and a peristaltic pump to force tap water up through the dry salt bed.

A set of experiments was designed to determine the optimum hydraulic characteristics of the brine generation system and the quantity and quality of effluent from the process for influent solutions that mimic or replicate the salt-contaminated pond 
water. For each experiment, $62 \pm 2 \mathrm{~kg}$ of road salt from a VDOT storage facility was used. A total of three experiments at two temperatures were conducted to obtain a minimum of $0.05 \mathrm{~m}^{3}$ of brine (Table 5 shows the experimental conditions) using tap water as a feed solution. Salt concentrations were measured every 5 to 10 min using a saltmeter. The flow rate, height of the salt bed, and turbidity were also measured every 5 to 10 minutes.

Table 5. Operational Conditions Used for Brine Generation

\begin{tabular}{|c|c|c|}
\hline Location & Water Temperature & Hydraulic Retention Time (min) \\
\hline \multirow{6}{*}{ Laboratory } & \multirow{3}{*}{$18^{\circ} \mathrm{C}$} & 17.9 \\
\hline & & 25.6 \\
\hline & & 45.0 \\
\hline & \multirow{3}{*}{$5^{\circ} \mathrm{C}$} & 21.6 \\
\hline & & 25.2 \\
\hline & & 37.0 \\
\hline \multirow{2}{*}{ Field } & \multirow{2}{*}{$25^{\circ} \mathrm{C}$} & 31.8 \\
\hline & & 132.0 \\
\hline
\end{tabular}

\subsubsection{Field Testing}

Presently, two VDOT maintenance facilities (Hanging Rock AHQ in the Salem Residency and Prince George AHQ in the Petersburg Residency) have invested in brine production equipment and have the capability to produce brine on site using municipal drinking water sources. These sites would have been logical choices for testing the effects of stormwater for brine production: however, because these two facilities do not have stormwater collection ponds, this was not feasible. Instead, the Boyd's Tavern AHQ (Charlottesville Residency) was chosen to perform the field experiments due to its proximity to the Virginia Center for Transportation Innovation and Research. 
The field test was conducted using the same brine generation system used in the laboratory. The Boyd's Tavern facility has a stormwater collection pond with a storage capacity of approximately 30,000 gal. Water quality analysis performed on site revealed a $\mathrm{NaCl}$ concentration of $110 \mathrm{mg} / \mathrm{L}(0.01 \%)$ and a turbidity level of $4.24 \mathrm{NTU}$.

The brine generation system was filled with approximately $62 \mathrm{~kg}$ of road salt collected from the salt-storage dome on site. Instead of feeding the unit with tap water, water was withdrawn from the stormwater pond using a Masterflex peristaltic pump. The influent was pumped through a coarse screen filter (mesh size 80) to remove large particles and other debris before being introduced to the brine generation system. Two operational conditions were tested (see Table 1). The brine produced was pumped back to the stormwater pond. Samples of the brine generated were collected every 5 and 15 min for the 31.8- and 132-min experiments, respectively. The samples were analyzed on site for salt content and turbidity.

\subsubsection{Benefit/Cost Analysis}

A benefit-cost $(\mathrm{B} / \mathrm{C})$ analysis of recycling stormwater runoff for brine generation was calculated assuming two methodologies for brine application (pre-wetting of dry sodium chloride and direct application of brine in conjunction with pre-wetting), different volumes of stormwater runoff potentially captured (i.e., accumulated statewide), different quantities of road salt applied during the winter season, and two disposal costs per gallon of runoff. This resulted in a total of 72 different hypothetical scenarios for which benefits were calculated. 
The values for maximum, average, and minimum volumes of stormwater runoff accumulated statewide were obtained from a previous study (Fitch et al., 2004) and are shown in Table 6. These values represent the estimated annual and winter runoff volumes collected in the stormwater ponds at VDOT's maintenance sites based on 38 years of rainfall data (Southeast Regional Climate Center, 2004) collected at 27 stations statewide and 30 years of evaporation data (Virginia State Climatology Office, 2001) from five regional stations.

Table 7 shows the quantity of road salt purchased by VDOT from 2000 through 2005. For the purposes of the benefit/cost analysis, the maximum, average, and minimum amounts from this five year period were used.

Table 6. Annual and Winter Treatment Volumes

\begin{tabular}{|l|l|l|}
\hline Value & Annual Volume (MG) & Winter Volume (MG) \\
\hline Minimum & 35 & 19 \\
\hline Average & 59 & 31 \\
\hline Maximum & 88 & 36 \\
\hline
\end{tabular}

Table 7. Road Salt Purchased by VDOT Over Recent 5-year Period

\begin{tabular}{|l|l|}
\hline Year & Tons \\
\hline $2000-01$ & 346,979 \\
\hline $2001-02$ & 138,706 (minimum) \\
\hline $2002-03$ & 519,084 (maximum) \\
\hline $2003-04$ & 341,021 \\
\hline $2004-05$ & 313,786 \\
\hline Average & 331,975 \\
\hline
\end{tabular}

Table 8 shows the estimated costs of the brine generation unit and additional accessories required for a maintenance facility that would apply brine. These values were conservatively approximated based on equipment costs found in other anti-icing and 
DOT synthesis studies (Alleman et al., 2004; O’Keefe and Shi, 2005). Currently, the majority of VDOT's salt spreader trucks have pre-wetting equipment (in the form of saddle tanks) to apply $\mathrm{CaCl}_{2}$ or $\mathrm{MgCl}_{2}$ solutions. It was assumed that this same equipment would be sufficient for pre-wetting with salt brine. For this analysis, it was also assumed that one brine generation unit would be purchased for 300 VDOT maintenance facilities. (In all likelihood, VDOT would not need to purchase the full complement of equipment for each facility as some locations would be able to share equipment and other facilities may not be utilized in the future due to privatization of maintenance tasks.) In addition to the capital costs, the annual operational costs were estimated to be 1 percent of the total capital investment.

Table 8. Initial Per Site Capital Investment for Pre-Wetting and Direct Application of Brine

\begin{tabular}{|l|l|l|}
\hline Equipment & Direct Application & Pre-wetting \\
\hline Brine generation unit & $\$ 10,000$ & $\$ 10,000$ \\
\hline Storage tank $(5,000$ gal $)$ & $\$ 3,500$ & $\$ 3,500$ \\
\hline Single line spreader & $\$ 12,700$ & - \\
\hline Total & $\$ 26,200$ & $\$ 13,500$ \\
\hline
\end{tabular}

The volumes of stormwater runoff potentially used for brine generation were estimated depending on the method of application. For the pre-wetting method, a rate of 15 gal per ton of road salt was assumed based on a range of 8 to 30 gal per ton, as found in the literature (Alleman et al, 2004; Ketcham et al, 1996; Wisconsin DOT, 2005). Based on the historical granular $\mathrm{NaCl}$ usage values for VDOT (as taken from Table 7), it was assumed that $20 \%$ of this volume would be applied as brine utilizing direct application. It was then assumed that the remaining $80 \%$ of granular salt applied would be pre-wet with a brine solution. Though this $20 \%$ direct brine application to $80 \%$ dry 
$\mathrm{NaCl}$ application ratio is purely hypothetical, it does fall within the ranges reported by other DOTs currently using brine for anti-icing (O'Keefe and Shi, 2005) and should be conservative for Virginia given that direct brine application is normally considered a good strategy when pavement temperatures are above $20^{\circ} \mathrm{F}$ (Blackburn et al, 2004). In all calculations, to obtain a brine solution at its eutectic point $(23.3 \%), 0.44$ gallons of water was used to dissolve each pound of road salt.

A statewide average value of $\$ 0.13$ per gallon was used as the first disposal cost of salt-water based on the findings of earlier research (Fitch et al., 2004). Because a second disposal cost of $\$ 0.55$ per gallon was recently incurred at the Prince George maintenance facility, it is included here as an example of possible variance in local disposal costs from the statewide average previously determined.

The annual benefits were calculated as the difference between the costs of disposal of the total annual volume of stormwater runoff accumulated and disposal of the volume remaining after the brine production (volume of water not used for brine generation would still need disposal at cost), plus the savings resulting from the use of the $\mathrm{NaCl}$ brine solution instead of $\mathrm{CaCl}_{2}$ or $\mathrm{MgCl}_{2}$ as the pre-wetting solution. For this analysis, a cost of $\$ 0.50$ per gallon for the $\mathrm{CaCl}_{2}$ and $\mathrm{MgCl}_{2}$ solutions was assumed though these chemicals can be significantly higher (O'Keefe and Shi, 2005). Put another way, the annual benefits can be calculated as forgone costs with the following equation:

$$
A B=\left(\text { volume }_{D A} \mathrm{x} d c\right)+\left[\left(\text { volume }_{P W} \mathrm{x}(d c+c c)\right]\right.
$$


where $A B$ is annual benefit (\$), volume $_{D A}$ is annual direct application volume (gal), $d c$ is the disposal cost $(\$ 0.13 / \mathrm{gal})$, volume $_{P W}$ is annual pre-wetting volume (gal), and $c c$ is the cost of other pre-wetting chemicals $(\$ 0.50 / \mathrm{gal})$. Operating costs were assumed to be negligible.

Each of the 72 scenarios was evaluated for the number of years required for forgone costs to exactly offset the initial investment in brine-generating equipment (i.e., the number of years required to obtain a net present value of zero). Net Present Value $(N P V)$ was calculated as follows:

$$
N P V=I+A B \frac{(1+i)^{n}-1}{i(1+i)^{n}}
$$

where $I$ is initial investment $(\$), A B$ is annual benefit (\$), and $i$ is the discount rate (\%). The discount rate assumed for this analysis was 5 percent.

\subsection{RESULTS AND DISCUSSION}

\subsubsection{Laboratory Experiments}

\subsubsection{Hydraulic Retention Time and Water Temperature}

Hydraulic retention time (HRT) and temperature are two key parameters for efficient brine generation in terms of the quality of the brine produced and production costs. The HRTs were selected to represent different operational conditions that might be used on site for brine preparation. The lowest HRT tested was just under 18 minutes, which is the minimum HRT recommended by the manufacturer. This HRT for the fullscale equipment corresponds to a flow rate of about $22 \mathrm{~m}^{3} / \mathrm{h}$. Because some maintenance 
facilities may not be able to obtain such high flow rates, higher HRTs (which correspond to lower flow rates) were tested. Water temperatures between $18^{\circ} \mathrm{C}$ and $5^{\circ} \mathrm{C}$ were selected to simulate fall and winter water temperature conditions that could be expected in the stormwater ponds (as compared to the average temperature of $12^{\circ} \mathrm{C}$ for groundwater).

During the laboratory phase of the study, salt concentration was determined every 3 to 10 minutes, depending on the HRT applied. Because the effluent was discharged directly to the sewage system, a mathematical expression was used to determine the percentage of $\mathrm{NaCl}$ (based on mass) that would be produced in the brine if it was collected in a completely mixed storage tank:

Accumulativesalt percentage $\%)=\frac{\left\lfloor\sum_{i=1}^{n}\left(c_{i+1}-c_{i}\right) \cdot\left(t_{i+1}-t_{i}\right) \cdot F \cdot 0.5+c_{i+1} \cdot\left(t_{i+1}-t_{i}\right) \cdot F\right\rfloor}{\left[\sum_{i=1}^{n}\left(c_{i+1}-c_{i}\right) \cdot\left(t_{i+1}-t_{i}\right) \cdot F \cdot 0.5+c_{i+1} \cdot\left(t_{i+1}-t_{i}\right) \cdot F\right]+F \cdot t_{i+1} \cdot \rho_{w}} \cdot 100$

where $c_{i}$ and $c_{i+1}(\mathrm{~kg} / \mathrm{L})$ are the salt concentrations in the effluent of the brine generation unit measured at times $t_{i}$ and $t_{i+1}(\mathrm{~min})$, respectively; $F(\mathrm{~L} / \mathrm{min})$ is the flow rate applied; and $\rho_{w}$ is the water density $(\mathrm{kg} / \mathrm{L})$ at the temperature of the experiment.

Figure 15 shows the percentage of salt in the brine produced at different hydraulic retention times and two temperatures. At both temperatures, the brine production, in terms of volume, decreased with the increase of the HRT. 

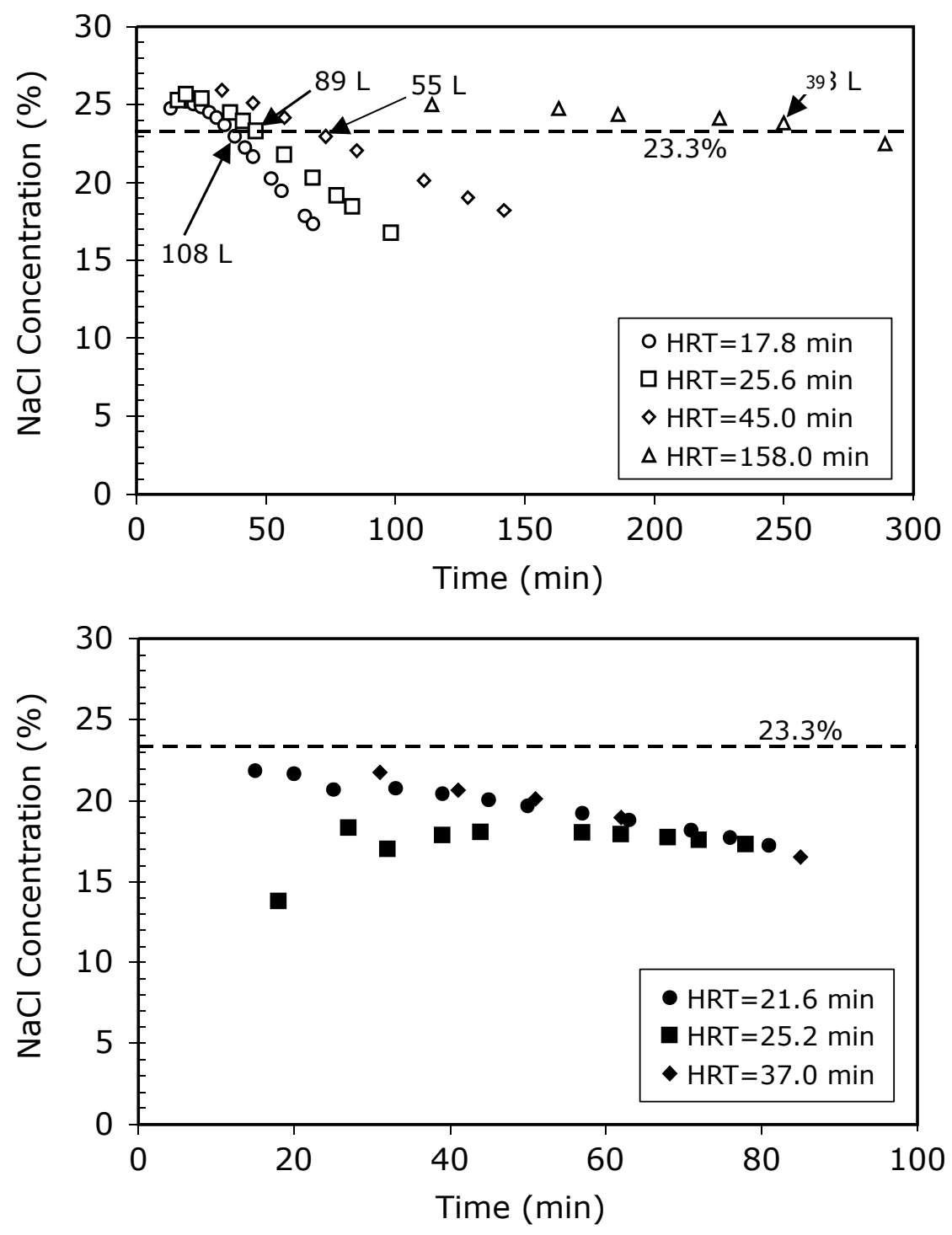

Figure 15. Percentages of Salt in Brine and Volume Produced as Function of Hydraulic Retention Time (HRT) and Temperature at $18^{\circ} \mathrm{C}$ (top) and $5^{\circ} \mathrm{C}$ (bottom). The horizontal dashed line represents desired effluent salt percentage $(\mathbf{2 3 . 3 \%})$

Low water temperatures had a negative effect on brine production. At $5^{\circ} \mathrm{C}$, the brine produced did not reach 23.3 percent salt at any of the HRTs. Decreasing temperature reduced the salt solubility and the rate of dissolution decreased. HRT and temperature also had an effect the height of the salt in the tank as a function of time. Figure 16 shows the height of the bed of salt versus time for the different operational 
conditions tested. Temperature changes seemed to have a stronger effect on the amount of salt dissolved than did variation of the HRT. With two similar HRTs, 83 percent of the salt was dissolved after 60 minutes at $18^{\circ} \mathrm{C}$ and only 70 percent of the salt was dissolved at $5^{\circ} \mathrm{C}$ in the same time period. Many of the salt crystals did not dissolve, even after 300 min of operation, and they remained as a residue at the bottom of the tank. Most of these undissolved crystals were relatively large; smaller salt crystals will likely promote higher specific surface areas and higher mass transfer (dissolution) rates.
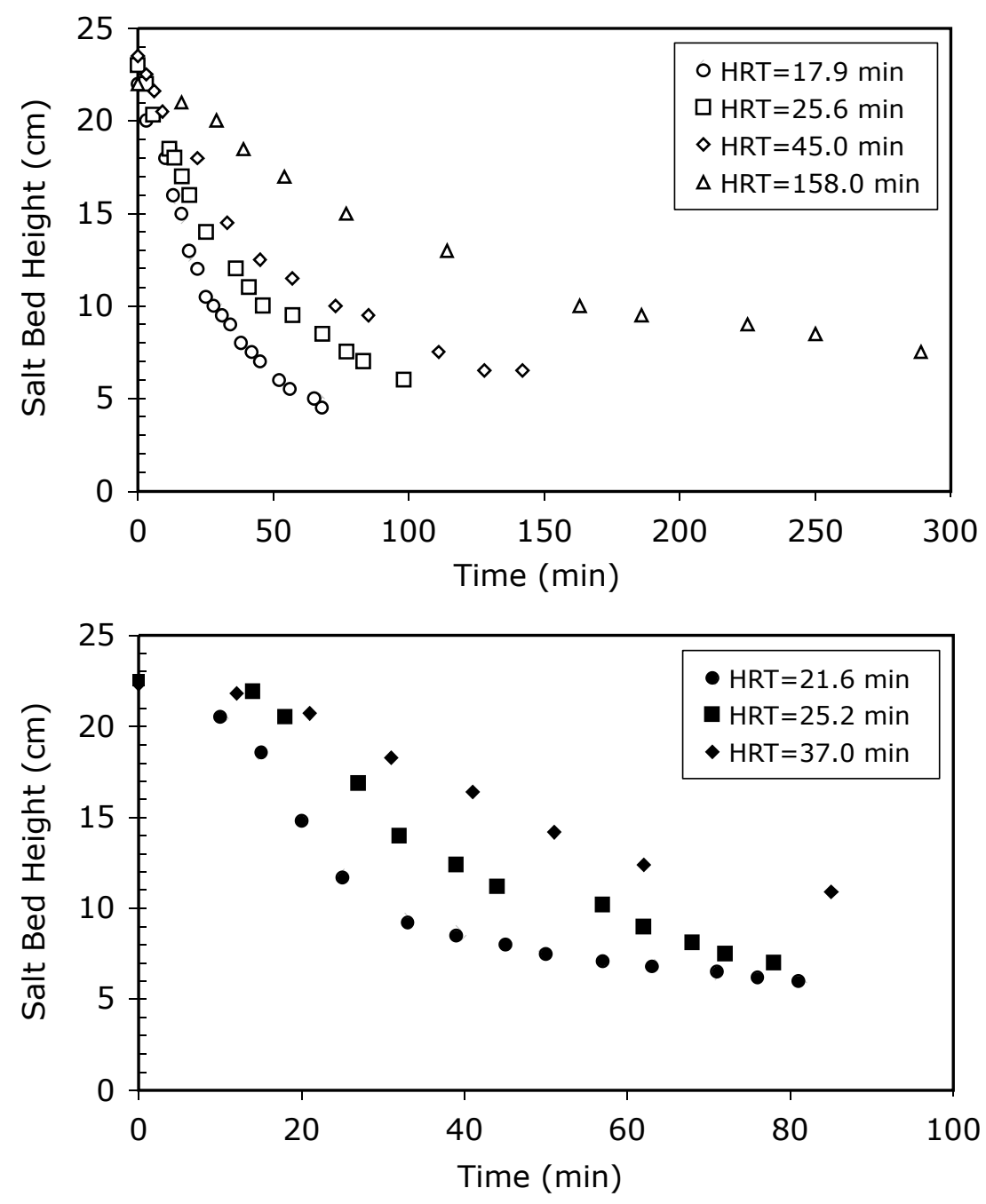

Figure 16. Height of Salt Bed as Function of Hydraulic Retention Time (HRT) and Temperature at $18^{\circ} \mathrm{C}($ top $)$ and $5^{\circ} \mathrm{C}$ (bottom) 


\subsubsection{Turbidity}

Turbidity was one of the major concerns with using stormwater for the creation of brine, stemming from the findings of the reverse osmosis study previously conducted (Fitch et al., 2006). It was concluded that the high turbidity levels were the cause of the microfiltration unit clogging and ultimately restricting the throughput available for filtration by the RO filter. There was concern that these same turbidity values would (1) hinder the production of brine, (2) potentially damage the brine manufacturing equipment, or (3) clog the brine application equipment. Figure 17 shows the turbidity values for effluent samples at each set of operating conditions. The effluent turbidity decreased rapidly from 2,000 NTU to 500 NTU after 10 minutes of operation at every experimental condition tested. The turbidity values at the end of every experimental period were lower than 100 NTU. The high turbidity detected in the brine for each experiment originated from the high concentration of TSS in the road salt and would therefore be present regardless of the TSS from the source water. This finding was somewhat surprising, but helped alleviate initial concerns that the turbidity of the stormwater runoff would hinder the brine production process or equipment since it was found in the earlier characterization study (Fitch et al., 2004) that the statewide average for TSS for water in the stormwater runoff ponds was $20 \mathrm{mg} / \mathrm{L}$. 

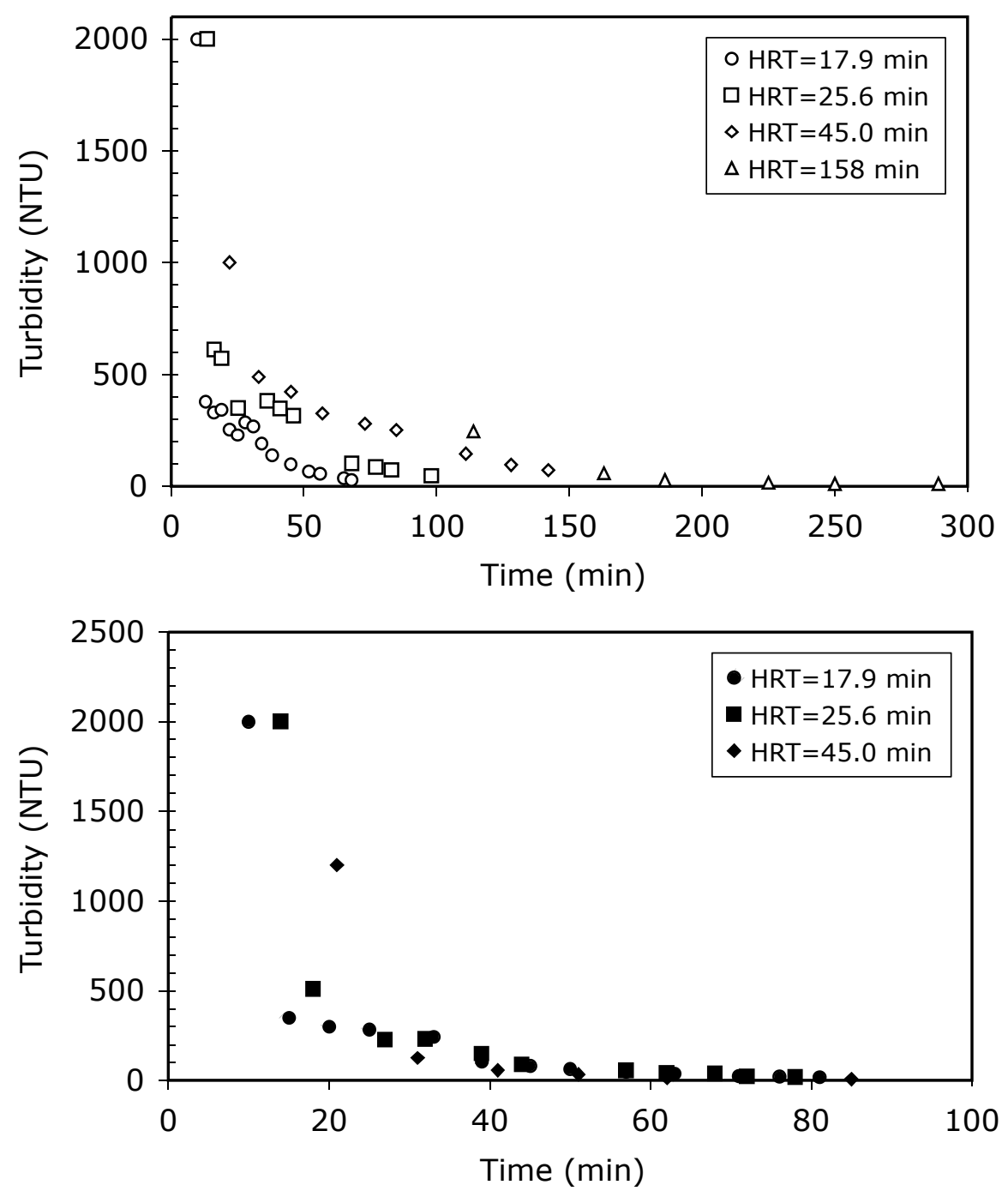

Figure 17. Effluent Turbidity as Function of Hydraulic Retention Time (HRT) and Temperature at $18^{\circ} \mathrm{C}$ (top) and $5^{\circ} \mathrm{C}$ (bottom)

The turbidity values for every sample were determined again after $4 \mathrm{hr}$ of settling (Figure 18). All samples analyzed exhibited turbidity reductions greater than 95 percent after each settling period. The elevated content of salt in the effluent promoted the sedimentation of colloidal particles in accordance with the diffuse double layer theory. So, despite the high content of TSS in the road salt, high levels of sedimentation are achieved in part because of the high salt concentration. This will result in less turbid 
water going to the brine application tanks and spreaders, but may also require increased maintenance of the brine manufacturing equipment.
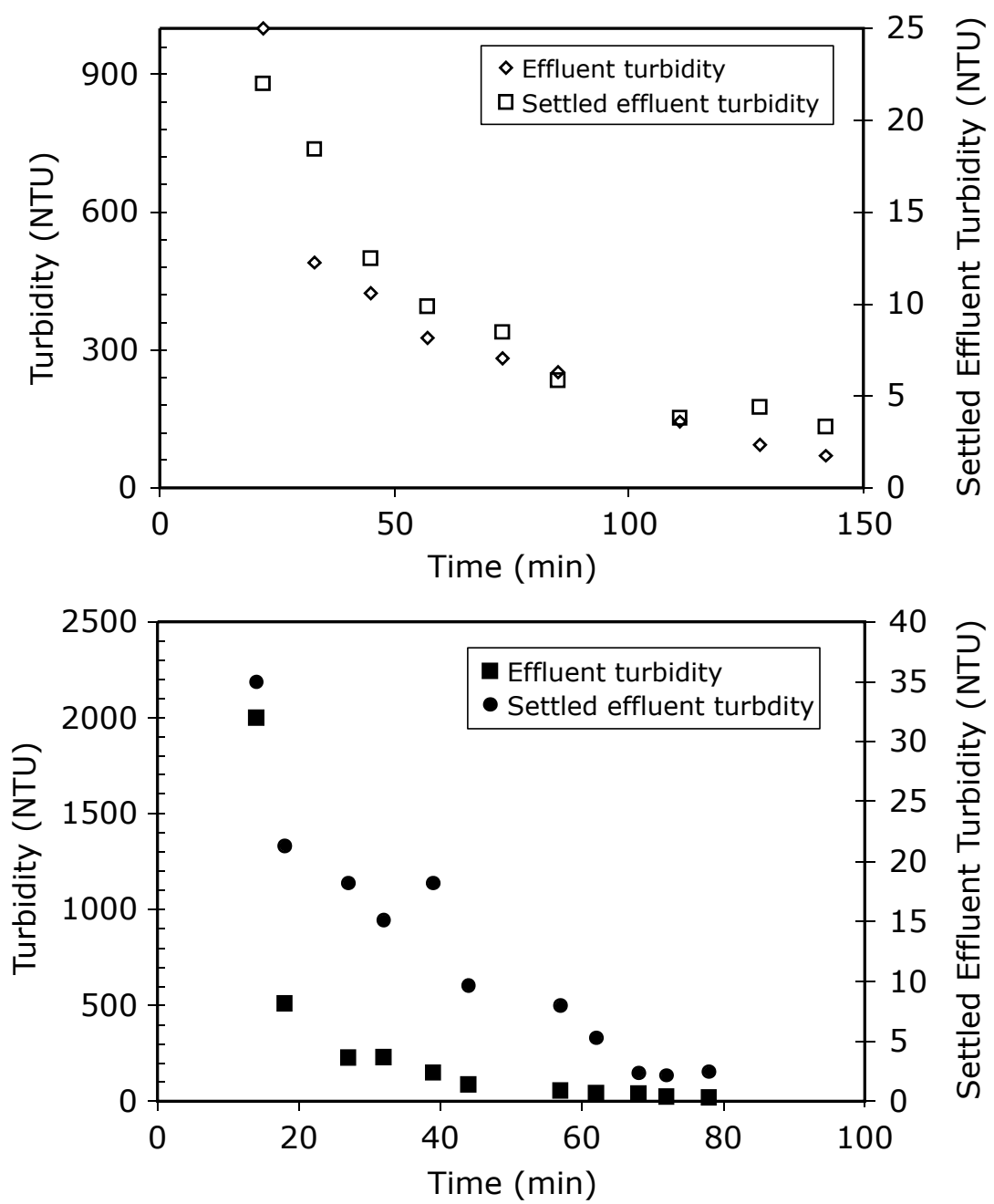

Figure 18. Comparison of Turbidity Values for Effluent Samples at Time of Collection and after 4 Hours of Settling for $18^{\circ} \mathrm{C}$ (top) and $5^{\circ} \mathrm{C}$ (bottom)

\subsubsection{Field Test}

The results of the field test were similar to those of the laboratory phase. Short HRTs were found to be more effective than long HRTs for brine generation (see Figure 19). Moving more water through the system in a shorter period of time resulted in higher 
dissolution rates which in turn resulted in a greater percentage of the salt in the unit being utilized. This was identical to what was found in the lab results. The dissolved $\mathrm{NaCl}$ in the pond water did not have a measurable effect on the final $\mathrm{NaCl}$ concentration in the effluent. This finding was not unexpected since the $\mathrm{NaCl}$ level of the pond was only $0.01 \%$ and the final concentration was approximately $23 \%$.
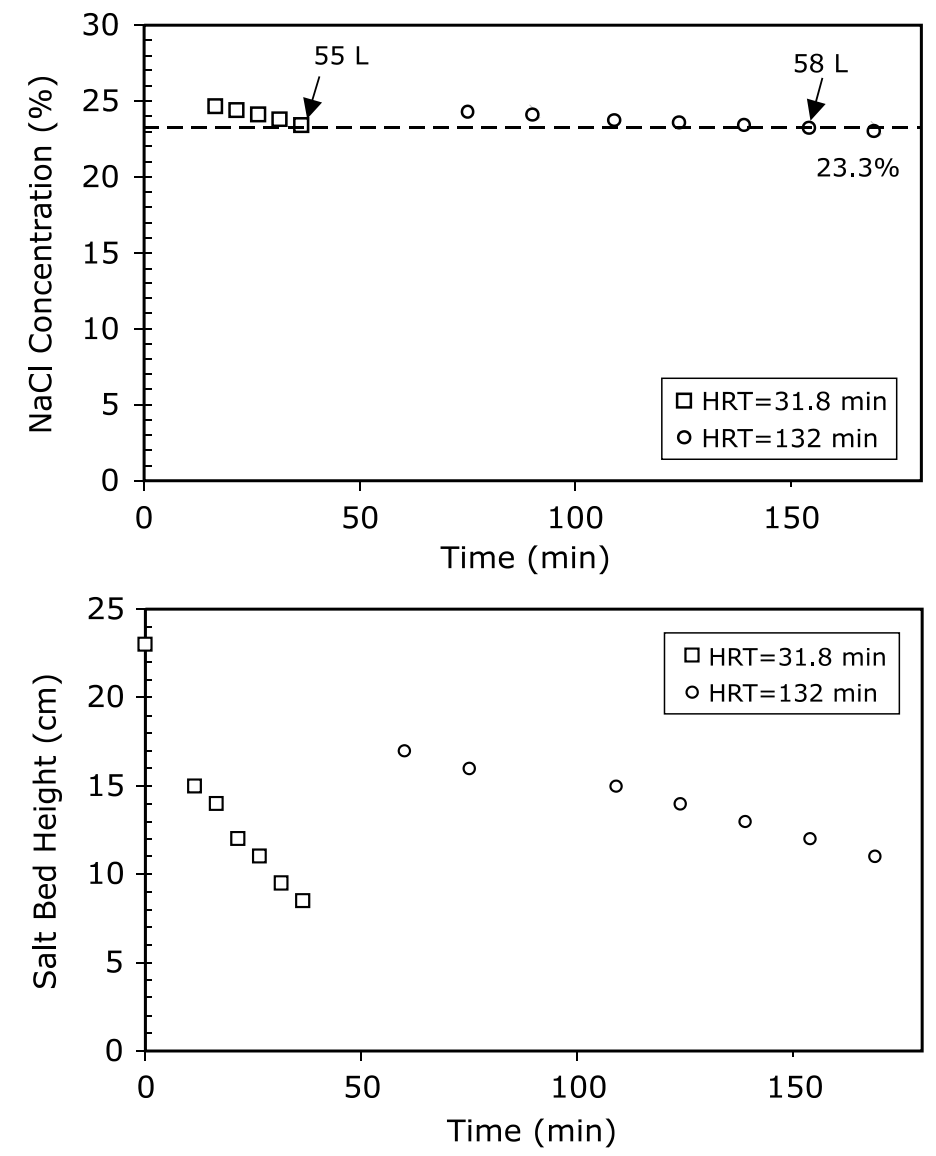

Figure 19. Top: Percentages of Salt in Brine and Volume Produced as Function of Hydraulic Retention Time (HRT). Bottom: Height of Salt Bed as Function of HRT.

As was expected based on the laboratory findings, the TSS content in the stormwater did not affect the brine production process (because of the already high turbidity values resulting from the salt). Turbidity values obtained for the effluent and 
settled effluent were similar to those obtained with tap water (turbidity lower than 0.3 NTU) during the laboratory tests (see Figure 20).
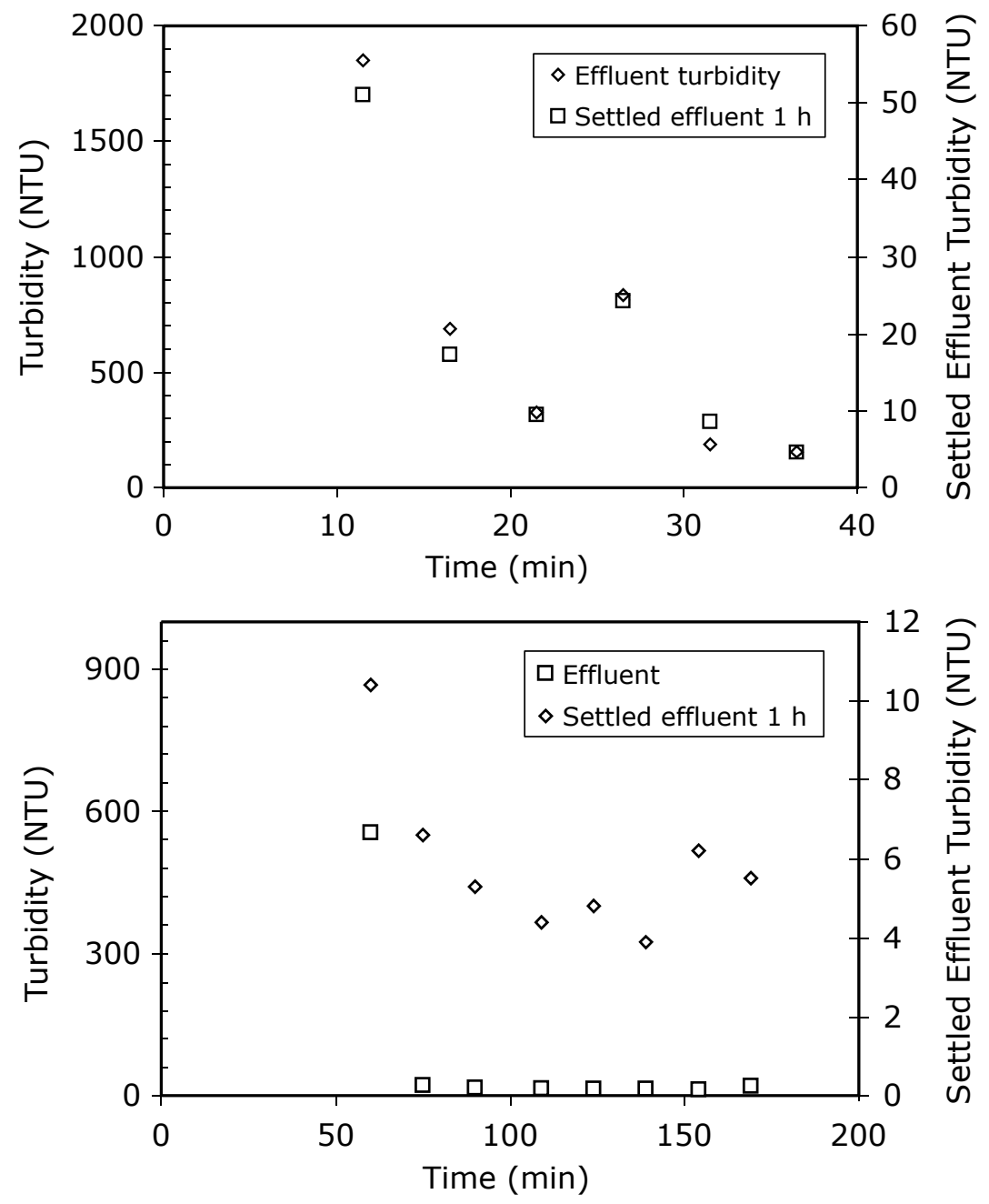

Figure 20. Comparison of Turbidity Values for Effluent Samples at Time of Collection and after 4 Hours of Settling for Hydraulic Retention Time $($ HRT) = 31.8 $\min ($ top) and HRT=132 $\min$ (bottom)

\subsubsection{Benefit/Cost Analysis}

The estimated volumes of water that would be used for pre-wetting only and direct application in combination with pre-wetting when assuming the low, average, and high $\mathrm{NaCl}$ annual application rates are shown in Figure 21. Only the volume of water 
that would be needed for direct application for the high chemical application rate significantly exceeds VDOT's average stormwater capture volume as calculated in Fitch et al. (2004, 2005).

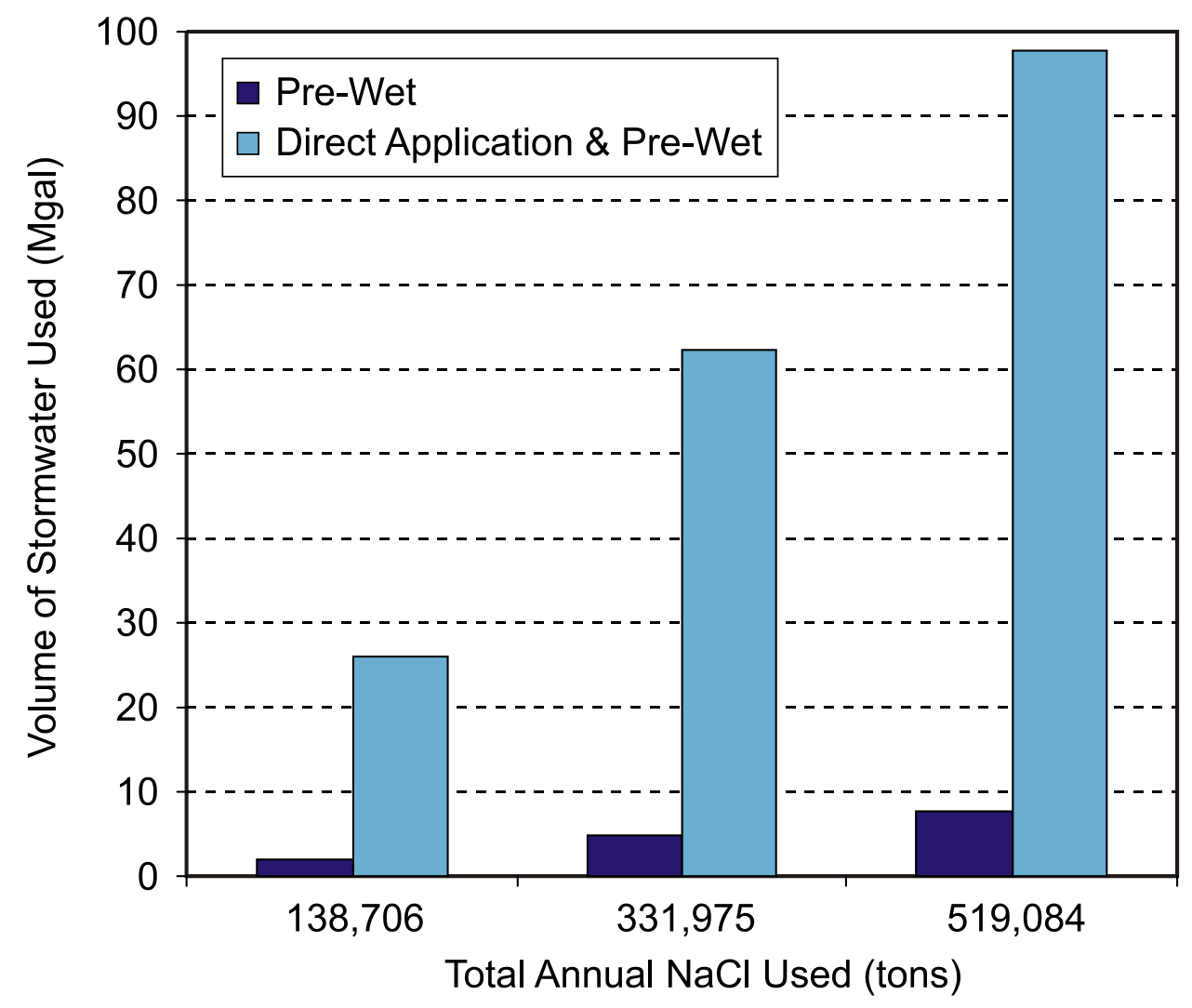

Figure 21. Estimated Annual Stormwater Usage for Pre-Wetting and Direct Application and Pre-Wetting Based on Low, Average, and High 5-year Total NaCl Application

The estimated annual benefits for 36 different brine utilization scenarios evaluated at the statewide average disposal cost per gallon are shown in Figure 22. The calculated values range from a low of just over $\$ 1$ million to a high of over $\$ 14$ million. The lowest value was calculated assuming less than 20 million gallons of stormwater are collected (the minimum winter volume), brine created from this stormwater is used exclusively for the purposes of pre-wetting, and a minimum volume of $\mathrm{NaCl}(138,706$ tons) is applied 
statewide. The greatest annual benefits were calculated assuming that brine is used for both direct application and pre-wetting purposes, nearly 90 million gallons of stormwater is collected (the maximum annual volume), and the highest total $\mathrm{NaCl}$ volume $(519,084$ tons) is applied. When assuming average stormwater volume collection and average total $\mathrm{NaCl}$ application, the benefits calculated for pre-wetting only versus adding and direct application to pre-wetting are approximately $\$ 3$ million and $\$ 6.5$ million respectively.

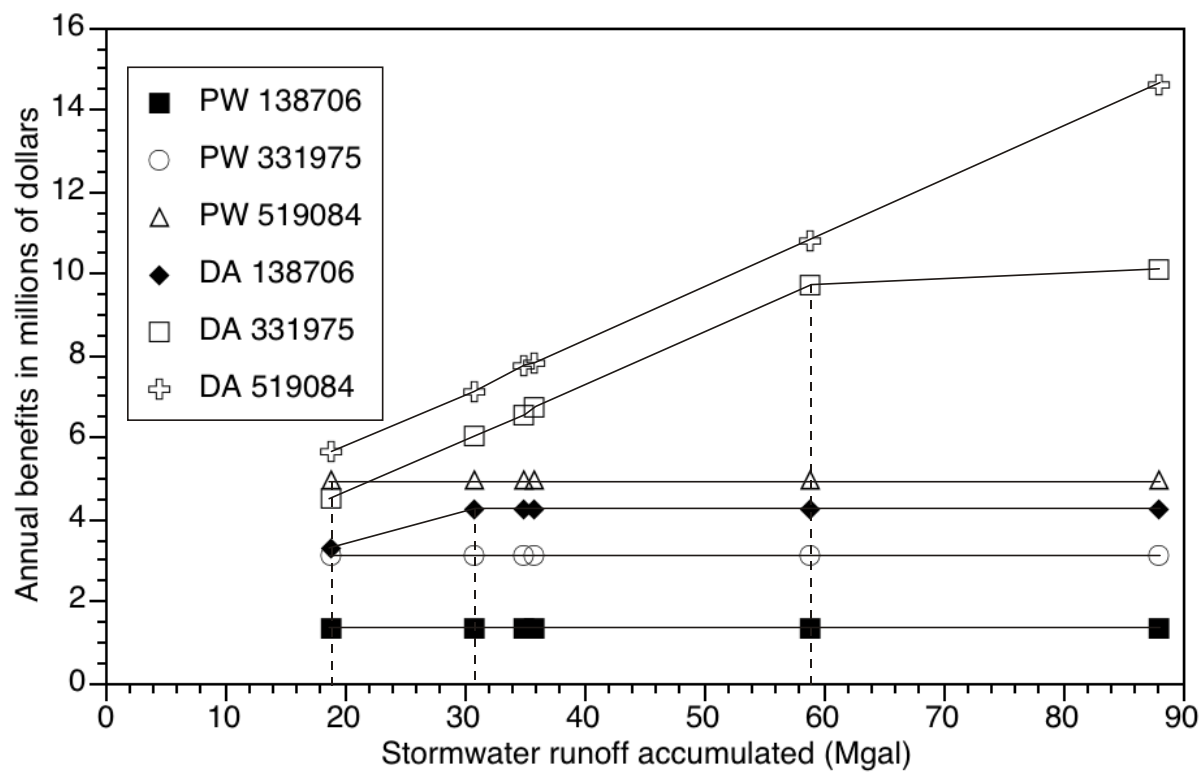

Figure 22. Annual Benefits Obtained by Use of Pre-Wetting (PW) or Direct Application (DA) Strategies as Function of Volume of Stormwater Runoff Accumulated and Amount of Road Salt Purchased. Quantities of Road Salt Used Were 138,706, 331,975 and 519,084 Tons, Respectively.

It is clear from this analysis that the greatest benefits are derived when direct brine application is used in conjunction with pre-wetting. It should also be noted that these benefits are primarily due to the reduced disposal costs of the collected stormwater. The other benefits of direct brine application and pre-wetting (i.e., reduced total chemical usage, increased level of service, etc.) as documented in the literature (Alleman et al., 
2004; Ketcham et al. 2006; O'Keefe and Shi, 2005; Wisconsin DOT, 2005) were not considered in this analysis.

This analysis also reveals the approximate optimum (with respect to benefits accrued) stormwater volumes collected for each total chemical volume used and application method utilized. These volumes are represented by the dashed lines. For all three salt-use scenarios where only pre-wetting is used, no additional benefits are accrued if additional stormwater is collected. This indicates that VDOT could generate all the brine used for pre-wetting with the minimum amount of stormwater captured.

Conversely, assuming the maximum chemical application scenario and direct application of brine in conjunction with pre-wetting, the maximum volume of stormwater potentially collected could be used in the making of brine necessary for these two application methods.

Table 9 summarizes the results for how long it would take forgone disposal and chemical additive cost to offset the brine-generating capital investment costs for each of the 72 scenarios. All alternatives yielded a return on the investment in less than 4 years. The reuse of stormwater runoff for brine to be used for pre-wetting offset the initial brine-generating equipment costs more rapidly as the amount of road salt used increased, regardless of the volumes of stormwater runoff accumulated during the year or winter season. For direct application in conjunction with pre-wetting, the number of years required to recoup the capital investment was significantly reduced when compared with the pre-wetting only. In addition, this alternative was more sensitive to the variation of the quantity of salt applied and to the variation of the volume of stormwater runoff accumulated. However, with all alternatives, the use of volumes of stormwater runoff 
higher than $30 \mathrm{MG}$ and road salt application higher than 332,000 tons per year resulted in the recovery of the capital invested in less than 2 years when assuming statewide average disposal costs.

Table 9. Number of Years Required to Recover Capital Investment for Pre-Wetting (PW) and Direct Application (DA) and Pre-Wetting as Function of Volume of Stormwater Runoff Accumulated and Amount of Road Salt Purchased

\begin{tabular}{|c|c|c|c|c|}
\hline $\begin{array}{l}\text { Application } \\
\text { Method }\end{array}$ & $\begin{array}{c}\text { Salt Volume } \\
\text { Applied (tons) }\end{array}$ & $\begin{array}{c}\text { Stormwater } \\
\text { Runoff } \\
\text { Accumulated } \\
\text { (million gallons) }\end{array}$ & $\begin{array}{l}\text { NPV \#1 Pay off } \\
\text { with Disposal = } \\
\$ 0.13 / \text { gallon } \\
\text { (years) }\end{array}$ & $\begin{array}{c}\text { NPV \#2 Pay off } \\
\text { with Disposal = } \\
\$ 0.55 / \text { gallon } \\
\text { (years) }\end{array}$ \\
\hline \multirow{18}{*}{ Pre-Wetting } & \multirow{6}{*}{138,706} & 19 & 3.6 & 2.0 \\
\hline & & 31 & 3.6 & 2.0 \\
\hline & & 35 & 3.6 & 2.0 \\
\hline & & 36 & 3.6 & 2.0 \\
\hline & & 59 & 3.6 & 2.0 \\
\hline & & 88 & 3.6 & 2.0 \\
\hline & \multirow{6}{*}{331,975} & 19 & 1.4 & 0.8 \\
\hline & & 31 & 1.4 & 0.8 \\
\hline & & 35 & 1.4 & 0.8 \\
\hline & & 36 & 1.4 & 0.8 \\
\hline & & 59 & 1.4 & 0.8 \\
\hline & & 88 & 1.4 & 0.8 \\
\hline & \multirow{6}{*}{519,084} & 19 & 0.9 & 0.5 \\
\hline & & 31 & 0.9 & 0.5 \\
\hline & & 35 & 0.9 & 0.5 \\
\hline & & 36 & 0.9 & 0.5 \\
\hline & & 59 & 0.9 & 0.5 \\
\hline & & 88 & 0.9 & 0.5 \\
\hline \multirow{18}{*}{$\begin{array}{c}\text { Direct } \\
\text { Application and } \\
\text { Pre-Wetting }\end{array}$} & \multirow{6}{*}{138,706} & 19 & 2.7 & 0.7 \\
\hline & & 31 & 2.0 & 0.5 \\
\hline & & 35 & 2.0 & 0.5 \\
\hline & & 36 & 2.0 & 0.5 \\
\hline & & 59 & 2.0 & 0.5 \\
\hline & & 88 & 2.0 & 0.5 \\
\hline & \multirow{6}{*}{331,975} & 19 & 1.9 & 0.7 \\
\hline & & 31 & 1.4 & 0.4 \\
\hline & & 35 & 1.3 & 0.4 \\
\hline & & 36 & 1.3 & 0.4 \\
\hline & & 59 & 0.9 & 0.2 \\
\hline & & 88 & 0.8 & 0.2 \\
\hline & \multirow{6}{*}{519,084} & 19 & 1.5 & 0.6 \\
\hline & & 31 & 1.2 & 0.4 \\
\hline & & 35 & 1.1 & 0.4 \\
\hline & & 36 & 1.1 & 0.4 \\
\hline & & 59 & 0.8 & 0.2 \\
\hline & & 88 & 0.6 & 0.2 \\
\hline
\end{tabular}


Depending on the method of brine application (pre-wetting or direct brine application) employed by VDOT, significant cost savings could be accrued.

Disregarding the cost savings touted in several recent anti-icing studies (Alleman et al., 2004; Ketcham et al. 2006; O’Keefe and Shi, 2005; Wisconsin DOT, 2005) resulting from a reduction in total chemicals needed and an increased level of service, for VDOT savings would result from the reuse of stormwater that would otherwise require disposal. Based on the most conservative chemical application, brine use, and total stormwater capture estimates, it was calculated that VDOT would save nearly \$1.5 million a year by pre-wetting with $\mathrm{NaCl}$ brine generated from its salt-laden stormwater. The equipment required to implement this practice statewide would have an estimated cost of approximately $\$ 4$ million.

When assuming average chemical application volumes and stormwater collection, if brine is applied directly in addition to being used to pre-wet granular $\mathrm{NaCl}$, savings could be as high as $\$ 6.5$ million a year with estimated capital costs of nearly $\$ 8$ million. Given this same scenario, it is calculated that it would take approximately 1.3 years for the forgone disposal and chemical additive costs to offset the brine generating and application capital investment costs when assuming a stormwater disposal cost of $\$ 0.13$ per gallon. Assuming a disposal cost of $\$ 0.55$ for stormwater, capital investment costs are offset in 0.4 years.

\subsection{CONCLUSIONS}

By way of this research task it was concluded that low HRTs and high temperatures were found to be the optimum conditions for brine generation in terms of 
time of operation and percentage of $\mathrm{NaCl}$ used. While lower HRTs will in turn require more frequent additions of road salt to the brine generation reactor, the lower water temperatures likely to result from the use of water from stormwater ponds during the late fall and winter will increase required HRT and reduce the efficiency of the brine making equipment as compared to water at a higher temperature coming from a groundwater source. Brine creation efficiency when using stormwater should be similar to using a municipal drinking water source since water temperatures from these two sources will be comparable.

Though the water temperature did affect brine making efficiency, the level of total suspended solids found in VDOT's captured stormwater - one of the department's primary concerns with using stormwater for brine generation - did not reduce the efficiency of the brine generation process. TSS values in the stormwater were relatively low as compared to the TSS found in granular $\mathrm{NaCl}$ source. Additionally, because it was found that stormwater from runoff storage ponds can be recycled for brine production without harm to the brine generation or distribution equipment, only minimal filtering will be required of the stormwater prior to its use for brine generation. Again, this is important since pre-filtering throughput was one of the limiting factors for RO treatment.

Based on the total annual stormwater collection estimate of 60 million gallons it is clear that VDOT captures sufficient water for all pre-wetting conditions and for the low and average direct application conditions (more water would only be needed during extremely high chemical application years). All of these factors contribute to the conclusion that the implementation of a recycling program using stormwater runoff for brine generation by VDOT appears economically feasible, though, based on the 
calculations done here, there will be large variations in the benefits accrued by the department depending on the volumes of stormwater runoff accumulated during the year, the total volume of $\mathrm{NaCl}$ applied, and local disposal costs. Given the two brine application alternatives examined, the combination of direct application with pre-wetting has a shorter period required for initial investment offset in 30 out of 36 scenarios.

Assuming average total $\mathrm{NaCl}$ application volumes, the maximum benefits derived from stormwater reuse are obtained when capturing less than $60 \mathrm{MG}$ of stormwater statewide. 


\section{CHAPTER 5. LIFE CYCLE ASSESSMENT}

\subsection{INTRODUCTION}

The majority of departments of transportation (DOTs) in the United States find it necessary to chemically treat roadways during winter weather events to ensure that the roads are safe for motorists. Similar to VDOT, the majority of these agencies rely on chloride-based deicing and anti-icing compounds to carry out this function because these compounds are inexpensive, effective, and many DOTs already have the capital equipment and expertise needed to handle and apply the chemicals (Transportation Research Board, 1991). The most common chloride-based compound is sodium chloride (i.e., rock salt or $\mathrm{NaCl})$ though magnesium chloride $\left(\mathrm{MgCl}_{2}\right)$ and calcium chloride $\left(\mathrm{CaCl}_{2}\right)$ are frequently used. A number of alternatives to chloride-based road treatments have been developed over the years but these represent a small fraction of the market because they are significantly more expensive (Levelton Consultants, 2007).

In spite of their heavy use, chloride-based road treatments have well-characterized detrimental impacts on roadway infrastructure and on vehicles (Callahan, 1989; Cody et al., 1996; Raupach, 1996). As a result of these studies, a number of mitigation techniques have been developed to preempt the negative consequences of chloride use on roads. The reinforcing steel now used in most concrete roads is coated to extend its life while automobiles are sold with fewer ferrous components exposed to the roadway (Koch et al., 2002). These stopgap measures have eliminated some of the impacts that chlorides have on engineered systems, but chloride application remains the single biggest determining 
factor in life of bridge decks and other crucial infrastructure life (Transportation Research Board, 1991).

In addition to impacting engineered systems, chloride-based compounds have well documented burdens on the natural environment (Cain. et. al., 2001; Corsi et al., 2010; Hanes et al., 1970; Jones and Jeffrey, 1986; Novotny, 1999). The published research is focused predominantly on three impacts associated with chloride applications: 1) the effect of chloride contamination on ground and surface water, 2) soil contamination, and 3) vegetation stress. Direct runoff from the roadway has been shown to contain exceedingly high chloride levels after application with a great deal of variability depending on precipitation conditions and road properties (Corsi et al., 2010). Watershed scale studies have demonstrated appreciable average accumulation of chloride over time, with chloride concentrations in some northern metropolitan areas exceeding U.S. Environmental Protection Agency chronic water quality levels even during the nonwinter maintenance period of May through October (Corsi et al., 2010). Similarly, the degree of soil contamination has been found to be dependent on the amount of highway drainage it receives (including splashing and spraying), slope, and soil type (Colwill et al., 1992). Both water and soil containing salt contribute to the vegetation stress, as does direct salt accumulation on the foliage (Bowers and Hesterberg, 1976).

Recognizing the engineering and environmental costs of chloride-based treatments, the Federal Highway Administration (FHWA) funded research aimed at identifying alternatives to these chemicals in the mid-1970's. Calcium magnesium acetate (CMA) is the most promising of the compounds to have emerged from those efforts. CMA has an ice melting capacity similar to that of $\mathrm{NaCl}$ and preliminary tests 
suggested that CMA had little to no impact on concrete and metal and it was not harmful to plants or animals (Transportation Research Board 1991). CMA is a mixture of calcium and magnesium acetate and is produced by reacting acetic acid and dolomitic limestone (Wise et al., 1991). Since its discovery in the 1970s by Dunn and Schenk (1980), it has been evaluated extensively to understand its feasibility as an alternative to chloride-based treatments (California Department of Transportation, 1989; Connolly et al., 1990; Horner, 1988; Manning and Crowder, 1989). There are some well documented shortcomings of CMA: it has a high biochemical oxygen demand when undergoing decomposition in receiving waters, and it is expensive to manufacture relative to salts (Leineweber, 2002). It is effective over a range of temperatures and is non-corrosive so overall, it was considered to be one of the best alternative chemical deicers available. It's high purchase price, which tends to be an order of magnitude higher than rock salt per unit mass, has inhibited its widespread adoption (Basu et al., 1999; Leineweber 2002; Ormsby 1999; Yang et al. 1999).

In light of the significant infrastructure and environmental impacts of chloride treatments, a number of research studies have sought to quantify the full cost of applying these compounds. These studies have monetized the indirect costs associated with infrastructure degradation and automobile damage as well as negative impacts to the natural environment (Environment Canada, 2006; Yunovich et al., 2006) Vitaliano et al. (1992) estimated that the true cost of using salt for winter maintenance was in the range of $\$ 400$ - $\$ 600$ per ton, as compared to its purchase price of approximately $\$ 50$ per ton. Such estimates make CMA appear more competitive with chloride-based treatments. In practice, DOTs are not responsible for many of the externalities associated with chloride 
use and so it is unlikely that they will change their treatment given that their imperative is to treat and maintain the most lane miles as effectively and inexpensively as possible. The efforts to monetize the impact of using these treatments have a great degree of uncertainty inherent in their estimates because precise cost numbers are highly dependent on key variables including the amount of chemical used over a specific period of time, the total volume of chemicals used, the type of system being maintained, and environmental conditions. Nevertheless, this full cost accounting does contribute to the perception that CMA might be an attractive alternative to chloride-based treatments (Levelton Consultants, 2007).

An important consideration for DOTs when evaluating alternative road treatments are the investments in infrastructure and expertise needed for the distribution, storage, and application of rock salt. Within these constraints DOTs have identified certain parameters that they can control that minimize the total amount of chemicals they use while maintaining service. For example, many DOTs have worked to cover their rock salt storage facilities since runoff from these facilities can result in significant, yet avoidable, flows of salt into the environment. Similarly, some DOTs have attempted to improve other handling practices, such as applying the treatments closer to the surface of the road to minimize material bouncing off the roadway surface, and others use road weather information systems to help optimize chemical application rates based on specific roadway conditions. While these have been useful in decreasing the amount of chlorides that enter the environment, no studies to date have assessed the overall systemslevel impacts of winter road treatments from a life cycle standpoint. 
Life cycle assessment (LCA) is a quantitative tool for evaluating the environmental impacts of products or processes over the entire life cycle from resource extraction to end of life treatment. In the context of winter road treatment, an LCA would enable the comparison of all steps in the delivery and use of a product from mining raw materials, manufacturing or processing the chemical, storage, application, and eventual fate in the environment. Such a comparison would aid DOTs that have historically only had access to a few of the stages in the road-treatment life cycle. Much like full cost accounting quantifies all the infrastructure and environmental costs of chloride-based treatments and its alternatives, LCA provides quantitative measures of the environmental consequences of different decisions. In particular, the use of process-level life cycle assessment wherein the system is modeled using each individual unit operation and process enables a detailed sensitivity analysis. This information would be very useful for DOTs along with chemical suppliers and environmental scientists seeking improvements in winter road treatment processes.

\subsection{PURPOSE \& SCOPE}

The purpose of this component of the research effort was to develop a life cycle model for three different winter maintenance approaches that could be used to maintain an acceptable level of service for a roadway during an average winter precipitation event. Both deicing and anti-icing treatments were considered. This is important because in as much as deicing implies that chemicals are not applied until after frozen precipitation has accumulated on the roadway surface and anti-icing involves the practice of applying chemicals to the roadway surface prior to the accumulation of frozen precipitation, they 
both involve different levels of application and different profiles of runoff. The model was developed for three geographic regions of Virginia in hopes of providing a useful contrast into how the model behaves for coastal, piedmont, and mountainous landscapes.

\subsection{METHODS}

\subsubsection{Evaluation of Three Winter Maintenance Treatments}

Three winter maintenance treatments were included in this study. The benchmark for the study was rock salt, modeled as dry, granular sodium chloride applied to the roadway following a small accumulation of frozen precipitation to the roadway surface. Subsequent applications of dry $\mathrm{NaCl}$ are used throughout the remainder of the storm event based on precipitation intensity and temperatures. This treatment is representative of the approach used by the vast majority of DOTs. The second approach utilizes the application of concentrated sodium chloride solution or brine followed by the application of the granular $\mathrm{NaCl}$ pre-wetted with brine. This anti-icing strategy, as discussed in earlier chapters, requires that DOTs apply the brine solution prior to the onset of the storm event to prevent the formation of a bond between the frozen precipitation and the road surface. Pre-wetting the granular $\mathrm{NaCl}$ for subsequent applications allows the sodium chloride to mix with water on the roadway more readily once it is applied and it results in less of the granular sodium chloride bouncing off the road during application. Brine application does require different equipment to store, load and apply the liquid treatment and so it is not a widespread practice even though it provides efficiency benefits over conventional dry application of sodium chloride. The third and final treatment is CMA solution. CMA use, as modeled here, is used for anti-icing in the brine 
form before the weather event but can also be applied in the pre-wetted granular form after the onset of the storm. The approach is similar to the method used for brine $\mathrm{NaCl}$ as it requires that DOTs obtain specialized storage and application equipment and the more expensive chemicals.

\subsubsection{LCA Model Development}

The life cycle model was developed to analyze the environmental impacts resulting from the acquisition of chemicals, transportation to storage, loading, and application to the roadway. The upstream system boundaries were drawn around the mining of the $\mathrm{NaCl}$ for the two salt-based alternatives and at dolomite mining and acetic acid production for the CMA-based approach. The downstream extent for all three approaches includes the disposal of runoff from the DOT storage facilities and the fate of runoff from the roadway. The environmental burdens for each of the steps identified was estimated using a combination of sources including those available in the literature, previous research conducted by the authors, and from SimaPro (Product Ecology Consultants, 2007) life cycle assessment software utilizing the ecoinvent database (Ecoinvent, 2007).

The model was built in spreadsheet format using the Crystal Ball (Oracle Corporation, 2009) stochastic modeling plug-in which enabled stochastic comparison of the data. The Monte Carlo tool within Crystal Ball allowed each input to be entered as a range or distribution depending on the availability of data. Each output was generated in the form of a distribution, which allowed the authors to provide meaningful estimates of the uncertainty associated with this modeling exercise. The functional unit for the 
assessment was selected to be 100 lane miles. The model was built such that a number of key assumptions could be varied to explore their sensitivity on the final results. For example, the chemical application rates, which are generally subject to guidelines but are variable in practice, could be changed to understand the impact on the results. Similarly, the total number of applications could be varied. Equivalent chemical volumes for each of the three approaches were based on information developed in the National Cooperative Highway Research Project 6-13 (Blackburn et al., 2004). This study provided the equivalent application rates for several ice control chemicals, taking into account the pavement temperature, initial ice-pavement bonding conditions, and dilution potential based on forecasted precipitation rates. Having the flexibility within the model to adjust these rates was important as the relationship between the volumes of $\mathrm{NaCl}$ to CMA used is not constant. For example, as pavement temperature decreases, the relative amount of CMA needed to adequately treat a given distance of roadway increases more readily than it does for sodium chloride.

The three winter maintenance treatments were evaluated on the basis of five relevant environmental impact factors. The first is total chloride emissions to the environment. Contamination of both surface and ground waters by runoff from salt application has been the primary concern related to the use of chloride based treatments. The second is biochemical oxygen demand (BOD). Alternatives to chloride-based treatments (such as CMA) are known to contribute to the BOD loading of receiving waters. The degradation of the organic constituents in these chemicals can result in a temporary reduction in the dissolved oxygen levels in the receiving waters. The third impact factor is total energy use. Energy consumption resulting from the production and 
application of each chemical treatment was estimated and reported. These results are of interest because energy use is often strongly correlated with price of a treatment and since most energy is derived from fossil-based fuels, it is proportional to the use of nonrenewable resources upstream. The fourth impact factor considered here is total greenhouse gas (GHG) emissions. DOTs are becoming increasingly pressured to reduce their GHG emissions but few efforts have been undertaken to evaluate the effect that winter maintenance could have on climate change. The fifth and final impact factor included in this study is overall fresh water consumption. Water was included because two of the methods here would require the production of an aqueous solution prior to application and this could be an environmental consequence of interest in more arid locations.

\subsubsection{Characteristic Weather Conditions}

Historical weather data from 2000 to 2010 (NOAA, 2011) was used to calculate the application rates in the model and since weather was expected to have an important impact on the results of the study, several characteristic regions were defined. The state of Virginia was divided into three geographic regions: mountain, piedmont, and coastal.

The hourly precipitation and temperature data taken from a total of eight weather stations was analyzed to determine the average storm characteristics for each region. The historical weather record confirmed that these three regions experience very different average temperature ranges and precipitation patterns due to their proximity to the Atlantic Ocean and the Blue Ridge and Appalachian mountain ranges. These different 
environmental conditions affect the frequency and methods of winter maintenance practices employed by the DOT.

\subsubsection{Transport}

Transport distance ranges for chemicals from the point of mining or manufacture to regional distribution sites were calculated assuming the salt mining locations and distribution sites shown in Table 10. Both the mining locations and the regional distribution sites were based on road salt purchasing contracts provided by VDOT. While these are specific to Virginia, it is assumed the transport distances would be similar for other states as well. Regional transport distances ranged from 314 miles to 574 miles. Energy consumption and emissions values were estimated assuming rail transport.

Table 10. Salt Mining Locations and Regional Distribution Sites

\begin{tabular}{ll}
\hline \multicolumn{1}{c}{ Mining/Processing Locations } & \multicolumn{1}{c}{ Regional Distribution Sites } \\
\hline Akron, OH & Baltimore, MD \\
Cleveland, OH & Chesapeake, VA \\
Lansing, NY & Dillwyn, VA \\
& Roanoke, VA \\
& Weyers Cave, VA \\
\hline
\end{tabular}

Transport distance ranges from the five regional distribution sites were calculated to 30 randomly selected VDOT maintenance locations (10 within each of the three geographic regions of the state). These local transport distances are shown in Table 11. Energy consumption and emissions were calculated assuming transport was conducted using a 40 ton gross weight tractor---trailer. 


\section{Table 11. Local Transport Distances (miles)}

\begin{tabular}{rrrr}
\hline \multicolumn{1}{c}{ Mountain } & Piedmont & Coastal \\
\hline 102 & 50 & 85 \\
47 & 39 & 72 \\
78 & 66 & 56 \\
94 & 21 & 62 \\
33 & 31 & 23 \\
16 & 60 & 14 \\
32 & 7 & 31 \\
57 & 3 & 82 \\
2 & 40 & 73 \\
Average: & $\mathbf{5 0 . 2}$ & 59 & 33 \\
\hline
\end{tabular}

\subsubsection{Storage and Handling}

Energy consumption and emissions estimates resulting from the transferring of dry chemicals to a covered storage facility were based on the assumption that the chemicals were dumped on the loading pad of the maintenance area and were then moved inside the storage area by way of a diesel powered front loader and/or tractor-PTO powered conveyor system. The reloading of these same chemicals to trucks used for distribution to the roadway was also assumed to be done by way of this same equipment. Fuel use was approximated using the following equation:

$$
F_{C}=T_{L} \times F C R
$$

where $\mathrm{F}_{\mathrm{C}}$ is the fuel consumption rate for the loader/tractor, $\mathrm{T}_{\mathrm{L}}$ is the loading time, and FCR is the fuel consumption rate. Values modeled here ranged from 5.6 -8.4 gph based on average non-road diesel construction equipment fuel consumption values (Frey et al. 2010; Zapata and Gambatese 2005). 
Emissions for this step were then calculated based on the carbon content of diesel as calculated below and taken from the Environmental Protection Agency's Emission Facts (2005).

$$
\begin{aligned}
& \mathrm{CO}_{2} / \text { gal }\{\text { diesel }\}=2,778 \text { grams }\{\mathrm{C}\} \times 0.99 \times(44 / 12)\left\{\mathrm{CO}_{2}\right\}=10,084 \text { grams } \\
& =10.1 \mathrm{~kg} / \text { gallon } \mathrm{CO}_{2} / \text { gal }
\end{aligned}
$$

Energy consumption and emissions associated with brine mixing and loading were calculated assuming that pumping was required to transfer the source water to the brine tank, mixing of tank contents, transfer of the solution from the brine tank to the brine storage tank, and transfer of the stored brine to the distribution vehicle prior to application on the roadway. Pumping specifications are shown in Table $12 . \mathrm{CO}_{2}$ emissions were calculated assuming $1.6896 \times 10^{-1} \mathrm{~kg} \mathrm{CO}_{2} / \mathrm{MJ}$ (US Department of Energy 2000).

\section{Table 12. Pumping Specifications*}

\begin{tabular}{ll}
\hline Pumping rate: & 40 gpm@ 20 ft; 130 gpm@ $50 \mathrm{ft}$ \\
Horse Power: & $1 / 3$ (low speed); $21 / 2$ (high speed) \\
Max Amps: & 3.5 (low); 11.9 (high) \\
Voltage: & 230 \\
* specifications based on minimum pumping requirements for 3000-5000 gph brine \\
generation systems as used by the Virginia Department of Transportation
\end{tabular}

The volumes of stormwater generated in association with chemical storage and the concentration of chlorides found in this stormwater were based on calculations and measurements from earlier research as shown in Table 1 in Chapter 2.

Based on the evaluations of the use of stormwater runoff for the purposes of brine generation as summarized in Chapter 4, it was assumed that a portion of the stormwater captured at the VDOT facilities could serve as the source water for the production of 
brine. By reusing this water, municipal or well water sources are conserved and the volume of waste water to be treated or disposed of is reduced. The volumes of stormwater runoff used for brine generation were estimated depending on the method of application. For the pre-wetting method, a range of 8 to 30 gal per ton was used, as found in the literature (Alleman et al. 2004; Ketcham et al. 1996; Wisconsin DOT 2005) and the remaining volumes were assumed to require disposal. Disposal impacts were calculated assuming transport to local municipal waste water treatment plants by way of tanker truck.

\subsubsection{Application}

Application transport consumption and emission values were calculated by methods similar to regional transport and emission calculations, with total transport distances ranging from 30 to 60 miles for both solid and liquid applications. This range of values was selected based on current VDOT chemical application routes which are determined primarily by anticipated maximum travel time during bad weather (approximately 2 hours). Dry chemical applications were assumed to utilize 8 and 10 ton capacity diesel powered dump trucks. Liquid chemical applications were assumed to utilize both tow behind tanker trailers and single unit tanker trucks ranging in capacity from 2,035 -3,135 gallons.

The total mass of dry chemicals applied for each model run was calculated using the following equation:

$$
C M_{T}=R_{A} \times N_{A} \times L M_{T}
$$


where $\mathrm{CMT}_{\mathrm{T}}$ is the total mass of chemical applied (tons/lane mile), $\mathrm{R}_{\mathrm{A}}$ is the application rate (tons/lane mile), $\mathrm{N}_{\mathrm{A}}$ is the number of applications, and $\mathrm{LM}_{\mathrm{T}}$ is the total miles of roadway treated.

The rate of application $\left(\mathrm{R}_{\mathrm{A}}\right)$ is primarily a function of pavement temperature, dilution potential, and ice-pavement bond conditions, and was determined using recommended application rates from work published in NCHRP 613 (Blackburn et al. 2004). The number of applications $\left(\mathrm{N}_{\mathrm{A}}\right)$ was calculated using the following equation:

$$
N_{A}=S_{L} \times C_{T}
$$

where $S_{L}$ is the length of the storm event and $C_{T}$ is the cycle time or the length of time between applications.

$\mathrm{C}_{\mathrm{T}}$ is dependent on a number of variables, including temperature and dilution potential. Dilution potential values (0 or 1$)$ were assigned to each of the three regions based on relative precipitation rates ascertained from the historical weather data. These values and summarized weather information for the three regions of Virginia are shown in Table 13 below (NOAA 2011).

Table 13. Summary Weather Data Used In Determining Chemical Application Rates

\begin{tabular}{llll}
\hline & \multicolumn{1}{c}{ Mountain } & \multicolumn{1}{c}{ Piedmont } & \multicolumn{1}{c}{ Coastal } \\
\hline Station Locations & Roanoke & Charlottesville & Newport News \\
& Winchester & $\begin{array}{l}\text { Danville } \\
\text { Richmond }\end{array}$ & Norfolk \\
& & Wakefield \\
Mean Event Duration (h) & 4.82 & 5.37 & 2.27 \\
Dilution Potential & 1 & 0 & 0 \\
Maximum Cycle Time (h) & 1.5 & 3.0 & 3.0 \\
Minimum Cycle Time (h) & 1 & 1.5 & 1.5 \\
\hline
\end{tabular}


Application rates for pre-wetting with brine and CMA were also taken from NCHRP 613 (Blackburn et al. 2004). Calculations were performed assuming a prewetting rate of 10 gallons of solution $(23 \% \mathrm{NaCl}$ brine and $25 \% \mathrm{CMA})$ per ton of granular chemical.

Emissions resulting from roadway water runoff were based on a $\mathrm{NaCl}$ runoff range of 55-83\% of the mass applied as found in the literature (Blackburn et al. 2004; Novotny 1999) and on the assumption that due to the conservative nature of $\mathrm{NaCl}, 100 \%$ of the chemical applied is being released into the environment, even if not directly measured in the runoff captured from the roadway.

The BOD emissions range modeled for BOD from roadway runoff containing CMA were assumed to range from a high of $75 \%$ of mass of chemical applied $(680 \mathrm{~kg}$ $\{$ BOD $\} /$ ton $\{\mathrm{CMA}\})$ to $0 \%$ based work done by Horner (1988) and Tanner \& Wood (2000).

\subsubsection{Evaluation of Model Output}

The model was run for the average temperature and precipitation conditions typically found in the three geographic regions of Virginia (mountain, piedmont, and coastal) during the months of November through March. To determine these regional averages, 10 to 15 years of hourly temperature and precipitation data collected at three weather stations within each region were downloaded from the National Oceanic and Atmospheric Administration's National Climatic data Center (National Oceanic and Atmospheric Administration, 2011). These data were analyzed to capture only those events where precipitation occurred and temperature was below freezing. This enabled 
the authors to estimate the storm durations for each region. Along with the storm conditions, e.g., temperature, it was possible to calculate the number of applications of each particular treatment type being analyzed.

Following the initial model runs, a sensitivity analysis was conducted in which the magnitude of each input was varied by $10 \%$ while holding all the other inputs constant. The resulting change in each of the model outputs was recorded and compared. Next, the processes contributing to each of the environmental burdens were then separated into two groups: (1) those that were not in the direct control of the transportation agency (i.e., those upstream), and (2) transportation agency-controlled steps. The sensitivity analyses were rerun for all three approaches and adjusted only those processes or steps within the control of the transportation agency. Based on the model output, comparisons were made across each of the five impact categories. Similarly, the total environmental burdens for each of the three winter maintenance approaches were calculated.

\subsection{RESULTS \& DISCUSSION}

\subsubsection{Evaluation of Three Winter Maintenance Treatments}

A schematic of the primary process steps for each of the three treatment strategies studied here is presented in Figure 23 and the data sources for each of the steps making up these processes are shown in Table 14. Even though there is some overlap between the three in terms of storage and application, key difference were found to result in important environmental impacts. The system boundaries set for each system are described here: 


\subsubsection{Salt}

Figure 23A shows the unit operations used in the application of rock salt. This treatment is the most straightforward of the three treatments modeled here and involves the fewest number of steps. In addition to the mining of $\mathrm{NaCl}$, there are several transportation steps, storage, and loading steps. Disposal of $\mathrm{NaCl}$ runoff generated at DOT storage facilities also requires the transport of large quantities of captured runoff to an offsite disposal facility.

\subsubsection{Brine}

The process steps involved in the storage and delivery of brine-based winter treatment are presented in Figure 23B. The delivery of brine involves many of the same processes involved in the delivery of salt with additional steps needed to obtain the water, create the $\sim 23 \%$ aqueous brine solution, and apply the liquid brine using trucks specifically designed to haul and apply liquid cargo. This approach also requires additional loading and storage steps but generally produces far less run off than solid sodium chloride storage.

\subsubsection{CMA}

The steps required in the delivery of calcium magnesium acetate are presented in Figure 23C. CMA is manufactured using dolomitic lime, which is mined, and acetic acid. Even though there are several industrially viable methods for producing CMA, one method utilizing natural gas for the production of a concentrated acetic acid solution which is then sprayed on dry lime to form CMA pellets is the most prevalent method and 
was selected for modeling here (Transportation Research Board, 1991). Upon delivery at the storage location for the DOT, the storage and application steps in the CMA lifecycle resemble those of sodium chloride brine. The similarities between CMA and rock salt from a DOT perspective are one of the reasons that CMA is widely thought to be an attractive alternative to sodium chloride.

a.

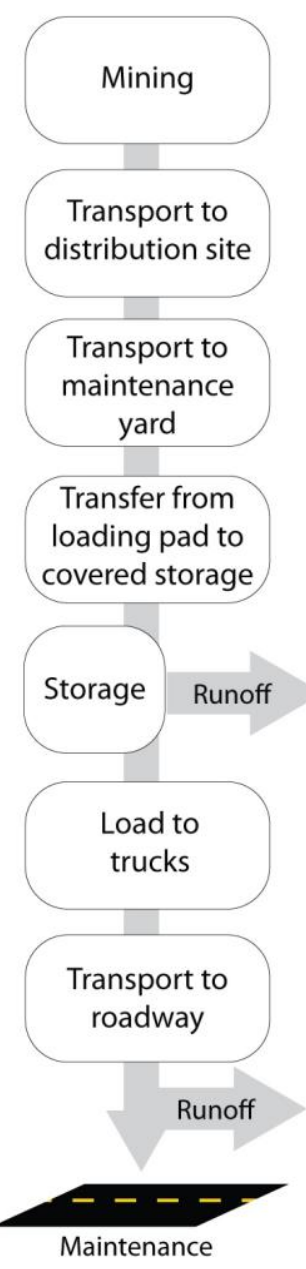

b.

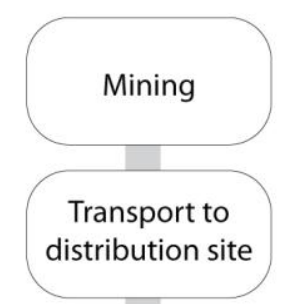

Transport to

maintenance yard

Transfer from loading pad to covered storage

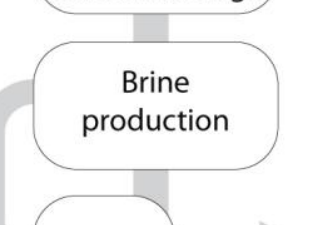

Storage Runoff
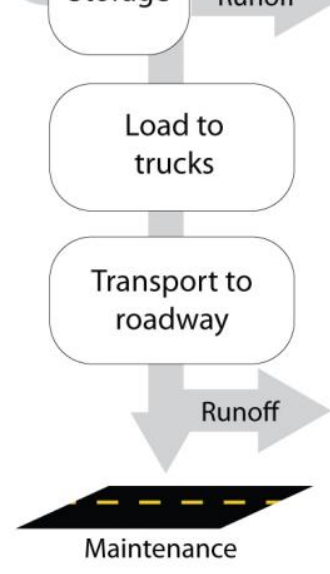

c.

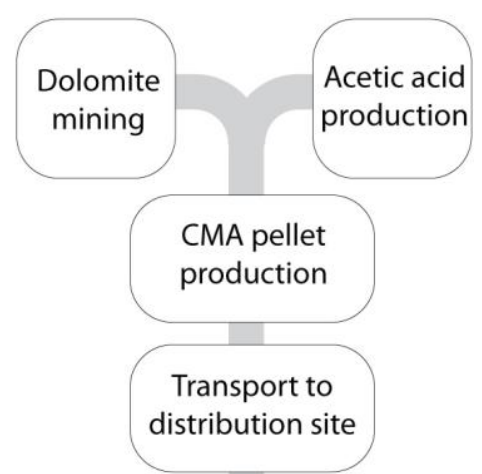

Transport to maintenance yard

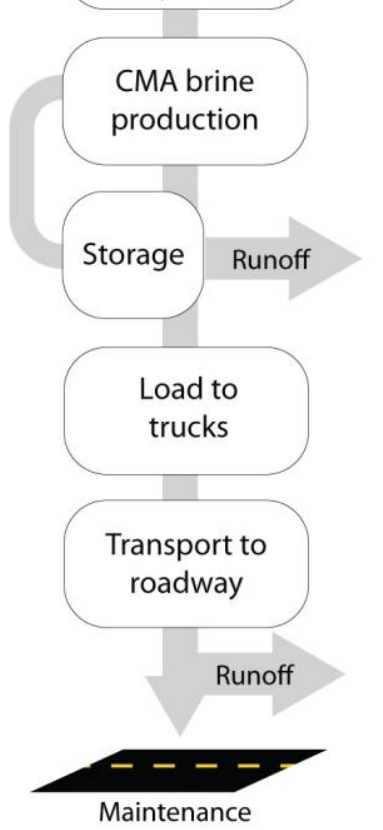

Figure 23. Schematic Representation of the Three Road Treatment Processes Included In This Analysis where A. is Rock Salt, B. is Sodium Chloride Brine, and C. is Calcium Magnesium Acetate (CMA) 
Table 14. Data Sources for the Primary Steps for All Three Winter Maintenance Treatment Methods

\begin{tabular}{|ll|}
\hline \multicolumn{1}{|c|}{ Process Step } & \multicolumn{1}{c|}{ Data Source } \\
\hline NaCl Mining & ecoinvent data v2.0 \\
\hline Acetic Acid Production & ecoinvent data v2.0 \\
\hline Dolomite Mining & ecoinvent data v2.0 \\
\hline Transport Distribution & ecoinvent data v2.0 \\
\hline Transport - Maint. Yard & ecoinvent data v2.0 \\
\hline Transfer-Covered Storage & Frey et al., 2010; USEPA 2005; Zapata and Gambatese, 2005 \\
\hline Brine Production & Craver et al., 2008; US Dept. of Energy, 2000 \\
\hline Storage & Novotney et al., 2009; Fitch et al., 2005; Snodgrass and Morin, 2000 \\
\hline Load-Brine Applications Trucks & USEPA, 2005; US Dept. of Energy, 2000 \\
\hline Load-Salt Application Trucks & Frey et al., 2010; Zapata and Gambatese, 2005 \\
\hline Transport-Brine Roadway Application & ecoinvent data v2.0; Alleman et al., 2004; Ketcham et al., 1996; \\
& Wisconsin DOT, 2005 \\
\hline Transport-Salt Roadway Application & ecoinvent data v2.0 \\
\hline Stormwater Runoff & Novotney et al., 2009; Blackburn et al., 2004; Snodgrass and Morin, \\
& 2000; Tanner and Wood, 2000; Horner, 1988 \\
\hline Roadway Maintenance & Xianming et al., 2010; Xianming et al., 2009; Bacchus, 1987 \\
\hline
\end{tabular}

\subsubsection{LCA Model Development and Output Evaluation}

Winter maintenance using dry $\mathrm{NaCl}$, brine, and $\mathrm{CMA}$ were compared on the basis of five environmental impacts over the entire life cycle and the results are summarized in Table 15. The sodium-chloride-based treatments are found to have significantly lower environmental impacts than CMA over the entire life cycle for four out of five impact areas. The standard deviation for each value is also presented. The model output distributions are all lognormal.

Table 15. Environmental Burdens Associated with Three Winter Maintenance Approaches

\begin{tabular}{|c|c|c|c|c|c|}
\hline $\begin{array}{l}\text { Maintenance } \\
\text { Approach }\end{array}$ & $\begin{array}{l}\text { Energy Use } \\
(\mathrm{MJ}) \times 10^{4}\end{array}$ & $\begin{array}{c}\text { GHG } \\
\text { Emissions } \\
\times 10^{3} \\
\end{array}$ & $\begin{array}{c}\text { Water Use } \\
\left(\mathrm{m}^{3}\right) \times 10\end{array}$ & $\begin{array}{l}\text { Cl Emissions } \\
(\mathrm{kg}) \times 10^{3}\end{array}$ & $\begin{array}{c}\text { BOD } \\
(\mathrm{kg}) \times 10^{2}\end{array}$ \\
\hline Salt (dry $\mathrm{NaCl})$ & $13.2 \pm 6.0$ & $10.5 \pm 2.9$ & $23.3 \pm 5.7$ & $20.4 \pm 2.0$ & $0.20 \pm 0.07$ \\
\hline Brine ( $\mathrm{NaCl}$ brine) & $8.7 \pm 3.7$ & $6.7 \pm 1.9$ & $15.0 \pm 3.5$ & $13.0 \pm 1.4$ & $0.12 \pm 0.04$ \\
\hline CMA (CMA brine) & $129.3 \pm 23.0$ & $40.7 \pm 6.9$ & $580.2 \pm 6.3$ & $0.53 \pm 0.2$ & $135.8 \pm 55.2$ \\
\hline
\end{tabular}


The total life cycle energy required to deliver CMA is almost ten times higher than rock salt and 15 times higher than brine. The majority of this energy is consumed during the manufacture of CMA. The acetic acid needed to manufacture CMA is produced by first converting natural gas (methane) to methanol and then converting methanol to acetic acid by way of methanol carbonylation. This natural gas requirement manifests itself in the high price for CMA. Additional research has been sponsored by FHWA in the hopes of identifying a less expensive method of producing the acetic acid needed for the production of CMA. Though several methods of production have been explored and some appear promising, to date none has proven to be feasible for mass production (Leineweber, 2002). Like CMA, the majority of the energy required to apply both salt and brine was associated with upstream resource extraction. Interestingly, brine was found to consume over one third less energy than dry rock salt. Even though brine application requires several additional steps that consume energy (i.e., pumping for brine production, loading of brine tanks, etc.), it uses less salt on a net basis and so the large upstream energy demands associated with mining can result in these important reductions in life cycle energy demand. Consistent with the energy results, CMA generates the largest GHG emissions. The emissions were four to five times greater than the other two methods. Again, because the synthesis of the acetic acid required for CMA was assumed to be dependent on the use of natural gas, $\mathrm{CO}_{2}$ emissions were high. It should be noted, however, that per unit of energy, GHG emissions are lower for natural gas than for petroleum based energy sources and this results in CMA having lower GHG emissions relative to its total energy requirements. 
In terms of water consumption, the disparity between CMA and the chloridebased treatments is even more pronounced. The CMA production process consumes appreciable amounts of water both in the production of the acetic acid and in the actual processing of the chemical into its palletized form. The volume of water that is used to produce the brine and the CMA solution that are applied to roads represents less than $1 \%$ of the total amount used of in both these systems. Over $90 \%$ of the water needed for these methods was used in resource extraction. This contradicts the assertion that use of brine for road treatment would disproportionately increase water consumption of the treatment process. Even more pronounced differences between the treatments are observed when considering the biochemical oxygen demand of the treatments. The total BOD emissions associated with CMA use are approximately 600 and 1000 times greater than for $\mathrm{NaCl}$ and brine respectively. This burden comes largely from acetic acid production but also from the runoff following application. CMA is an organic chemical that contributes to the BOD of receiving waters in a way that the chloride compounds do not. Since as much as $75 \%$ of the total CMA volume applied ultimately ends up in water bodies (Horner, 1988), this represents a significant drawback to adopting CMA. For any given location, these estimates might be much higher or lower depending on the dilution potential of the receiving streams but given the dramatic difference between the treatment chemicals, the impact of CMA is likely to always be greater than rock salt regardless of hydrologic conditions (Horner, 1988).

As expected, the one impact factor for which CMA is a major improvement is chloride emissions to the environment. Both the salt and brine systems emit more than 30 times more chloride than CMA. Most of these emissions occur as a direct result of 
runoff from treated lanes. In total, it was estimated that approximately $20,400 \mathrm{~kg}$ of $\mathrm{Cl}^{-}$ are released per 100 lane miles during a typical storm in the piedmont region of Virginia. This compares to only $530 \mathrm{~kg} \mathrm{Cl}^{-}$released when using CMA. Treating the roads with brine releases $13,000 \mathrm{~kg} \mathrm{Cl}^{-}$, or approximately $36 \%$ less than the salt approach.

The results presented in Table 11 indicate that CMA, often touted as the environmentally preferable alternative to chloride-based winter maintenance chemicals, has life cycle environmental burdens that are higher than the conventional treatments. In four of the five impact areas included in this study, CMA performed many times worse than the chloride based options. While comparison between impact factors involves value judgments that LCA cannot address (e.g., in some cases it might be desirable to reduce chloride emissions to a watershed at the cost of increased energy use and emissions upstream) the overall picture suggests that CMA does not reduce overall environmental burdens as intended. Interestingly, the data in Table 2 suggest that brine solutions of salt could result in important reductions in all impact areas modeled here when compared to dry rock salt. Improvements for all impact factors of 30 to $40 \%$ are possible by using brine rather than dry sodium chloride. DOTs have the ability to switch to brine with minimal start-up costs.

The 'Base case' results presented in Table 11 were calculated using timeaveraged temperature, storm duration, and storm intensity data characteristic of the Piedmont region of Virginia. Because these average weather parameters are different for the other two geographic regions of Virginia, so too are the maintenance protocols used to treat the average storms for these areas. To determine how the environmental burdens differ between dry salt applications and the use of brine for the three regions, the model 
was run using varying storm duration or intensity, resulting in different pre-treatment to in-storm-treatment ratios (or brine application ratio). The effect of brine composition was explored for each of the impact factors studied here and the results are presented in Figure 24. They suggest that, in general, as storm duration and/or intensity increases (as is the case when moving from coastal to piedmont to mountain regions), there is a decrease in the environmental benefits of using the brine winter maintenance approach in place of dry salt. This is because pre-treatment with brine - and the advantage it provides by reducing the volume of salt needed for treatment - only occurs once, regardless of the length of the storm. Because the ratio of pre-treatment to in-storm-treatments changes with storm duration, the environmental benefits derived from the use of brine becomes less with increasing storm length. The environmental advantages of using brine are maximized for those areas where small, frequent storms occur (i.e., the coastal region of Virginia). Areas such as this normally experience small storms that have durations of fewer than 12 hours. Areas that normally have storm durations longer than 18 or so hours still will see relatively large decreases in total environmental burdens if using brine in place of dry salt, they will just not be as great. 


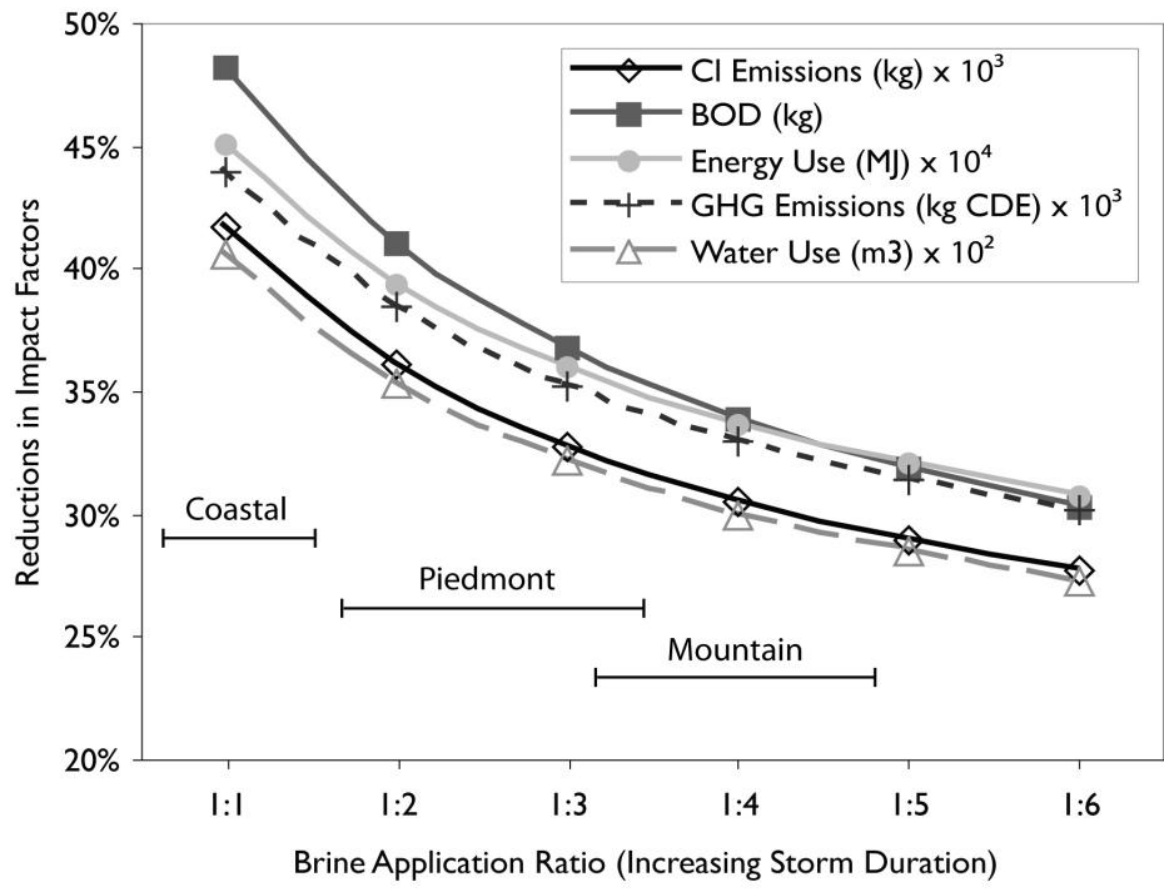

Figure 24. Effect of Brine Application to Solid Chemical Application Ratios in Driving the Environmental Impacts of Winter Maintenance

\subsubsection{Implications for Departments of Transportation}

The life cycle results presented here provide a new perspective on which attributes constitute an environmentally preferable winter maintenance treatment. It is important to delineate between those impacts that can be controlled by the transportation agency and those that originate upstream. Of course, all impacts are ultimately the direct result of treatment selection by the decision maker at the transportation agency. But other decisions can impact the overall burdens of winter maintenance so it was useful to explore the breakdown of the impacts as shown in Figure 25. Those impacts originating during the course of operations carried out by the DOT are colored gray and those occurring upstream are black. 


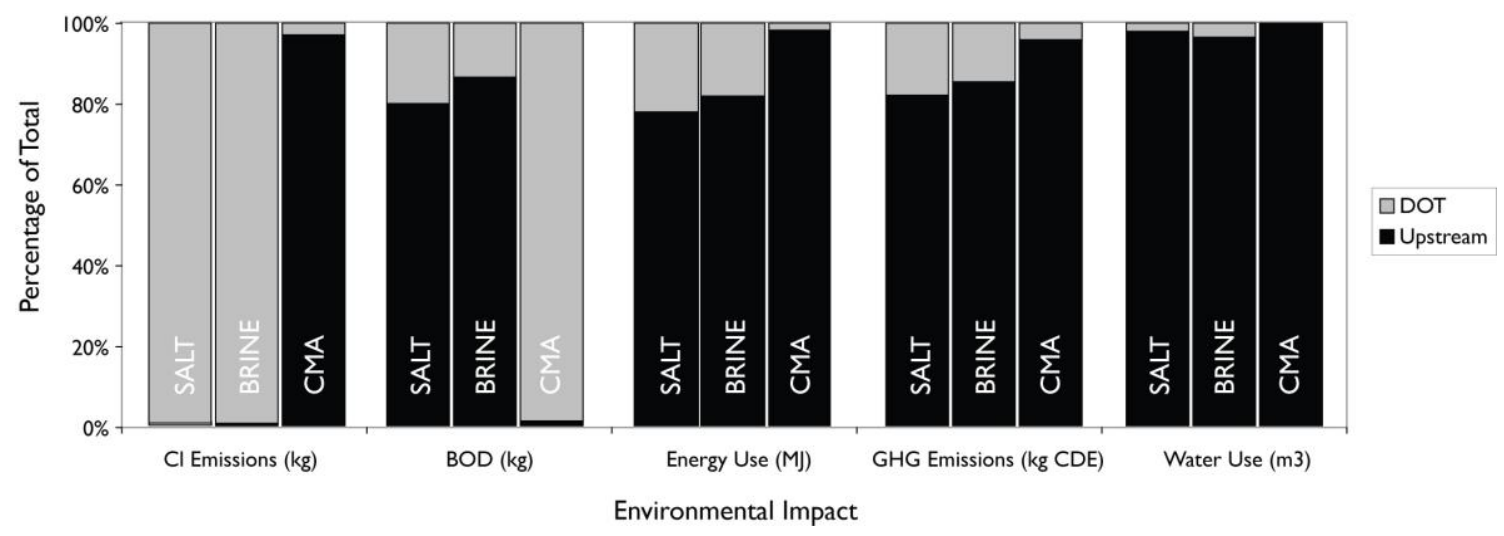

Figure 25. The Distribution of Burdens (Upstream V. at The DOT) for Each of the Impact Factors Shows Clearly that Even Though DOT Decision Makers Can Influence Certain Emissions (E.G., Cl Emissions, BOD, and To A Lesser Extent Energy and Ghgs Emission), Their Influence Is Highly Constrained In Other Regards (Note That The Impacts Are Expressed Here As A Percent Of Total)

With the exception of BOD and salt runoff to receiving water, most of the impacts associated with winter maintenance do not occur where the road is located but instead originate upstream where the treatment chemical is produced. This suggests that there are fewer opportunities for improvement via best management practices and other activities that are typically touted as effective means to reduce the impacts from winter maintenance. Production improvements in efficiency and so on could result in important reductions in many of the impact areas reported here but this is outside of the control of many DOTs. For the case of salt emissions to the environment, the transportation agency has almost all of the responsibility.

To provide additional insight into those processes that a transportation agency can control, a sensitivity analysis was performed on the model. Tornado plots were generated to depict the sensitivity of each impact factor to the model inputs. The results for total energy use, chloride emissions, and water use for the brine case are presented in Figure 
26. Those parameters that can be controlled by the DOT are in bold. The energy use plot suggests that improving the energy consumed for the transport of salt, from DOT maintenance yard to the roadway where it is applied, results in the greatest variance in the total energy consumption from a DOT operations standpoint. While the system is considerably more sensitive to the way in which $\mathrm{NaCl}$ mining is carried out, DOTs do not generally have control over mining practices and as such are unable to influence this aspect of the life cycle. DOTs could realize the greatest reduction in energy consumption by improving the transport processes used for chemical application. Examples of this might be improving the energy efficiency of the fleet used for application or optimizing the routing process used by application trucks. The chloride emissions plot clearly shows that reducing runoff containing salt has the greatest potential for minimizing the total amount of chlorides entering the environment. The water consumption plot indicates that most of the water needed for this treatment option is used during the mining process and, by comparison, the volume of water used for the production of brine is very small.

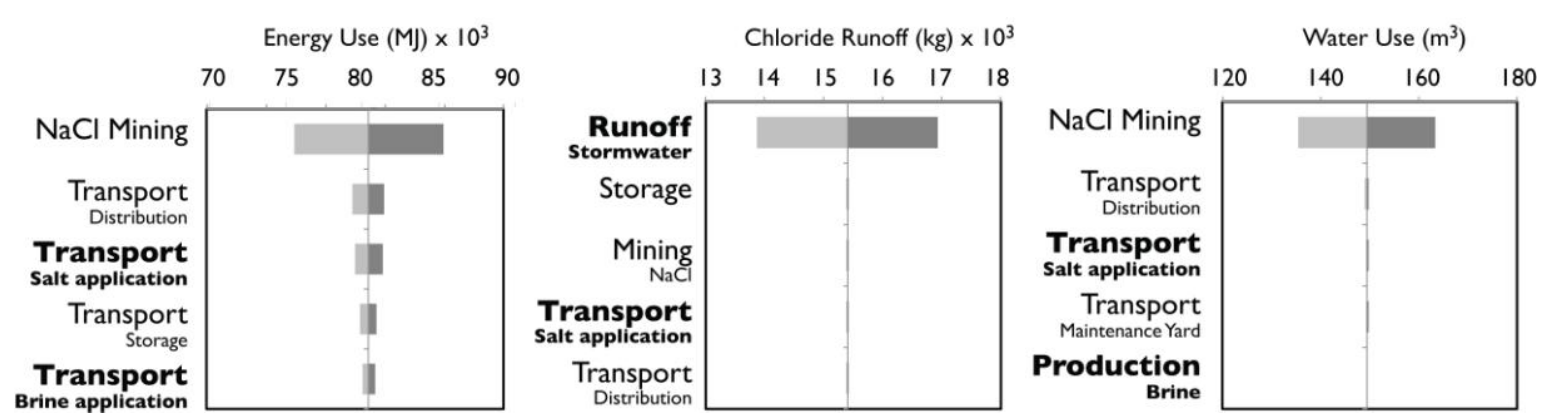

Figure 26. Sensitivity Analysis Plots for Energy Use, Chloride Emissions, and Water Use for Brine Indicating the Steps that Have the Greatest Effect for Each Impact Area (Steps in Bold are Those Controlled by the DOT; Non-Bold Steps Occur During Chemical Production or Transport to the DOT) 


\subsection{CONCLUSIONS}

The results of the LCA suggest that of the three approaches evaluated here, the use of brine appears to be the best option available to DOTs. This option requires less total energy, releases fewer GHGs, consumes less water, and emits less BOD than either CMA or dry salt. A sensitivity analysis revealed several specific activities at the transportation agency with the greatest impact on emissions. In particular the transportation of the salt during the application process was found to be the highest energy consuming DOT-controlled step, runoff from the roadway is the highest contributor to the total chloride emissions, and the volume of water needed for brine production is extremely small compared to the total water used for the salt mining process.

Storm conditions were found to have an important effect on the savings that could be realized using brine and so several different geographic regions of Virginia were modeled with different characteristic storm durations and intensities. For regions where the storm intensities tend to be relatively mild, the benefits associated with using brine are even more significant. Still, the benefits of using brine over using dry salt were significant, typically on the order of $30-40 \%$.

The results also indicate that CMA, which has been long considered one of the most environmentally promising treatment chemicals available to transportation agencies, has significantly higher emissions than chloride-based treatments. As expected CMA does reduce overall chloride emissions relative to salt treatment but this comes at the cost of significantly higher life cycle energy, water, BOD, and greenhouse gas emissions. 
Most of the emissions associated with using CMA occur upstream of the DOT. Consequently, it is unlikely that DOTs can further reduce the impacts associated with the use of this chemical by improving their application or management practices. Any significant improvements associated with the environmental burden of this alternative will almost certainly need to come from improvements in the production process.

Even though this result does not point to any obvious approaches that will eliminate the environmental impacts associated with winter maintenance of roadways, the study does suggest that modest steps at the DOT level can result in meaningful reductions in lifecycle impacts. In particular, a switch to using salt brines as a treatment method, rather than rock salt, enhances efficiency and reduces total energy use, water use, and greenhouse gas emissions without requiring significant financial investment by the DOT. This serves as a good example of how DOTs in general, and VDOT specifically, can simultaneously improve their environmental footprint and their economic bottom line in anticipation of a more sustainable winter treatment. 


\section{CHAPTER 6. CONCLUSIONS}

There is a great deal of variability in the winter maintenance operating procedures employed by VDOT as well as in the characteristics of the facilities used for these operations. This results in a wide variation in the extent of the winter maintenance issues experienced by the department, such as the volume of salt-laden stormwater runoff collected. Still, because of the high price and limited options available for disposal of this water, stormwater disposal options, proper handling of this water constitutes one of the major environmental concerns for its winter maintenance practices.

It appears that VDOT could realize significant cost savings by reducing the volume of water it captures at its chemical storage facilities. This could be achieved by directing water away from collection ponds and tanks through a combination of loading pad size reductions and clean water diversion during periods when the stormwater generated onsite does not contain salt. If employed correctly, these would result in a reduced volume of water requiring treatment or disposal, but would not increase the risk potential for ground or surface water contamination.

Adding to the importance of volume reduction is the fact that among the three treatment options evaluated, only RO was found to be technically feasible, given the volumes and chemical characteristics of the stormwater captured and stored by VDOT. Though low pressure RO, when used in combination with ultrafiltration, has the potential to be a less expensive alternative than normal disposal practices and on average could be expected to reduce $\mathrm{Cl}$ levels well below $250 \mathrm{mg} / \mathrm{L}$, the treatment rate or throughput volume of this type of system is likely to make its use on a large scale impractical. The 
high turbidity levels found in most captured stormwater requires the additional steps of pre-filtering and filter cleaning. When these limitations are combined with the large volumes of water VDOT would be required to treat given its limited capacity to safely store the water long term, the extent to which $\mathrm{RO}$ could be used appears inadequate. Also, when treating stormwater containing $\mathrm{NaCl}$ in the range of 2,000 to $3,000 \mathrm{mg} / \mathrm{L} \mathrm{a}$ total volume reduction of only $50 \%$ would be expected. This would again further reduce the volume of water that could be treated in a given period of time.

Though treatment options are - at the very best - extremely limited, the potential for reuse of the captured stormwater for the purposes of brine generation appear very promising, both from a technical and economic perspective. Alhough the low water temperatures that are expected to result from the use of water from stormwater ponds during the late fall and winter will reduce the efficiency of the brine making equipment as compared to water at a higher temperature coming from a groundwater source, stormwater from runoff storage ponds can be recycled for brine production without harm to the generation or distribution equipment with minimal filtering; the level of suspended solids found in the captured stormwater did not diminish the efficiency of the brine generation process. Based on VDOT's historical $\mathrm{NaCl}$ application rates and stormwater collection volumes, the department could significantly reduce the volume of stormwater it would need to dispose of, assuming the stormwater volume collection reduction steps are instituted and the practice of applying exclusively dry $\mathrm{NaCl}$ was replaced with the use of brine, both for pretreating the roadways and pre-wetting of the granular $\mathrm{NaCl}$ for subsequent applications. 
Switching to the use of $\mathrm{NaCl}$ brine as the primary method of winter maintenance would not only benefit VDOT in terms of costs and liability associated with stormwater management, based on the life cycle assessment of three winter maintenance techniques, the use of brine appears to be the best option available to DOTs from an overall environmental perspective. As modeled here, not only does this option reduce the chloride loading associated with the use of dry $\mathrm{NaCl}$, it also requires less total energy, releases fewer GHGs, consumes less water, and emits less BOD, with the benefits typically on the order of 30-40\%. Additionally, results suggest that CMA, which has been long considered one of the most environmentally promising treatment chemicals available to transportation agencies, has significantly higher emissions than then either of the salt-based treatments.

Though the results of this analysis do not point to any obvious approaches that will completely eliminate the environmental impacts associated with winter maintenance of roadways, the study does suggest that modest steps at the DOT level can result in meaningful reductions in lifecycle impacts. By switching to the use of brine as a treatment method, rather than dry salt, VDOT would significantly reduce its total chloride loading and virtually eliminate the need to dispose of salt-laden stormwater captured at its maintenance facilities. 


\section{REFERENCES}

Alleman, J., Indiana Department of Transportation, Personal communication, September 11, 2003.

Alleman, J.E., Partridge, B.K., Yeung, L., Innovative Environmental Management of Winter Salt Runoff Problems at INDOT Yards. FHWA/IN/JTRP-2001/27. Purdue University Joint Transportation Research Project, West Lafayette, 2004.

Anderson, C., New York State Department of Transportation, personal communication, August 26, 2004.

American Public Health Association, American Water Works Association, and Water Environment Federation. Standard Methods for the Examination of Water and Wastewater, $19^{\text {th }}$ ed. Washington, D.C., 1995.

Bacchus, A., Financial Implication of Salt vs. CMA as a Deicing Agent: Costs \& Benefits Estimated by an MTO Expert Group. Report ME-87-20. Ontario Ministry of Transportation, Research and Development Branch, 1987.

Baboian, R. The Automotive Environment. In Automotive Corrosion by Deicing Salts (R. Baboian, ed). National Association of Corrosion Engineeers, Houston, 1981. 
Basu, R., et al. Calcium Magnesium Acetate at Lower Production cost: Production of CMA Deicer from Biomass, Publication No. FHWA RD-98-055, Federal Highway Administration, Washington DC, 1999.

Bernhard, L., Utah Department of Transportation, personal communication, July 21, 2003.

Bester, M.L., Frind, E.O., Molson, J.W., and Rudolph, J.L. Numerical Investigation of Road Salt Impact on an Urban Wellfield. Ground Water, Vol.44, 2005, pp.165175.

Blackburn, J., Ontario Ministry of Transportation, personal communication, September 1, 2004.

Blackburn, R.R., Bauer, K.M., Amsler, D.E., Boselly, S.E., and McElroy, A.D. Guidelines for Snow and Ice Control Materials and Methods. Final Report of NCHRP Project 6-13. Midwest Research Institute, Kansas City, Missouri, 2002.

Blackburn, R.R., Bauer, K.M, Amsler, Sr., D.E., Boselly, S.E. and McElroy, A.D. Snow and Ice Control: Guidelines for Materials and Methods. NCHRP Report 526, TRB National Research Council, Washington, D.C., 2004. 
Bowers, M.C. and Hesterberg, J.H. Environmental Implication of Highway Deicing Agents on White Pine in Marquette County, Michigan. The Michigan Botanist, Vol. 15, pp. 75-89, 1976.

Bubeck, R.C., Diment, W.H., Deck, B.L., Baldwin, A.L., and Lipton, S.D. Runoff of Deicing Salt: Effect on Irondequoit Bay, Rochester, New York. Science, Vol. 172, 1971, pp. 1128-1132.

Cain, N. P. et al. Review of the Effects of $\mathrm{NaCl}$ and Other Road Salts on Terrestrial Vegetation in Canada, Environment Canada, Commercial Chemicals Evaluation Branch, 2001.

California Department of Transportation, Technical Report: A Summary of CMA Use and Research and Development, Specifically in California. Division of Technology and research, Sacramento, 1989.

Callahan, M.R., Deicing Salt Corrosion with and without Inhibitors. Transportation Research Record 1211:12-17, 1989.

Code of Federal Regulations. Title 40 Protection of Environment. Washington, D.C., 2002. 
Cody, R.D., Cody, A.M., Spry, P.G., and Gan, G.L. Experimental Deterioration of Highway Concrete by Chloride Deicing Salts. Environmental and Engineering Geoscience, Vol. 2, No. 4: 575-88, 1996.

Colwill, D.M., Thompson, J.R., and Rutter, A.J., An Assessment of the Condition of Shrubs Along Motorways, Report 1061, U.K. Transport and Road Research Laboratory, Crowthorne, Berleshire, England, 1992.

Connolly, J.P., Paquin, P.R., Mulligan, T.J., Wu, K., and Devanzo, L., Calcium Magnesium Acetate Biodegradation and It s Impact on Surface Water. In The Environmental Impact of Highway Deicing, Goldman, C.R., and Malyj, G.J., (eds.) Publication 33. Institute of Ecology, University of Califormia at Davis, Davis.

Corsi, S.R., Graczyk, D.J., Geis, S.W., Booth, N.L., and Richards, K.D. A Fresh Look at Road Salt: Aquatic Toxicity and Water-Quality Impacts on Local, Regional, and National Scales. Environmental Science and Technology, Vol._44, No. 19, pp. 7376-7382, 2010.

Craver, V.O., Fitch, G.M., and Smith, J.A. Recycling Of Salt-Contaminated Stormwater Runoff For Brine Production At Virginia Department Of Transportation RoadSalt Storage Facilities. Transp. Res. Rec., (2055), p. 99-105. 2008. 
Cunningham, M.A., Snyder, E., Yonkin, D., Ross, M., and Elsen, T. Accumulation of Deicing Salts in Soils in an Urban Environment. Urban Ecosystems, Vol. 11, 2008, pp. 17-31.

Demers, C.L., and Sage R.W. Effects of Road Deicing Salt on Chloride Levels in Four Adirondack Streams. Water, Air, and Soil Pollution, Vol. 49, 1990, pp. 369-373.

Dennis, H.W. Salt Pollution of a Shallow Aquifer: Indianapolis, Indiana. Groundwater, Vol. 11, No. 4, 1973, pp. 18-22.

Dunn, S.A., and Schenk, R.U., Alternate Highway Deicing Chemicals. Federal Highway Administration, Report No. FHWA-RD-79-108, March 1980.

Durham, B. Membrane Pretreatment of Reverse Osmosis: Long Term Experience on Difficult Waters. Desalination, Vol. 110, 1997, pp. 49-58.

Ecoinvent Centre. Ecoinvent Data v2.0, 2007. Accessed 3/1/2011. http://www.ecoinvent.org/

Environment Canada. Socio-Economic Background and Options Study on the Canadian Salt Industry, The Green Lane, Environment Canada's World Wide Web site, May, 2006, Accessed 4/1/2011. http://www.ec.gc.ca/nopp/roadsalt/reports/en/socio.cfm 
Environment Canada, Winter Road Maintenance Activities and the Use of Road Salts in Canada: A Compendium of Costs and Benefits Indicators. In Road Salts: Reducing the risk of road salts to the environment while keeping our roads safe. The Green Lane, Environment Canada's World Wide Web site: http://www.ec.gc.ca/nopp/roadsalt/reports/en/winter.cfm

Fay, L., and Shi, X., Laboratory Investigation of Performance and Impacts of snow and Ice Control Chemicals for Winter Road Service, Journal of Cold Regions Engineering. Accepted August 26, 2010; posted ahead of print August 31, 2010.

Federal Highway Administration, US Dept. of Transportation, Summary of Environmental Legislation Affecting Transportation, December, 1998, Accessed 3/31/2011. http://www.fhwa.dot.gov/environment/env_sum.htm

Federal Highway Administration, US Dept. of Transportation, Highway Statistics 2008, Public Road Length 2008 Miles by Ownership, October 2009, Accessed 3/29/2011. http://www.fhwa.dot.gov/policyinformation/statistics/2008/hm10.cfm

Federal Highway Administration, , "How Do Weather Events Impact Roads,” Federal Highway Administration Web Page,Accessed at May 3, 2005. http://ops.fhwa.dot.gov/Weather/q1_roadimpact.htm 
Federal Highway Administration. Preparation of high quality calcium magnesium acetate using a pilot plant process, FHWA, RD-86/006.

Fitch, G.M., Smith, J.A., and Bartelt-Hunt, S.L. Characterization and Environmental Management of Stormwater Runoff from Road-Salt Storage Facilities. VTRC 05R15. Virginia Transportation Research Council, Charlottesville, 2004.

Fitch, G.M., Bartelt-Hunt, S.L. and Smith, J.A.. Characterization and Environmental Management of Stormwater Runoff from Road Salt Storage Facilities. In Transportation Research Record, Journal of the Transportation Research Board, No. 1911, TRB, National Research Council, Washington, D.C., 2005.

Fitch, G. M., Craver, V. O., and Smith, J. A. Potential Use of Reverse Osmosis in Managing Salt-Water Waste Collected at Road-Salt Storage Facilities. VTRC 06-R26. Virginia Transportation Research Council, Charlottesville, 2006.

Fitch, G.M., Oyanedel-Craver, V, Bartelt-Hunt, S.L., Fuller, M., and Smith, J.A. SaltWater Recycling for Brine Production at Road-Salt-Storage Facilities. Environmental Progress \& Sustainable Energy, Volume 28, No. 4, American Institute of Chemical Engineers, 2009, pp. 565-575. 
Fitch, G.M., Smith, J.A., and Clarens, A.F. Environmental Life Cycle Assessment of Winter Maintenance Treatments for Roadways. Submitted to the Journal of Transportation Engineering, American Society of Civil Engineers, May 2011.

Frey, H.C., Rasdorf, W., Lewis, P. Comprehensive Field Study of Fuel Use and Emissions of Nonroad Diesel Construction Equipment. Transp. Res. Rec., (2158), p. 69-76, 2010.

Goldman, C.R. and Horne, A.J. Linmology. McGraw-Hill Book Co., New York, 1983, $321 \mathrm{pp}$.

Golub, E., Dresnack, R., Konon, W., Meegoda, J., and Marhaba, T. Salt Runoff Collection System. FHWA NJ - 2003-026. New Jersey Department of Transportation, Neward, 2008.

Greb, S.R., Bannerman, R.T., Corsi, S.R., and Pitt, R.E. Evaluation of the Multichambered Treatment Train: A Retrofit Water-Quality Management Practice. Water Environment Research, Vol. 72, 2000, pp.207-216.

Hanes, R.E., Zelazny, L.W., Blaser R.E. Effects of Deicing Salts on Water Quality and Biota: Literature Review and Recommended Research, NCHRP Report 91, National Cooperative Highway Research Program, Washington DC, 1976. 
Horner, R. R. Environmental Monitoring And Evaluation Of Calcium Magnesium Acetate (CMA). NCHRP Report (305), National Cooperative Highway Research Program, Washington DC, 1988.

Howard, K.W.F., and Beck, P.J. Hydrogeochemical Implications of Groundwater Contamination by Road De-icing Chemicals. Journal of Contaminant Hydrology, Vol. 12, 1993, pp. 245-268.

Hughes, T.D., Butler, J.D., and Sanks, G.D. Salt Tolerance and Suitability of Various Grasses for Saline Roadsides. Journal of Environmental Quality, Vol. 4, No. 1, 1975, pp. 65-68.

Jett, S.C., Kentucky Department of Transportation, personal communication, September 11, 2003.

Jones, P. H., et al. Environmental Impact of Road Salting-State of the Art, Ontario Ministry of Transportation Technical Report RR237, 1986.

Kelly, V.R., Findlay, S.E.G., Schlesinger, W.H., Menking, K., and Chatrchyan, A.M., Road Salt: Moving Toward the Solution. The Cary Institute of Ecosystem Studies, 2010. 
Ketcham, S.A., Minsk, L.D., Blackburn, R.R., Fleege, E.J. Manual of Practice for an Effective Anti-Icing Program: A Guide for Highway Winter Maintenance Personnel. FHWA-RD-95-202. Office of Engineering Research \& Development, Federal Highway Administration, Turner-Fairbank Highway Research Center, McLean, 1996.

Kinker, B., Virginia Department of Transportation, personal communication, September 17, 2004.

Koch, G.H. et al., Corrosion Cost and Preventive Strategies in the United States. Report No. FHWA-RD-01-156. US Department of Transportation, Federal Highway Administration, Office of Infrastructure Research and Development, 2002.

Labadia, C.F., and Buttle, J.M. Road Salt Accumulation in Highway Snow Banks and Transport Through the Unsaturated Zone of the Oak Ridges Moraine, Southern Ontario. Hydrological Processes, Vol. 10, 1996, pp. 1575-1589.

Landers, J. California Drainage Project to Rely on Local Disposal. Civil Engineering, Vol. 73, 2003, pp. 24-27.

Leineweber, D.B., Production of Calcium Magnesium Acetate (CMA) from Dilute Aqueous Solutions of Acetic Acid, Master of Science Thesis, University of Wisconsin-Madison, 2002. 
Levelton Consultants, Inc. Guidelines for the Selection of Snow and Ice Control Materials to Mitigate Environmental Impacts, NCHRP Report 577, Transportation Research Board, National Research Council, Washington, DC, 2007.

Lord, B.N. Program to Reduce Deicing Chemical Usage, Design of Urban Runoff Quality Controls, 1988.

Mallevialle, J., Odendaal, P.E., and Wiesner, M.R. Water Treatment Membrane Processes. McGraw-Hill, New York, 1996.

Manning, D.G. and Crowder, L.W. A Comparative Field Study of Calcium Magnesium Acetate and Rock Salt During the Winters of 1986-87 and 1987-88. Ontario Ministry of Transportation, Research and Development Branch, MAT-88-06, 1988.

Manning, D.G., and Crowder, L.W. Comparative Field Study of the Operational Characteristics of Calcium Magnesium Acetate and Rock Salt. In Transportation Research Record 1246, TRB, National Research Council, Washington, DC, 1989. 
Mason, C.F., Norton, S.A., Fernandez, I.J., and Katz, L.E. Deconstruction of the Chemical Effects of Road Salt on Stream Water Chemistry. Journal of Environmental Quality, Vol. 28, 1999, pp. 82-91.

National Cooperative Highway Research Program, Environmental Monitoring and Evaluation of Calcium Magnesium Acetate, Transportation Research Board, NCHRP Report 305, Washington DC, April 1988.

National Oceanic and Atmospheric Administration, National Climatic Data Center web site. Accessed 3/16/2011. http://cdo.ncdc.noaa.gov/ulcd/ULCD

Novotny, V., et al. Urban and Highway Snowmelt: Minimizing the Impact on Receiving Water, Water Environment Research Foundation, Project 94-IRM-2, 1999.

Ohno, T. Levels of Total Cyanide and $\mathrm{NaCl}$ in Surface Waters Adjacent to Road Salt Storage Facilities. Environmental Pollution, Vol. 67, 1990, pp.123-132.

O’Keefe, K. and Shi, X. Synthesis of Information on Anti-icing and Pre-wetting for Winter Highway Maintenance Practices in North America. Western Transportation Institute, Montana State University, Bozeman, 2005. 
Oracle Corporation. Oracle Crystal Ball [computer software], Redwood Shores, CA, 2009.

http://www.oracle.com/technetwork/middleware/crystalball/overview/index.html

Ormsby, W.C. New Technologies Improve Cost-Effectiveness of CMA. In Public Roads, US Department of Transportation, Federal highway Administration, Vol. 63, No.3, 1999.

Ostendorf, D.W., Hinlein, E.S. Rotaru, C., and DeGroot, D.J. Chloride Contamination of Groundwater by Outdoor Highway Deicing Agent Storage. Journal of Hydrology, Vol. 326, 2006, pp. 109-121.

Pianca, F. An Assessment of CMA as an Alternative De-icer. Ontario Minsitry of Transportation, Research and Development Branch. ME-84-02, 1984.

Pierstorff, B.W., and Bishop, P.L. Water Pollution from Snow Removal Operations. Journal of the Environmental Engineering Division (ASCE), Vol. 106, 1980, pp. $377-388$.

Product Ecology Consultants. SimaPro Life Cycle Assessment [computer software], Amersfoort, The Netherlands, 2007. http://www.pre-sustainability.com/ 
Raupach, M. , Chloride-Induced Macrocell Corrosion of Steel in Concrete- Theoretical background and Practical Consequences, Construction and Building Materials, Vol. 10, No5: 329-338, 1996.

Redondo J.A. Brackish-, Sea and Wastewater Desalination. Desalination, Vol. 138, 2001, pp. 24-40.

Rosenberry, D.O., Bukaveckas, P.A., Buso, D.C., Likens, G.E., Shapiro, A.M., and Winter, T.C. Movement of Road Salt to a Small New Hampshire Lake. Water, Air, and Soil Pollution, Vol. 109, 1999, pp. 176-206.

Roosevelt, D.S. A Survey of Anti-Icing Practice in Virginia. VTRC 98-R19. Virginia Transportation Research Council, Charlottesville, 1997.

Roosevelt, D.S. Technical Memorandum: Pilot Test of Direct Liquid Anti-Icing Application in Snow Removal and Ice Control Operations, Virginia Transportation Research Council, Charlottesville, 2008.

Santengelo, T., Colorado Department of Transportation, personal communication, August 31, 2004.

Schenk, R.U. Physical and Chemical Properties of Calcium Magnesium Acetate. In Wse, D.L, Levendis, Y.A., and Metghalchi, M. (ed.) Calcium Magnesium Acetate, An 
Emerging Bulk Chemical for Environmental Applications. Industrial Chemistry Library, Vol.2, Elsevier, Amsterdam, 1991.

Shang-Tian yan, et al. Calcium Magnesium Acetate at Lower Production Cost: Production of CMA Deicer from Cheese Whey, Publication No. FHWA-RD-98174, Federal Highway Administration, Washington, DC 1999.

Shi, X., Fay, L., Gallaway, C., Volkening, K., Peterson, M.M., Pan, T., Creighton, A., Lawlor, C., Mumma, S., Liu, Y., and Nguyen, T.A. Evaluation of Alternative Anti-Icing and Deicing Compounds Using Sodium Chloride and Magnesium Chloride as Baseline Deicers - Phase I. Report No. CDOT-2009-1 Final Report, Colorado Department of Transportation DTD Applied Research and Innovation Branch, 2009.

Shi, X., Fay, L., Peterson, M.M., Yang, Z. Freez-Thaw Damage and Chemical Change of a Portland Cement Concrete in the Presence of Diluted Deicers. Materials and Structures, (43) p. 933-946, 2010.

Scott, W.S. Occurrence of Salt and Lead in Snow Dump Sites. Water, Air, and Soil Pollution, Vol. 13, 1980, pp. 187-195.

Scott, W.S., and Wylie N.P. The Environmental Effects of Snow Dumping: A Literature Review. Journal of Environmental Management, Vol. 10, 1980, pp. 219-240. 
Southeast Regional Climate Center. Historical Climate Summaries and Normals for the Southeast. Accessed 3/2004. http://www.dnr.state.sc.us/climate/sercc/climateinfo/historical/historical.html.

Snodgrass, W.J. and Morin, D.. Patrol (Maintenance/Works) Yards. Supporting Document For The Road Salts PSL Assessment: Report submitted to the Environment Canada CEPA Priority Substances List Environmental Resource Group on Road Salts. Commercial Chemicals Evaluation Branch, Environment Canada, Hull, Quebec, 2000.

Tanner, D.Q., Wood, T.M., The Effects of Calcium Magnesium Acetate (CMA) Deicing Material on the Water Quality of Bear Creek, Clackamas County, Oregon, 1999. Water-Resources Investigations Report 00-4092U.S. Department of the Interior, U.S. Geological Survey. Portland, 2000.

Taylor, J., and Jacobs, E. Reverse Osmosis and NanoFiltration. In Water Treatment: Membrane Process, J. Mellavialle, P. Odendaal, and M. Wiesner, Editors. McGraw-Hill, New York, 1997.

Transportation Research Board, Highway Deicing: Comparing Salt and Calcium Magnesium Acetate, Transportation Research Board Special Report 235, National Research Council, Washington, DC, 1991. 
Transportation Association of Canada. Syntheses of Best Management Practices: Road Salt Management. Ottawa, September 2003.

Transportation Research Board. Toward a Sustainable Future: Addressing the LongTerm Effects of Motor Vehicle Transportation on Climate Ecology. special Report 251. Washington, DC, 1997.

U.S. Code of Federal Regulations, Title 40, Protection of Environment, Chapter 1, Part 143, National Secondary Drinking Water Regulations. Government Printing Office, Washington, DC, July 1, 2002.

U.S. Department of Energy and U.S. Environmental Protection Agency. Carbon Dioxide Emissions from the Generation of Electric Power in the United States. 2000. http://www.eia.doe.gov/cneaf/electricity/page/co2_report/co2emiss.pdf

U.S. Department of Transportation, Research and Innovative Technology Administration (RITA), National Transportation Statistics, Table 1-6 Estimated U.S. Roadway Lane-Miles by Functional System. Bureau of Transportation Statistics, 2010. Accessed 4/2/2011. http://www.bts.gov/publications/national_transporationstatistics/html/table_01_06.html 
U.S. Environmental Protection Agency, Emission Facts: Average Carbon Dioxide Emissions Resulting from Gasoline and Diesel Fuel. EPA420-F-05-001. Office of Transportation and Air Quality, 2005.

U.S. Environmental Protection Agency, Storm Water Management Fact Sheet, Minimizing Effects from Highway Deicing. Office of Water, Washington, D.C. EPA 832-F-99-016, September 1999.

Vasek, R., Minnesota Department of Transportation, personal communication, September $12,2003$.

Virginia State Climatology Office. Regional Evaporation Rates from 1971-2000. Charlottesville, 2001.

Virginia State Water Control Board. 9 VAC 25-260 Water Quality Standards. Richmond, February 12, 2004.

Vitaliano, D.F., An Economic Assessment of the Social Costs of Highway Salting and the Efficiency of Substtuting a New Deicing Material. Journal of Policy Analysis and Management, Vol. 11, No3, 1992, 397-418.

Walton, G.S. Phytotoxicity of $\mathrm{NaCl}$ and $\mathrm{CaCl}$ to Norway Maples. Phytopathology, Vol. 59, pp. 1412-1415. 
Washington State Department of Transportation, Long-Term Corrosion Impacts from Highway Snow and Ice Control Chemicals, Federal Highway Administration, Washington D.C., 2007.

Wilcox, D. The Effects of Deicing Salts on Water Chemistry in Pinhook Bog, Indiana. Water Resource Bulletin, Vol. 22, 1986, pp. 57-65.

Wisconsin Department of Transportation, Bureau of Highway Operations. Anti-icing Technique, Guideline 32.35. State Highway Maintenance Manual, 2005

Wise, D. L., Levendis, Y. A., Metghalchi, M. Calcium Magnesium Acetate : An Emerging Bulk Chemical for Environmental Applications, Elsevier, Amsterdam ; New York, 1991.

Yang, S., Huang, Y.,L, Jin, Z., Huang, Y., ZHU, H., Qin, W. Calcium Magnesium Acetate At Lower-Production Cost: Production Of Cma Deicer From Cheese Whey. Publication No. FHWA-RD-98-174, Federal Highway Administration, Washington, DC., 1999.

Yunovich, M. Tohmpson, N.G., Balvanyos, T., and Lave, L. Corrosion Costs of Highway Bridges, 2006. http://www.corrosioncost.com/pdf/highway.pdf 
Zapata, P. and Gambatese, J.A., Energy Consumption of Asphalt and Reinforced Concrete Pavement Materials and Construction. Journal of Infrastructure Systems. Vol. 11, No. 1, p. 9-20., 2005. 